\title{
CANADIAN SMART CITIES: A CASE FOR THE CIRCULAR ECONOMY IN THE AGE OF "SMART" INNOVATION
}

By

\author{
Vickey Simovic \\ Bachelor of Arts (Honours), Brock University, 2011
}

\author{
A Major Research Paper \\ presented to Ryerson University \\ In partial fulfillment of the requirements for the degree of \\ Master of Planning \\ in \\ Urban Development
}

Toronto, Ontario, Canada, 2019

(C) Vickey Simovic 2019 


\section{AUTHOR'S DECLARATION FOR ELECTRONIC SUBMISSION OF A MRP}

I hereby declare that I am the sole author of this MRP. This is a true copy of the MRP, including any required final revisions.

I authorize Ryerson University to lend this MRP to other institutions or individuals for the purpose of scholarly research.

I further authorize Ryerson University to reproduce this MRP by photocopying or by other means, in total or in part, at the request of other institutions or individuals for the purpose of scholarly research.

I understand that my MRP may be made electronically available to the public. 


\title{
CANADIAN SMART CITIES: A CASE FOR THE CIRCULAR ECONOMY IN THE AGE OF "SMART" INNOVATION
}

(C) Vickey Simovic 2019

\author{
Master of Planning \\ in \\ Urban Development \\ Ryerson University
}

\begin{abstract}
The Canadian Smart Cities Challenge enabled municipalities across the country to reflect on how smart city technology can be used to solve their unique community challenges, embrace the possibility of impactful projects, create collaborations, and create a suite of digital tools. This paper analyses whether governments can be catalysts in adopting circular economy thinking in the age of digital innovation. In reviewing the SCC applications, five proposal submissions were analysed in depth against a circular economy framework. Recommendations for further development in smart city thinking centre around future Smart Cities Challenges, and building circular assumptions into the challenge questions, whereby ensuring circular principles are a priority for municipalities as they continue to grow and adapt to smart city technological advances.
\end{abstract}

Key words: Smart Cities Challenge, circular economy, smart city technology, innovation, sustainable, reuse, sharing, remanufacturing and repurposing 


\section{Acknowledgements}

Thank you to my supervisor Professor Pamela Robinson for her support and guidance throughout this writing process. Thank you to my second reader, Professor Zhixi Zhuang for taking the time from her busy schedule to review my work. And thanks for all of my friends and family for their patience and support throughout this process. Especially to my Niko - I wouldn't have been able to do this without you.

This MRP was funded, in part, through research grants held by Dr. Pamela Robinson (SSHRC Grants: 892-2018-0046 and 895-2012-1023). 


\section{Table of Contents}

$\begin{array}{lr}\text { Acknowledgements } & 4\end{array}$

$\begin{array}{ll}\text { Table of Contents } & 5\end{array}$

$\begin{array}{lr}\text { Executive Summary } & 6\end{array}$

$\begin{array}{lr}\text { Chapter 1: Introduction } & 8\end{array}$

$\begin{array}{ll}\text { About the Challenge } & 11\end{array}$

$\begin{array}{ll}\text { Chapter 2: Literature Review } & 13\end{array}$

2.1 Municipalities as Innovation Drivers 13

2.2 Sustainable Cities 14

2.3 Circular Economy Defined $\quad 15$

$\begin{array}{ll}2.4 & \text { Cities and the Circular Economy } \\ 2.5 & 17\end{array}$

2.5 Circular Economy Solutions 18

2.6 A Circular Economy Framework 18

2.7 Circular Design Strategies 20

$2.8 \quad$ Educating Circular Economy Leaders 22

2.9 Policy Levers that Enable Circular Economy Transitions 23

$\begin{array}{ll}\text { Chapter 3: Method } & 26\end{array}$

Chapter 4: Problem Investigation/Evidence and Findings 31

4.2 Case Study 1: City of Port Alberni, British Columbia 31

4.3 Case Study 2: District of Squamish, British Columbia 34

4.4 Case Study 3: The City of Guelph and Wellington County, Ontario 37

4.5 Case Study 4: The Municipality of Hope Town, Quebec 41

4.6 Case Study 5: The City of Coquitlam, British Columbia 43

$\begin{array}{lll}4.7 & \text { Summary of Analysis } & 47\end{array}$

Chapter 5: Conclusion/Recommendations for Practice and Future Research 48

$\begin{array}{ll}\text { References } & 54\end{array}$

$\begin{array}{lr}\text { Appendices } & 59\end{array}$ 


\section{Executive Summary}

At the heart of creativity, innovation and growth, cities play a central role as motors of the global economy (Iles, 2017). This is demonstrated by the fact that $54 \%$ of the world's population live in urban areas, and that cities account for $85 \%$ of global Gross Domestic Product (GDP) generation (ibid). However, cities are also aggregators of materials and nutrients, which accounts for $75 \%$ of natural resource consumption, $50 \%$ of global waste production, and between $60-80 \%$ of greenhouse gas emissions (ibid). Currently, existing cities operate within a global economic system that is based on the linear 'take-make-dispose' model, where resources are extracted and products are created and waste is a by-product of the process (EMF, 2017). Challenges of this model include environmental pollution, inequality, congestion and high levels of non-renewable waste (Sukhdev et al, ND, p.1). These challenges cannot be ignored and will worsen if no action taken. Furthermore, as greater rates of urbanisation are expected in the next coming decades and significant infrastructure investments and developments will be required, the task of examining our consumption habits to live more sustainably is paramount.

To bring the natural system into balance, a new economic model is needed - one that is sustainable and respects the limits of natural resources and the functions of ecosystems. This requires a shift in how we value, use and dispose of resources, creating a circular system where waste becomes a resource (van Ham, 2018). As cities influence economic, social and environmental change, it is important to study how a circular economy could unfold in an urban context, and how its framework could steer cities towards greater prosperity, resilience and livability (Prendeville et al, 2018, p. 171). A circular city can be a desirable place to live as it addresses the key challenges that cities face.

One way to employ sustainable, circular practices is through the advancement of smart city technology in city building initiatives. A "smart city" is defined as a resilient, inclusive and 
collaboratively built city that uses technology and data to better the quality of life for all people (FFC, 2018, p. 4). Smart city technology is a disruptive technology that creates the potential to change how we think and operate within our daily lives. It fosters new innovations - new ideas, new practices and offers a new lense in which to approach challenges. The evolution of smart cities presents an opportunity to reconsider how we treat old problems, and reevaluate our assumptions and priorities. How we can use technology to rethink our current practices and create better solutions.

Today, cities are driven by emerging practices in governance and participation, new technologies, the availability of urban data, and new sources and forms of capital investment (FCC, 2018 , p. 3). This rapid adoption of digital technology in cities has enabled a fundamental shift in the way the economy functions. This transition offers possibilities for greater efficiency in product use and material flows, as well as creating new ways of operating and participating in the global economy (Sukhdev et al, ND, p.3). Through the collection and analysis of data on materials, people and external conditions, digital technology has the potential to identify the challenges of material flows in cities, outline the key areas of structural waste, and inform more effective decision-making on how to address these challenges and provide systemic solutions (ibid).

This paper seeks to assess whether governments can catalyse circular economy principles as they modernize and adopt smart city approaches to their governance and operations. Using the Canadian Smart Cities Challenge (the SCC/the Challenge), this paper will explore the connections between the application submissions and circular economy efforts. Through examining the applications submitted by Canadian municipalities involved in the Challenge, this paper studies whether a circular economy approach was used within the proposal submissions, and explores the ways in which circular economy thinking can be further integrated into Smart Cities Challenges going forward. 


\section{Chapter 1: Introduction}

The earth's ecosystems have evolved into diverse and complex biological communities that live in balance with their environment. Over the last century, globalization and the impacts of human activity on natural ecosystems have led to wild plants and animals at risk of extinction, deforestation, land degradation, water scarcity, erosion, and climate change in many parts of the world (van Ham, 2018). Most of us do not realise that what we use is directly related to the natural balance of the planet. Almost all consumer goods contain natural minerals and metals: a mobile phone can contain 50 different materials, and yet no country is self-sufficient in these materials (ibid). Global trade also comes with environmental and social costs; a growing use of synthetic fertilizer in food production now sustains about half of the world's population but also causes pollution of air, water, and soils, and fossil fuels provide energy to many but only at the cost of rising atmospheric CO2 concentrations and global warming (WWF, 2016). Our current system of consumption is unsustainable, and the negative impacts to our planet can not be ignored.

Sustainable economic development is necessary to create a future that is in harmony with nature and disentangles economic development from environmental degradation. Sustainable development is a wide-ranging concept that is forward thinking. It focuses on meeting our current needs without compromising the ability of future generations to meet their own needs (WCED, 1987). It is a holistic approach that considers ecological, social and economic dimensions, recognizing that all three dimensions must be considered together to find lasting prosperity (University of Alberta, 2013). Cities are excellent places to create this change, as they are full of innovative ideas, business opportunities, and creative minds (van Ham, 2018).

Adopting sustainable practices in city-building activities can significantly contribute towards the reduction of GHG emissions. The Government of Canada states that the transportation, energy, and buildings sectors contribute almost $75 \%$ of Canada's total greenhouse gas (GHG) 
emissions (2016). Our current practices rely extensively on fossil fuels, which emit large amounts of GHG emissions into the atmosphere and contribute to climate change (Government of Canada, 2018). Our quality of life is affected by climate change and its effects of global warming - a trend that can be reversed.

With more than half of the global population expected to live in cities, the contributions to and threats of climate change including increased occurrences of floods, droughts, and storms in cities are significant, and the future protection of cities should be a primary concern among decision makers (ibid). Local governments have extensive knowledge of their environment, and the administrative autonomy over urban planning, water, waste and public transportation systems (ibid). Therefore local decision makers should be at the forefront of exploring ways and seizing opportunities for creating and maintaining resilient urban systems that will be inherited by future generations. Urban planners and policy makers should be trained and engaged to lead on urban sustainability issues and to tackle the effects of climate change at the city-level.

One way to employ sustainable practices is through the advancement of smart city technology in city building initiatives. A smart city is defined as a resilient, inclusive and collaboratively built city that uses technology and data to better the quality of life for all people (FFC, 2018, p. 4). Smart city technology is a disruptive technology that creates the potential to change how we think and operate within our daily lives. This is especially significant to the urban context as local decision makers have a unique opportunity to use smart city innovations as a catalyst for building sustainable and resilient communities. Smart city initiatives are spreading all around the world with the ambition to increase increase the quality of life of citizens through innovation, better public services and a cleaner environment (Paolo Appio et al, 2018, p.1). Although innovation and digital advancement of cities are exciting aspects of smart city technology, there is need to reconcile them with sustainability efforts. One option to think about is 
circular economy efforts, which focuses on the preservation, restoration and regeneration of natural, social and financial capital. The concept of circular economy involves structuring the economy is a sustainable way, with the main priority of using materials efficiently, reducing and ultimately eliminating waste flows (Baker-Brown, 2017, p. 22). The aim of the circular economy is to maximise the circularity of materials within an industrial society, by designing products and buildings that can be dismantled and refurbished and reused, avoiding the creation of waste (ibid). The circular economy concept suggests that extending the lifespan, or reuse, of products can be achieved in various ways, such as repair, upgrading, remanufacturing or remarketing of the same product.

The concept of the circular economy is relevant to the urban context as it offers planners, designers, policymakers, and businesses a framework to rethink systems of how we design and operate them in a manner that will preserve, restore and regenerate natural, social and financial capital (Sukhdev et al, ND, p.2). Technology and data have a role to play in creating circular economies in cities, as new digital capabilities can benefit sustainability through the wise management of natural resources. For instance, data can be used to more efficiently manage waste, energy, and water, improve building infrastructure and mobility (EMF, 2015).

To bring the natural system into balance, a new economic model is needed; one that is sustainable and respects the limits of natural resources and the functions of ecosystems. This requires a shift in how we value, use and dispose of resources, creating a circular system where waste becomes a resource (van Ham, 2018). Cities are uniquely positioned to drive a global transition towards a circular economy with their high concentration of resources, capital, data, and talent contained in a small geographic territory; they also stand to greatly benefit from the outcomes of a transition to a circular economy (ibid). As cities influence economic, social and environmental change, it is important to study how a circular economy could unfold in an urban 
context, and how its framework could steer cities towards greater prosperity, resilience and livability (Prendeville et al, 2018, p. 171). A circular city can be a desirable place to live as it addresses the key challenges that cities face.

This paper seeks to assess whether governments can catalyse circular economy principles as they modernize and adopt smart city approaches to their governance and operations. Using the Canadian Smart Cities Challenge (the SCC/the Challenge), this paper will explore the connections between the application submissions and circular economy efforts. How are municipalities encouraging circular economy principles? At what capacity? Can they do it alone? Through examining the applications submitted by Canadian municipalities involved in the Challenge, this paper studies whether a circular economy approach was used within the proposal submissions, and explores the ways in which circular economy thinking can be further integrated into Smart Cities Challenges going forward.

The following section outlines the current literature surrounding circular economy thinking and urban leadership. Next the SCC process is described and five responsive case studies are examined, using principles from the Ellen MacArthur Foundation's ReSOLVE framework (which is a circular economy framework) to determine the level of circular economy thinking that currently exists amongst responding municipalities. Lastly, based on the literature review and assessment of the SCC applications, a number of recommendations are put forward that seek to prioritize and establish a foundation to build circular economy thinking into Canadian municipalities. 


\section{Chapter 2: Literature Review}

\subsection{Municipalities as Innovation Drivers}

Cities have always been natural incubators for experimentation, change and progress (Tomalty, 2017, p.3). This is likely because they are the locus of complex problems that are difficult to address, including air pollution, traffic congestion, alienation from nature, income and environmental inequality, inadequate housing, urban sprawl, and crumbling infrastructure (ibid). Due to the high concentration of talent, capital, data and resources in a small geographic area, cities are well positioned to embrace and lead creative city building solutions. Cities play a vital role as drivers for innovation and entrepreneurship as they act as a living laboratory where collaborative, innovative solutions are developed and tested (Care et al, 2018, p.502). For example, not having an option (ie. available land) of where to store physical waste, forces cities to creatively find alternatives to managing waste. This creative problem solving ability of cities lends itself well to the innovative thinking required for sustainable development solutions.

Today, cities are on the brink of a new wave of innovation, driven by emerging practices in governance and participation, new technologies, the availability of urban data, and new sources and forms of capital investment (ibid). Both large cities and small municipalities can be "innovation drivers", if there is a willingness among municipal leaders to share responsibility for addressing urban issues with outside stakeholders (Tomalty, 2017, p.4). It is through innovation drivers that successful solutions can be created, implemented, maintained and refined. City problems such as traffic congestion, crumbling infrastructure and air pollution cannot be solved by local governments alone. They require collaboration and partnerships with many stakeholders who bring different experiences, views and motivations to the table. Sustainable urban solutions must be studied through a variety of lenses, including economic, social and environmental dimensions. 


\subsection{Sustainable Cities}

Derived from the 1987 World Commission on Environment and Development (WCED) definition of sustainable development, a city can be defined to be sustainable "if its conditions of production do not destroy over time the conditions of its reproduction" (Ahvenniemi et al., 2017, p. 235). This refers to the rate of use and consumption of natural resources within the economic economic system. Taking this one step further, urban sustainable development has more recently been characterized as "achieving a balance between the development of urban areas and protection of the environment with an eye toward income equity, employment, shelter, basic services, social infrastructure and transportation in urban areas" (ibid, p. 235). As cities continue to grow and become even more complex and interconnected, holistic sustainable urban development solutions become a necessary step for future growth and prosperity.

Over the last century, globalization and the impacts of human activity on natural ecosystems have led to natural species extinction, deforestation, land degradation, water scarcity, erosion, and climate change in many parts of the world (van Ham, 2018). The rise of industrial development has brought enormous economic growth, alongside increasing pressure on our planet's resources. Globally, material consumption has grown eightfold over the past 100 years and is expected to triple our current rate by 2050 (UNEP, 2011). The likely consequences of our habits include scarcity of resources including fertile land, clean water and air (Prendeville et al, 2018, p. 171). The current linear economic system is unsustainable, and the negative impacts to our planet can not be ignored.

Currently, existing cities operate within a global economic system that is based on the linear 'take-make-dispose' model, where resources are extracted and products are created and waste is a by-product of the process (EMF, 2017). Urban economies mirror and amplify the challenges of this model, including environmental pollution, inequality, congestion and high levels 
of non-renewable waste; all of which lead to global price volatility (Sukhdev et al, ND, p.1). Our current linear economic system and consumption patterns cannot be sustained. Globally, we are beginning to see businesses and governments adopting circular economy principles as a route to resource efficiency in the face of rising material prices and climate change (ibid). Cities of the future are not sustainable without circularity - they will need to include a strong circular foundation.

\subsection{Circular Economy Defined}

A circular economy is restorative by design, and keeps products, components and materials at their highest utility and value, at all times (Webster, 2015, p.16). It is a global economic model that decouples economic growth and development from the consumption of finite resources. It distinguishes between and separates technical and biological materials, keeping them at their highest value at all times; and focuses on effective design and use of materials to optimize their flow and maintain or increase technical and natural resource stocks (ibid). A circular economy provides new opportunities for innovation across fields such as products design, service and business models, food, farming, biological feedstocks and products; and establishes a framework and building blocks for a resilient system able to work in the longer term (ibid).

The circular economy concept is a transformation in the way the economy works. It is a long term solution that adds social and environmental capital and flows (ibid). By rethinking the way we produce, work and buy, we can generate new opportunities and create new jobs (Baker-Brown, 2017, p. 21). The term "use", and the optimisation of the use and utilisation of manufactured objects, is at the core of the circular economy. Whereas the term "reuse" implies a change in utilization, ownership or location. This distinguishes the circular economy from the linear industrial economy, which optimises the production of the same objects up to the point of sale (ibid, p. viii). 
The concept of circular economy involves structuring the economy is a sustainable way, with the main priority of using materials efficiently, reducing and ultimately eliminating waste flows (ibid, p. 22). The materials cycle is the central issue. The aim of the circular economy is to maximise the circularity of materials within an industrial society, by designing products and buildings that can be dismantled and refurbished and reused, avoiding the creation of waste (ibid). The circular economy concept suggests that extending the lifespan, or reuse, of products can be achieved in various ways, such as repair, upgrading, remanufacturing or remarketing of the same product.

The image below illustrates the concepts of our current linear degenerative economy, as well as the regenerative circular economy model. As you can see, the linear economy principles of take-make-dispose create waste as a by-product of the process that has nowhere to go. Whereas the circular economy concept creates cycles of materials that regenerate natural capital and maintain, reuse or recycle technical products, and which do not create waste, rather waste is a resource that is fed back into the system.

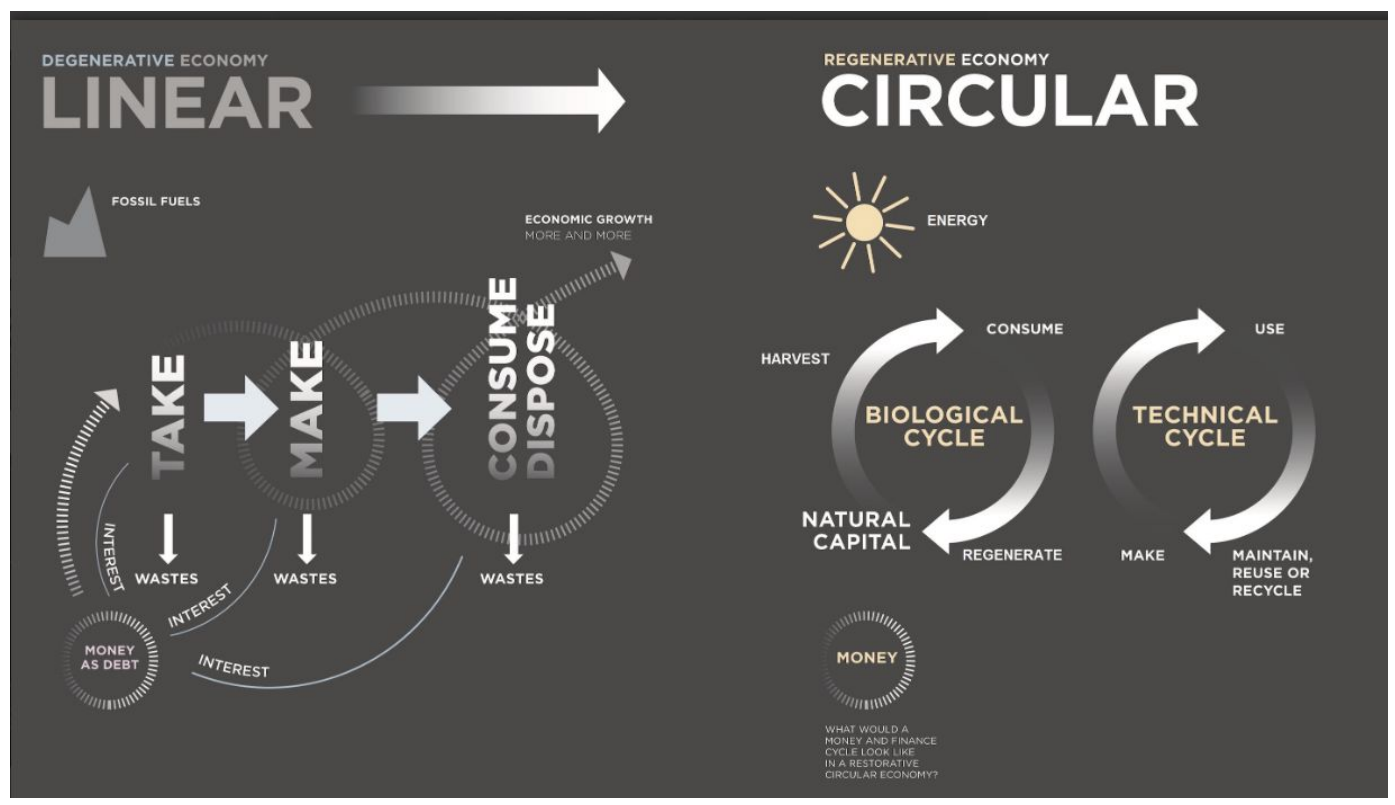

Source: Webster, Ken. (2015). The Circular Economy: A Wealth of Flows. The Ellen MacArthur Foundation 


\subsection{Cities and the Circular Economy}

Cities are mirrors of our economy (lles, 2017). They are responsible for more than half of global population and GDP, and well as $75 \%$ of global natural resources and $80 \%$ of the global energy supply consumption (ibid). Therefore, the transition to a circular economy needs to focus on cities. Cities provide the space in which a circular economy can flourish, as they amplify the impact through the proximity of people, materials and data which are all contained in a small geographic territory. Cities play a key role as centres for change. Their proximity to the everyday concerns and needs of urban citizens and businesses, and the policy levers they have at their disposal gives them this key role. City governments see, experience and often manage the negative consequences of the current "take-make-waste" linear economy, which includes funds spent on solid waste management, costs incurred from structural waste; cost of underutilized buildings, economic costs of congestion, health costs of air and noise pollution (EMF, 2019). The challenges of a take-make-waste linear economy concentrate in cities, but cities can catalyse larger system transformation.

Furthermore, cities are also typically faster to adopt digital solutions, whether it's new apps, maker spaces, or sharing platforms. Digital technology solutions start to bloom in cities as the urban population is, more often than not, open to new technology, and the concentration of people and things make it easier to gain momentum (as long as solutions touch upon real needs, such as sharing rides or spaces because there isn't so much space and transport is expensive) (ibid). There is an opportunity that is created with having a lot of people in a small area that is rich with data and digital communications, and can enable more local innovation, that feeds off rethinking asset utilisation and keeping products and materials at their highest utility and value at all times (ibid). That is the power of cities in the circular economy. 


\subsection{Circular Economy Solutions}

The circular economy is about reusing, sharing, remanufacturing and repurposing (Bleriot, 2016). There is a lot of pressure on our already constrained resources, which will only increase with population growth. If we are able to remove some of the budget constraints through utilising assets, then governments and city planners can have more budget for things like education or green spaces (Iles, 2017). The circular economy can also help raise disposable income, which is relevant for all of us. It can help create business opportunities in cities which is appealing for the business and innovation community (ibid).

The circular economy concept solves for a number of important challenges with regard to urban issues, including waste management, built environment, mobility, bioeconomy, local production and employment. The majority of circular economy initiatives that currently exist focus on waste management, with a handful of initiatives going beyond increasing recycling rates and a higher use of secondary raw materials (Bleriot, 2016). There is a need to push the upstream elements of the circular model to the forefront - elements such as design, materials choice editing, etc (ibid).

\subsection{A Circular Economy Framework}

As cities transform to accommodate smart technology, this presents an opportunity to redesign systems and incorporate circular economy principles at the core. Incorporating digital technology is essential for our society to accelerate the systemic shifts needed to create a circular economy (Ramkumar, 2017). Research has shown that political leadership, adaptable future visions, experimental approaches (such as living labs), development of contextual knowledge about resource use, and diverse stakeholder engagement are important steps in adopting a circular economy strategy (Prendeville et al, 2018, p.173). 
The Ellen MacArthur Foundation has created a ReSOLVE framework, which is a set of six circular city principles: Regenerate, Share, Optimize, Loop, Virtualize and Exchange (EMF, 2015). This framework considers the social, economic and environmental dimensions of circularity and sustainability. The Regenerate principle refers to the shift to renewable energy and materials - to reclaim, retain, and restore health of ecosystems and return recovered biological resources to the biosphere (ibid). The Share principle refers to sharing assets (e.g. cars, rooms, appliances), and prolong the life of materials through maintenance, design for durability, upgradability and encouraging reuse/second-hand (ibid). Optimise means to increase performance/efficiency of a product, remove waste in production and supply chain, and leverage big data (ibid). Loop refers to remanufacturing products or components; resources are processed, looped around and put back into the economy, rather than lost in a landfill (ibid). The Virtualize principle is in reference to dematerializing directly and indirectly (for example: e-readers replacing physical books, or a Netflix subscription replacing material DVDs) (ibid). Lastly, the Exchange principle refers to the process of replacing old technologies with advanced non-renewable materials, applying new technologies (such as 3D printing) and choosing new products/services (ibid).

The purpose of a conceptual framework is to provide a lens through which to understand the ways circular economy could manifest in a city. Policymakers play a role in stimulating bottom-up business, citizens and community activities for urban sustainability (Prendeville et al, 2018, p.176). Top-down change is institution-driven change, such as strategy and policy decisions including public-private partnership projects that are concerned with developing and facilitating market initiatives (ibid). Bottom-up change can describe social movements and social innovation, such as initiatives and entrepreneurial activities initiated and run by civil society, NGOs, communities and businesses (ibid). 
The following table illustrates the ReSOLVE Framework by using top-down and bottom-up examples of circular economy principles in action (Prendeville et al, 2018, p.176).

\begin{tabular}{|c|c|c|}
\hline Principle & Top-Down Example & Bottom-Up Example \\
\hline Regenerate & $\begin{array}{l}\text { Utilizing rooftops as solar fields, } \\
\text { developing green space for biodiversity } \\
\text { and to improve air quality. }\end{array}$ & $\begin{array}{l}\text { Personal acquisition of renewable } \\
\text { energy; solar panels, urban farming, } \\
\text { electric or biogas fuelled mobility. }\end{array}$ \\
\hline Share & $\begin{array}{l}\text { Policy innovation to support the } \\
\text { collaborative economy, regulate sharing } \\
\text { tax and fiscal measures incentivizing } \\
\text { sharing. }\end{array}$ & $\begin{array}{l}\text { Car sharing, appliance sharing } \\
\text { (washing machines, tools), repair } \\
\text { (repair cafes), reuse (clothing, furniture, } \\
\text { vehicles, appliances) }\end{array}$ \\
\hline Optimize & $\begin{array}{l}\text { By using gathered data on traffic flows, } \\
\text { the efficiency of cities' major } \\
\text { transportation can be optimized, } \\
\text { decreasing congestion. Installing smart } \\
\text { LED lighting throughout the city to save } \\
\text { energy. Retrofitting old buildings to } \\
\text { increase their energy efficiency. }\end{array}$ & $\begin{array}{l}\text { Smart citizen labs, Fab Labs, smart } \\
\text { grids, smart communities. }\end{array}$ \\
\hline Loop & $\begin{array}{l}\text { Waste separation and recycling, district } \\
\text { heating, bio-based economy, reverse } \\
\text { logistics. }\end{array}$ & $\begin{array}{l}\text { Community recycling initiatives, } \\
\text { upcycling initiatives, community } \\
\text { bio-digesters. }\end{array}$ \\
\hline Virtualize & $\begin{array}{l}\text { Virtual city hall counters. Autonomous } \\
\text { public transportation and semi-private } \\
\text { transportation like taxis. Virtualization } \\
\text { of public libraries, archives, legal } \\
\text { information. A paperless municipality. }\end{array}$ & $\begin{array}{l}\text { Community-led digital platforms, } \\
\text { citizen-science climate monitoring. }\end{array}$ \\
\hline Exchange & $\begin{array}{l}\text { Circular construction/demolition } \\
\text { materials and processes, electric } \\
\text { powered public transportation, } \\
\text { procurement of circular office furniture. }\end{array}$ & $\begin{array}{l}\text { Electric mobility, organic and } \\
\text { locally-sourced (super)markets, } \\
\text { eco-fashion, e-readers. }\end{array}$ \\
\hline
\end{tabular}

Figure 1: Examples of the Ellen MacArthur Foundations ReSOLVE Framework. Source: Prendeville et al, 2018, p.176.

\subsection{Circular Design Strategies}

Promoting sustainable design will lessen the ecological impact of wasteful manufacturing practices. A sustainable design uses materials that age gracefully and develop quality overtime, 
which can generate greater levels of emotional longevity from consumers (Baker-Brown, 2017, p. 155). This applies to all types of products - from cell phones, to clothing, to cars, trains, transit systems and residential and commercial buildings. Designing products that can be designed to be easy to repair, upgrade and maintain throughout their lifespan is has significant ecological benefits. These are effective product life extension strategies, and while they can come at an increased cost at point of purchase, they can generate revenue downstream (ibid).

Another important aspect of sustainable design is remanufacturing. Remanufacturing is defined as bringing a product back from the use phase, and through industrial processes, disassembling the product at a component level, and testing and inspecting every component (Nasr, 2016). It allows product components to be used again at high quality, while reducing energy demand by $80 \%$ in some instances (ibid). Through sophisticated industrial processes, some products can be brought back to the same specification as new, while others are made into a new product, consisting of new and remanufactured materials/components without compromising performance and operational quality (ibid). Remanufacturing is an important solution that can be applied to existing products, as well as to future design that will generate less waste, and allows for waste to become a resource, through the repair and reuse of materials.

Taking this one step future, repairing and remanufacturing products and materials has positive social impacts as well. Although most people have some awareness of environmental issues and suspect that consuming things isn't going to us happier, it is not enough to alter individual behaviour, and so we continue to acquire new stuff, rather than making or reusing things (Gauntlett, 2011, p. 57). The acts of repairing and remanufacturing materials and products require individual creativity, which have social impacts as they can contribute to personal well-being and a sense of connectedness within a community and nature (ibid). There is much to be gained from shopping less and creating and recycling more. 
Thinking and working within a circular economy challenges the profligate use of our resources, material and energies (Baker-Brown, 2017, p. 166). It forces us to rethink, re-engineer and rebalance our behaviours in such a way that we become more mindful of the value and finite nature of the world's resources. Waste is simply "matter out of place"; it is part of the natural order of things (ibid). This can be applied in the context of the circular economy which posits that there is no such thing as waste, rather just stuff in the wrong place. We need to start thinking of waste as a resource, rather than a byproduct of the linear consumption process.

\subsection{Educating Circular Economy Leaders}

Every organisation or individual has its role to play in creating and maintaining a successful circular economy. Each level of government is an enabler; businesses are drivers and people become users, instead of consumers of products (Garrigou, 2017). The circular economy offers business leaders and government a clear opportunity for long-term growth that is less dependent on cheap materials and energy, and which can restore and regenerate natural capital (EMF, 2015). It seeks to rebuild financial, manufactured, human, social or natural capital by ensuring enhanced flows of goods and services. In a circular economy, growth comes from 'within', by increasing the value derived from existing structures, products and materials (ibid).

Furthermore, understanding where is the most circular value could be optimized will allow for system effectiveness and the reduction of negative externalities such as pollution, dangerous chemicals, health hazards, and scarce resource hungry systems (ibid). Educating all stakeholders about what a circular economy is, what it solves for and the various forms it takes, is an important step to advance a successful circular economy in a coordinated fashion.

\subsection{Policy Levers that Enable Circular Economy Transitions}

The Ellen MacArthur Foundation identifies 10 policy levers that local decision makers can 
use enable urban circular economy transitions. These policy levers are interlinked and work to enable that waste and pollution to be designed out of products and urban systems; materials to be kept in use and maintain their value; and for natural systems in and around cities to regenerate (EMF, 2019). The policy levers broken down are:

1. Legislation and regulation involve shaping bylaws that stimulate circular economy practices. Take for example, organic waste treatment requirements for large commercial food retailers;

2. Fiscal measures can be used to discourage or incentivize certain behaviours or market developments (including taxes, charges, fees, fines). An example of this could be tax benefits for circular economy products or businesses; tax reductions on use of recycled materials; tax increases on undesirable waste streams and tax reductions for activities involved in the share, repair and recycle businesses;

3. Financial support in the form of grants, subsidies, direct and indirect investments and procurements through which city governments can enable circular city developments within local governments, public asset management, public procurement and capacity building;

4. Public procurement refers the purchase of goods and services by the public sector. It can range from the purchase of everyday office goods and services to large scale urban infrastructure projects. Integrating circular economy criteria within public procurement policies and practices can stimulate the circular design, provision, management and servicing of goods. City governments have a large purchasing power which gives them the ability to create demand and shift the market to new ways of providing goods and services, from the individual product level to the system level;

5. Asset management refers to the management of city-owned physical assets, including land, buildings, roads and bridges, water and sewage systems, amongst other items. The use of 
circular economy principles can help to unlock opportunities ranging from cost-savings to maximizing resource value, use and circulation (in the evaluation of the assets life cycle costs);

6. Urban planning as a policy lever refers to the physical shaping and development of a city. It assesses physical, social, and environmental factors and determines the allocation, development and usage or urban structures such as buildings, infrastructure and parks. It has a powerful impact on how people and goods move around in a city and can have strong impact on whether materials, products and nutrients can be recaptured and kept in use. It can also create long term housing, mobility and behavioural lock-ins. Decisions in urban planning contribute significantly to how materials, products and nutrients flow between people and sites in the city. They can also influence how people work and travel and how organizations operate;

7. Capacity building refers to training and advisory support programmes for individuals, companies and organizations, to help mainstream circular economy understanding and practices within society, such as incubator programmers, and material-exchange platforms.

8. Raising awareness of circular economy opportunities is key to supporting local transitions (which includes knowledge sharing and communication campaigns);

9. Convening and partnering. Local governments have the ability to convene, facilitate and spur collaboration between public, private and civic leaders. Engaging multiple stakeholders in public policy creation and delivery is particularly valuable when innovating and making system changes (for enabling and developing circular opportunities). It can also help to achieve greater scale, shared ownership and mutually beneficial impact; 
10. Lastly, roadmaps and strategies set a direction of travel for a city, help orientate other policy levers and offer an invaluable opportunity to raise ambitions and engage stakeholders in addressing future opportunities for the city (EMF, 2019) All of these tools can be used by any level of government, and any level of policy maker to help encourage the use of circular economy principles, and create of circular processes that improve the environment and quality of life for residents.

The next part of this paper dives into the SCC Challenge submissions to evaluate how Canadian municipalities are embracing circular economy principles and assessing whether governments can be catalysts to bring circular economy thinking to the forefront of innovation and smart city technology adoption. The following section will describe the methodology that was used for this paper. 


\section{Chapter 3: Method}

This research will paper seeks to explore to what extent is circular economy thinking tied to smart city efforts in Canada. To answer this question, this research project reviewed submissions to the Government of Canada's Smart Cities Challenge (SCC/the Challenge) for evidence of circular economy efforts.

In November 2017, Infrastructure Canada announced the Smart Cities Challenge for municipal governments and Indigenous communities to leverage data and technology towards meaningful outcomes for residents (Code for Canada \& FCC, 2018). The Government of Canada has pledged $\$ 300$ million over 11 years for Infrastructure Canada to launch the Smart Cities Challenge that seeks to empower local communities to become more liveable, inclusive and economically prosperous by encouraging innovation and the use of data and connected technology (ibid). The Challenge is a competition open to all municipalities, local or regional governments, and Indigenous communities across Canada (Impact Canada, 2018). It inspired communities across the country to define their future with the help of their residents through the use of a smart cities approach (ibid).

130 applicants from all 13 Canadian provinces and territories engaged residents about the most pressing issues they face in their communities and submitted impactful, ambitious, and transformative applications to the first competition of the SCC (ibid). Communities of all sizes, with

populations ranging from 185 residents to 2.7 million residents are demonstrating their commitment to harnessing technology for people. Winning communities will be awarded with prize money to help implement their smart cities approach. Prizes include: one prize up to $\$ 50$ million (open to all communities, regardless of population); two prizes of up to $\$ 10$ million each (open to all communities with populations under 500,000 people); and one prize of up to $\$ 5$ million (open to all communities with populations under 30,000 people). The Smart Cities Challenge includes three 
competitions, the first wrapping up in the Spring of 2019 (ibid). In the first round of applications, 10 proposals were shortlisted and were tasked to further develop their proposals by March 2019. At that point, the Challenge organizers will review the shortlisted communities final submissions and choose 5 successful applications. The winners will be announced in summer 2019 and awarded the prize money as appropriate.

The SCC defines a "smart cities approach" as achieving meaningful outcomes for residents by leveraging the fundamental benefits that data and connected technology have to offer, including: openness, integration, transferability and collaboration (ibid). Openness refers to when communities make their data truly accessible, usable and barrier free, allowing their decision-making processes to become transparent, empowering citizens and strengthening the relationship between residents and public organizations (ibid). Integration refers to data and connected technology empowering communities to break down silos that exist within local governments and public organizations (ibid). Transferability means when tools and technological approaches are open-source, transparent, and standardized, they can be used by communities across the country, no matter their size or capacity (ibid). Lastly, collaboration means connected technology enables communities to bring traditional and non-traditional partners together to collaborate (ibid).

The SCC is a step towards the development and implementation of smart city innovations in Canadian communities. Many communities throughout the country have started to establish roles and units within local government, which range from directors of innovation and chief digital officers, to civic innovation and smart city offices (ibid). These investments increase the public sector's capacity to develop, test and implement solutions by applying technology, data analysis and design thinking to the challenges our cities face (ibid). The Challenge represents an opportunity to pair the potential of smart city technologies with the unique challenges facing various 
communities across Canada, and develop innovative solutions that will contribute to an improved quality of life for residents. The Challenge sought to propel innovation and thinking big, and create opportunities for communities to build new partnerships and networks. The SCC also provides an opportunity to bring sustainability and in particular, circular economy principles, to the forefront of city building.

Each applicant was to indicate their preferred area of focus for the challenge, based on mobility; healthy environment; healthy lifestyle and recreation; economic opportunity; safety and security; and empowerment and inclusion (ibid). A maximum of two focus areas was permitted (ibid). The application process was comprised of a series of questions, including the following more relevant aspects:

- Define a challenge statement in a single sentence that guides the preliminary proposal, which describes the outcome(s) that address(es) an important problem in your community and should state the aim to be achieved by implementation of the proposal. The outcomes must be measurable, ambitious, and achievable through the proposed use of data and connected technology.

- A description of the outcome(s) that the proposal seeks to achieve (state specific goals, identify baseline data and evidence to establish metrics, rationale for applying a smart city approach to achieving the identified outcome, and a strategy for measuring progress).

- Describe the community engagement techniques used to shape the challenge statement with residents, businesses, organizations and other stakeholders. The challenge statement should reflect the concerns and needs of the residents, and that the results of the consultations and engagements activities will inform and guide the development of the final proposal going forward.

- Describe the preliminary proposal and its activities or projects (planned activities or projects to achieve the outcome, clear links from the identified projects to the attainment of the outcome, scope and size of each project, and measures put in place to make the proposal open, interoperable, scalable, and replicable; and enable other uses of the technology, innovation and data in your proposal). The proposal qualifies as a smart city proposal if it achieves positive outcomes for residents by leveraging connected technology and data. 
- Describe the ways in which the proposal supports the community's medium and long-term goals, strategies, and plans and your community's readiness and ability to successfully implement your proposal.

- Describe the partners that are or will be involved in the proposal, including private sector, not-for-profit, public utilities, research/academia, civil society, public or national organizations/groups and project incubators.

The SCC provides an opportunity for local and regional governments to adopt a smart cities approach to improve the lives of their residents through innovation, data and connected technology (ibid). The goals of the challenge focus on innovation and thinking big, creating opportunities for communities to build new partnerships and networks, and create an opportunity to scale these programs to other communities. It also provides an opportunity to bring circular economy principles to the forefront of city building

To assess the extent to which circular economy thinking is present, 102 of the 130 submission the Smart City Challenge were reviewed ${ }^{1}$. Firstly, a keyword search was conducted in a database ${ }^{2}$ containing key informational elements about the 102 application submissions used for this research project. The categories within the database include the challenge statement, main proposal themes and keywords, areas of focus, technologies involved, and the role of a smart city approach in selecting/achieving outcomes. Conducting a keyword search within the database was sufficient, as these categories breakdown the intent of each application, where information pertaining to circular economy principles would be found. The following terms were searched: circular economy, sustainable, waste, zero waste, waste management, local, manufacturing, innovation, and culture of innovation. These terms are indicative of circular economy principles and as such, were ideal for the keyword search. In reviewing the SCC information database.

\footnotetext{
1102 of the 130 applications were reviewed as not all were accessible. Some of the applications were in french, while others were not available.

2 This database belongs to Professor Pamela Robinson, School of Urban and Regional Planning, Ryerson University and it was assembled to support research on Round One of the SCC.
} 
Using this approach, a shortlist of municipalities was created. In the process of conducting the keyword search of all the terms, five applications kept coming up. Ultimately these five applications were deemed responsive based on the search criteria. The applications were from: the City of Port Alberni (British Columbia), the District of Squamish (British Columbia), the City of Guelph and Wellington County (Ontario); Hope Town (Quebec) and the City of Coquitlam (British Columbia). Next, the full applications that were analysed in depth, through a case study analysis. Using the Ellen MacArthur Foundation's (EMF) circular city principles of Regeneration, Sharing, Optimization, Looping, Virtualization and Exchange (the ReSOLVE framework), each application was evaluated. The ReSOLVE framework was selected as it considers the social, economic and environmental dimensions of circularity and sustainability. An analysis of opportunities for further harmonization of circular economy principles was also conducted. The framework for analysis includes an evaluation of whether or not the application mentions principles of a circular economy as per the ReSOLVE framework? Are the principles recognized? How far does each submission go in addressing circular economy principles? Does a circular economy focus comprise the entire application or only partially? What other principles are prioritized in the application (such as economic, social development and environmental sustainability goals)? Is there an opportunity for further integration?

Secondary resource case studies were used to assess the level of circular economy thinking. The Challenge submissions and proposals are a good first signal of thinking and acting that may follow. Case study research allows the exploration and understanding of complex issues (Zainal, 2017, p.1). It can be considered a robust research method particularly when a holistic, in-depth investigation is required. Secondary research case studies are recognised as a tool in many social science studies, the role of case study method is prominent when dealing with issues 
regarding education, sociology and community based problems such as poverty, unemployment, drug addiction, and illiteracy (ibid).

There are a number of advantages in using case studies. First, the examination of the data is often conducted within the context of its use - within the situation in which the activity takes place (ibid, p. 4). Further, the detailed qualitative accounts often produced in case studies help to explore or describe the data in real-life environment, and help to explain the complexities of real life situations which may not be captured through experimental or survey research (ibid, p.4)

Research limitation: It is important to note that a limitation is this study is that this is a subjective assessment of applications. It is subjective, based upon the criteria drawn from the literature review conducted in Chapter 2 of this research paper. 


\section{Chapter 4: Problem Investigation/Evidence and Findings}

\subsection{Case Study 1: City of Port Alberni, British Columbia}

\subsubsection{Description}

The City of Port Alberni is located in British Columbia and hosts a population of 17,678 people. Port Alberni applied for the $\$ 10$ million prize category, however was not selected as a finalist. It's challenge statement focused on becoming a truly resourceful community, striving to become Canada's first true zero waste community and fully utilize the natural resources in it's coastal area. Port Alberni's primary objective is to reduce solid waste to zero within five years, which is defined as being achieved "when no solid waste is burned or buried in its regional landfill". Their second objective is to help local resource-based industries, specifically fishing and forest resources, fully utilize the ocean and forest resources they harvest, by reducing waste in their operations.

The application states that "humans have become efficient at making waste disappear, which makes the environmental, economic, and social costs invisible to citizens. For for most people, their immediate "environment" is their home and workplace, and that we all feel pride when we keep this environment clean. Cleaning, however, usually includes throwing things away" (p. 3). It is difficult for residents to see a connection between their consumption and disposal habits, and their associated impacts on the physical environment. The application recognizes waste as a form of consumption that consumes the City's land, time, and money and capacity of the atmosphere to absorb greenhouse gases (GHGs).

The application indicates that the regional expenditures on the landfill operation total $\$ 2$ million per year, which does not account for future expansion of waste facilities. Further, there are hidden costs of the lost economic and social opportunities to recover value from wasted materials, and to create jobs in the process. Through their smart city initiative, they seek to encourage local 
economic development, based on enterprises that recover value from waste, and allow for the associated economic benefits to remain within their community, as well as addressing social aspects of waste within the community. The City plans on tapping into an underutilized resource: the creativity, ingenuity, and caring of its citizens. The City seeks to learn from the traditional wisdom of the Tseshaht First Nation and Hupačasath First Nation people, about their relationships with the environment, natural resources, consumption, and waste.

The application indicated that planning will be guided by the understanding that they cannot achieve zero waste incrementally, and radical re-thinking is needed. The City will rely on the following principles:

1. Waste is a resource in the wrong place, and every waste is a potential resource.

2. Every resource has a highest and best use and value, including social and economic value.

3. Everything in nature is connected.

4. First consider what wasted resources are available (e.g. food waste), then ask what markets exist for recovered materials (e.g. biomethane and fertilizer), and finally consider which conversion technologies (e.g. anaerobic digestion) will result in the highest value for the community.

Smart data collection to track the amount of waste collected was proposed as a solution.

Taking the form of mobile and desk app to be called "ReStore"; it will help people feel satisfaction from returning and from buying, showing where materials can be recycled, and showcase the full story of waste. The data generated within the app would be used to charge for waste disposal through a "Re Pay" app, which will charge per kilogram of waste and gradually increase in an effort to improve effort to separate food waste into green bins and recycling.

Another solution proposed by the City is a "ReLent" app will help users connect with others in their vicinity to share goods such as cars, tools, and lawn mowers, whereby reducing consumption and waste of durable goods. Further, if Port Alberni's application is successful, the City plans invest in two different kinds of resource recovery initiatives. Firstly, it will conduct a feasibility study to determine if an anaerobic digester can be created to recover biomethane and 
fertilizer from organic waste, as organic waste comprises over $40 \%$ of solid waste. Secondly, investment in the startup (and expansion) of resource recovery businesses, including: producers of packaging materials made from cellulose (which could come from local paper mill and sawmill waste) and plant-based material; businesses which up-cycle waste materials into useful products; and services to re-furbish mobile phones, computers, and other electronics for re-sale.

\subsubsection{Analysis of Port Alberni's Application}

Overall, the City of Port Alberni relies on and refers to principles of a circular economy throughout its application. The following is an evaluation of the application:

\begin{tabular}{|l|l|}
\hline Principle & Assessment from the Final Application Submission \\
\hline Regenerate & $\begin{array}{l}\text { The City plans to undertake a feasibility study to enable the creation of an anaerobic } \\
\text { digester, which can be used to recover biomethane and fertilizer from organic waste } \\
\text { (which represents 40\% of its waste output). }\end{array}$ \\
\hline Share & $\begin{array}{l}\text { Sharing assets is enabled through the use of the "ReLent" desk and mobile app, } \\
\text { which incentivizes borrowing/reuse rather than buying. The application also states } \\
\text { that the City plans on tapping into an underutilized resource: the creativity, ingenuity, } \\
\text { and caring of its citizens. As such, it recognizes the economic and social } \\
\text { opportunities to recover value from wasted materials, and to create jobs in the } \\
\text { process. }\end{array}$ \\
\hline Optimize & $\begin{array}{l}\text { By using gathered data on waste generation, Port Alberni can monitor consumption } \\
\text { habits, which will be shared with residents and potentially lead to a re-evaluation of } \\
\text { their habits. Data can allow disposal methods to be optimized by decreasing } \\
\text { traditional waste management solutions. Furthermore, the application seeks to } \\
\text { encourage local economic development based enterprises which can recover value } \\
\text { from waste, thus allowing economic benefits to remain within their community. }\end{array}$ \\
\hline Loop & $\begin{array}{l}\text { Waste separation and recycling is encouraged through the "Re Pay" app, which is a } \\
\text { model that charges based on individual household waste production behaviour. The } \\
\text { City's intended investment in startup resource recovery businesses introduces } \\
\text { opportunities for looping materials and services. }\end{array}$ \\
\hline Virtualize & $\begin{array}{l}\text { Virtualization of individual waste disposal habits is created through the use of the } \\
\text { mobile and desk apps. However, the creation of apps to directly replace materials is } \\
\text { not suggested in the application. }\end{array}$ \\
\hline Exchange & $\begin{array}{l}\text { The exchange principle, which focuses on replacing old technologies with advanced } \\
\text { non-renewable materials is achieved through the investment of waste recovery }\end{array}$ \\
\hline
\end{tabular}


businesses and upcycling of waste materials into other consumer products.

The application envisions the City of Port Alberni to become Canada's first true zero waste community. Waste management and environmental sustainability goals are the main drivers of the application, with social development goals considered as well. The City's second stated objective of helping local resource-based industries fully utilize the ocean and forest resources they harvest, by reducing waste in their operation - is not fully addressed in the challenge statement and accompanying proposal. The submission would benefit from more discussion of the opportunities around utilizing the surrounding natural coastal resources, and could aid the City of Port Alberni's plans to transition to a circular economy.

\subsection{Case Study 2: District of Squamish, British Columbia}

\subsubsection{Description}

The District of Squamish is located in British Columbia and hosts a population of 19,512 people. The District applied for the $\$ 10$ million prize category, however was not selected as a finalist. It's challenge statement focused on a zero-waste action plan that engages and empowers the community to sustainably grow while reducing overall waste, and turning waste into assets (such as clean energy, renewable materials and new products). Squamish believes that its action plan will power its economy, create future-focused jobs, all while exceeding government waste and GHG emission targets.

As the population in Squamish is estimated to double by 2036, the District seeks to use the circular economy principles of restorative and regenerative design to grow its geographic area sustainably. Relying on system-wide innovation, Squamish aims to redefine products and services to design waste out, while minimizing negative impacts. Powered by data and connected 
technology, it envisions all stakeholders working together to ensure an overall waste reduction, and also to turn waste into valuable assets.

The District's envisioned goal is to exceed provincial waste diversion targets through the transition to a circular economy and achieve a waste diversion rate of $79 \%$ by 2025 . It also aims to reduce the number of commuters by $5 \%$ via the creation of 200 new jobs that will contribute directly to its local economy. Its residents and businesses currently have little incentive to shift attitudes or habits that relate to waste. Currently, the District is spending $\$ 3 M$ annually on waste management and the local landfill has reached capacity, requiring a $\$ 5 \mathrm{M}$ vertical landfill expansion. The application states that beyond reducing and diverting overall waste, capitalizing on technologies that better manage landfill operations will be critical to address increasing capacity requirements due to constant growth.

Waste materials such as grain waste from the beverage industry or wood waste generated through the forest industry present an opportunity of waste becoming an asset, thereby shifting from a cost to a revenue stream. These wood biomass volumes could alternatively become a net economic contributor for the industry and our community. With more than $70,000 \mathrm{~m}^{3}$ of annual waste stock available from active logging operations and related activities, wood waste has the potential to be managed by data and connected technology to power industrial operations, homes and buildings in Squamish - ultimately displacing fossil fuels and reducing GHG emissions.

Furthermore, there are more than 6,600 housing units currently in the District's development pipeline. Squamish seeks to address the waste generated as a result of construction activity by using reduction strategies such as gamification, technology to streamline landfill operations and the diversion of biomass to renewable energy. These strategies are all seen as practical and achievable options to better manage, monetize and reduce construction debris. The District's goal is to mitigate impacts from population growth by creating knowledge platforms for 
innovation focused on remanufacturing, value chains and byproduct sharing. And use data to drive more productive and profitable decisions, improving business processes, community management and personal impact.

The District's proposed smart city solutions include smart tracking. By developing an asset tracking to energy program and working with the local business community, the District will help identify, quantify, grade and value industrial/ commercial byproducts through the use of asset-tracking technology for use in clean energy production. Connecting the asset tracking to energy program, the District will work to generate and store clean energy through energy management systems to power homes, buildings and municipal infrastructure.

Further, the Squamish Zero-waste Platform will work with partners, integrating marketplaces, gamification and knowledge transfer with insights from data and connected technology. In addition, a byproduct marketplace will be created for residents and local business to share byproducts of what they make to be used for other applications and manufacturing processes. Lastly, a knowledge and innovation hub will be created to grow the collective knowledge base, sharing insights from activities, providing training and education, and encouraging new data and connected technology innovations in waste reduction and diversion.

\subsubsection{Analysis of the District of Squamish's Application}

Overall, the District of Squamish relies on the principles of a circular economy throughout its application. The following is an evaluation of the application:

\begin{tabular}{|l|l|}
\hline Principle & Assessment from the Final Application Submission \\
\hline Regenerate & $\begin{array}{l}\text { The application is focused on the creation of a zero-waste action plan that } \\
\text { engages and empowers the community to sustainably grow while reducing } \\
\text { overall waste, and turning waste into assets (such as clean energy, renewable } \\
\text { materials and new products). }\end{array}$ \\
\hline Share & $\begin{array}{l}\text { Sharing services and materials is enabled through the use of the byproduct } \\
\text { marketplace, in which makers share their byproducts to be used for other }\end{array}$ \\
\hline
\end{tabular}




\begin{tabular}{|l|l|}
\hline Optimize & $\begin{array}{l}\text { applications and manufacturing processes. There is lots of discussion about } \\
\text { design for durability and zero-waste throughout the application. The creation of } \\
\text { knowledge and innovation hub will share information. }\end{array}$ \\
\hline Loop & $\begin{array}{l}\text { The application focuses on reducing overall waste by incentivizing behaviour } \\
\text { and encouraging smarter, more efficient practices. For example, implementing } \\
\text { smart landfill technologies for reverse vending and waste separation, as well as } \\
\text { to measure sorting yields, will help optimize waste streams for the District and } \\
\text { associated expansion costs. }\end{array}$ \\
\hline Virtualize & $\begin{array}{l}\text { Waste separation and recycling is encouraged throughout the application. } \\
\text { The District's goal is to mitigate impacts from population growth by creating } \\
\text { knowledge platforms for innovation focused on remanufacturing, value chains } \\
\text { and byproduct sharing. }\end{array}$ \\
\hline Exchange & $\begin{array}{l}\text { The Squamish Zero-waste Platform integrates gamification and knowledge } \\
\text { transfer using insights from data and connected technology. }\end{array}$ \\
\hline & $\begin{array}{l}\text { Implementing smart landfill technologies for reverse vending and waste } \\
\text { separation will replace old landfill technologies. }\end{array}$ \\
\hline
\end{tabular}

The application is very clear in that the District of Squamish intends to invest in using circular economy principles of restorative and regenerative design to grow sustainably. Relying on system-wide innovation, it aims to redefine products and services to design waste out, while minimizing negative impacts. Economic, social development and environmental sustainability goals are all at the forefront of the application, and embedded in the proposed technology solutions. There an opportunity for further integration of circular economy principles, to connect more thoroughly the District's aim for a 5\% reduction in the number of commuters via the creation of 200 new jobs that will contribute directly to its local economy.

\subsection{Case Study 3: The City of Guelph and Wellington County, Ontario}

\subsubsection{Description}

The City of Guelph and Wellington County (Guelph-Wellington) is located in Ontario and hosts a population of 222,726 people. Guelph-Wellington applied for the $\$ 10$ million prize category, and were selected as finalists. It's challenge statement focused on becoming Canada's first 
technology-enabled Circular Food Economy, creating a food-secure ecosystem that increases access to affordable, nutritious food by $50 \%$, where waste becomes a resource, to create 50 new circular businesses and collaborations, and increase circular economic revenues by $50 \%$ : $50 \times 50 \times 50$ by 2025 .

The basic structure of the current linear "take-make-dispose" food system is economically, socially and environmentally unsustainable. Guelph-Wellington aims to become Canada's first circular food economy, bringing its food system and communities back into healthy balance. Situated in Ontario's Innovation Corridor, Guelph-Wellington is an already existing hub of food innovation and environmental sustainability. Leveraging local expertise, big data and the latest technology to transform the food ecosystem into a connected "living lab" where researchers, social innovators, farmers, entrepreneurs and other community partners can collaborate to solve complex food problems.

Smart technologies are already helping farmers produce more food with fewer inputs - by optimizing seeding, fertilizer use, and herd health. There are also opportunities to use smart technology throughout the food system. To become Canada's first data and technology enabled circular food community, Guelph-Wellington will re-imagine a "smart" food system that better ensures food security and healthier outcomes, implicitly recognizes equity and dignity for all, better manages food resources to serve a diverse and vibrant community, and celebrates the importance of good food in daily life.

Guelph-Wellington's proposed solutions include the creation of baseline asset and behaviour mapping which will seek to understand what currently exists in the community and where gaps lie, and identify geographic and demographic priorities areas. The analysis of multiple layers of data, including behaviour, will also provide insights for public health interventions and a 
platform for community-wide evidence-based decision-making. This data will be used to develop a Food Security and Health Action Plan for the region.

With regard to its goal of creating of 50 new circular collaboration partnerships, businesses and jobs, in its application Guelph-Wellington states that this involves developing a circular innovation ecosystem that leverages social innovation and technology to advance new business models and collaborations to tackle local and global food problems. This will be done accomplished by the establishment of "collision" spaces that promote new business collaborations and innovations to solve food system challenges through a technology-enabled platform to identify challenges and seek solutions. Further, the establishment of a Circular Food Economy Lab will consist of partnerships and collaborations that applies data, technology and social innovation to re-invent local food systems and solve local food problems that are globally relevant. The project will create hubs for collaborators in the agri-food, clean tech, social innovation sectors to address circular food challenges and drive outcomes.

Guelph-Wellington also seeks to create new opportunities and sources of revenue by valuing waste as a resource, resulting in a $50 \%$ increase in circular revenue across the community. It will re-imagine, re-use and re-value food ecosystem inputs and outputs by maximizing their use, eliminating waste, optimizing economic value and reducing negative environmental impacts. A circular food economy will design waste out of the system, repurposing it to create new inputs that produce both nutrition and energy. Business tools and services will be developed, curated and shared to create a suite of tools, business diagnostics and services to help public organizations and businesses reinvent their processes and business models. This will support the creation of value from "waste" by-products that are currently under-used or discarded, recovering chemicals, nutrition, medicinal compounds and energy. It would involve applying blockchain technology to the 
agri-food supply chain to increase transparency and reduce waste, developing new tools and business models that can be shared with others.

To help other local businesses buy and sell their own GHG/carbon offsets, Guelph-Wellington is exploring the potential of developing a secure, open and accessible digital marketplace powered by blockchain technology. Having access to this system will encourage more companies to reduce their carbon footprint by buying offsets generated from food waste.

Meanwhile, companies that generate carbon offsets can find local buyers for those credits, keeping the monetary and social value circulating in the Guelph-Wellington community. This project will both reduce waste and create new revenue streams out of wasted resources. In addition, it will create new circular businesses in the community.

\subsubsection{Analysis of the City of Guelph and Wellington County's Application}

Overall, the City of Guelph and County of Wellington rely on the principles of a circular economy throughout its application, for the creation of a circular food economy. The following is an evaluation of the application:

\begin{tabular}{|l|l|}
\hline Principle & Assessment from the Final Application Submission \\
\hline Regenerate & $\begin{array}{l}\text { The application seeks to create new opportunities and sources of revenue by valuing } \\
\text { waste as a resource, and by re-imagining, re-using and revaluing food ecosystem } \\
\text { inputs and outputs by maximizing their use, eliminating waste, optimizing economic } \\
\text { value and reducing negative environmental impacts. }\end{array}$ \\
\hline Share & $\begin{array}{l}\text { The application discusses developing a circular innovation ecosystem that shares } \\
\text { information and leverages social innovation and technology to advance new business } \\
\text { models and collaborations to tackle food problems. }\end{array}$ \\
\hline Optimize & $\begin{array}{l}\text { The creation of baseline asset and behaviour mapping will help decision makers } \\
\text { understand the systems strengths and weakness and identify priorities for the } \\
\text { community. The analysis of data will provide insights for public health interventions } \\
\text { and a platform for evidence-based decision-making. }\end{array}$ \\
\hline Loop & $\begin{array}{l}\text { To help other local businesses buy and sell their own GHG/carbon offsets, Guelph is } \\
\text { exploring the potential of developing a digital marketplace powered by blockchain }\end{array}$ \\
\hline
\end{tabular}




\begin{tabular}{|l|l|}
\hline & $\begin{array}{l}\text { technology to encourage more companies to reduce their carbon footprint by buying } \\
\text { offsets generated from food waste. }\end{array}$ \\
\hline Virtualize & $\begin{array}{l}\text { Guelph is exploring the potential of developing a secure, open and accessible digital } \\
\text { marketplace powered by blockchain technology, to help other local businesses buy } \\
\text { and sell their own GHG/carbon offsets. }\end{array}$ \\
\hline Exchange & $\begin{array}{l}\text { "Collision" spaces will be established to promote new business collaborations and } \\
\text { innovations to solve food system challenges through a technology- enabled platform. }\end{array}$ \\
\hline
\end{tabular}

The Guelph-Wellington application addresses many principles of the circular economy in its proposal to create a circular food economy. Social, economic and environmental sustainability goals are equally prioritized in the proposal. There is an opportunity for further integration of the exchange principle in replacing old technologies with advanced materials or new technologies, such as cash-less markets.

\subsection{Case Study 4: The Municipality of Hope Town, Quebec}

\subsubsection{Description}

The Municipality of Hope Town is located in Quebec and hosts a small population of 339 people. The Municipality of Hope Town applied for the $\$ 5$ million prize category, however was not selected as a finalist. Mount Hope's challenge statement focused on coupling existing infrastructure and mobile technologies to re-engineer the "thrift shop" model of reusing consumer goods, to create a platform to combat poverty and social inclusion, encourage sustainable consumer goods consumption/ waste reduction through a social capital exchange and reinvigorate a devitalized rural community.

The Municipality intends to use mobile and web based technology to create a consumer goods and community resource exchange platform, which will be called the "Hope Town Resource Center". The project will offer a physical location to store and distribute consumer goods that are able to be reused or repurposed; create a digital platform where consumers can conveniently 
participate in this exchange; and create a social capital exchange, where users can buy or sell consumer goods and services in exchange for social capital rather than currency.

The application begins by stating that modern society is trending towards a circular economy (production, distribution, consumption, reuse/repair/upcycle, return to production) rather than a linear economy (resource extraction, production, distribution, consumption, waste). This model will have the backing of the population which will result in a community networking dynamic, that fosters the free exchange of ideas, sharing of resources and collaboration towards common development goals.

Hope Town's proposed solutions include a "social credit" system will allow individuals with restricted incomes to afford quality goods. Individuals who wish to acquire social credits can do so as payment for either selling a product or service on the exchange platform. Products and services would include: excess garden produce, seamstress services, volunteer hours with local community organizations, repaired, refurbished or upcycled goods, handicrafts and other hand made items. The application states that there is no limit to the innovative ways that an individual may use their particular talents to offer a desired good or service to the community at large. In addition to acquiring the social credits, which can in turn be redeemed on the exchange, individuals living with social exclusion can find their way to interact in a meaningful and productive way with the community at large.

The promotion of community groups will be built right into the platform, which would generate awareness of community groups and the work that they do for the community at large. Hope Town believes that rooting the project in a physical location is a key element to achieving outcomes. While the digital exchange platform provides broad and uniform access, a physical location is required to bring the deliverables directly to the people, and to root the project within the community. The physical location will offer essential support to those individuals who do not have, 
or are not at ease with online access or mobile technologies.

\subsubsection{Analysis of the Municipality of Hope Town's Application}

The Municipality of Hope Town included a few elements of circular economy thinking in its application. The following is an evaluation of the application:

\begin{tabular}{|l|l|}
\hline Principle & Assessment from the Final Application Submission \\
\hline Regenerate & This principle is not used in the application. \\
\hline Share & Sharing services and assets is enabled through the social credit system. \\
\hline Optimize & This principle is not used in the application. \\
\hline Loop & $\begin{array}{l}\text { Reuse, repair, refurbishment and upcycled goods is mentioned in the application } \\
\text { and is encouraged through the social credit system. }\end{array}$ \\
\hline Virtualize & $\begin{array}{l}\text { The application uses a digital platform to run ths social credit system, but also } \\
\text { notes the importance of a physical location for residents that do not have means } \\
\text { of using technology to access the system. }\end{array}$ \\
\hline Exchange & $\begin{array}{l}\text { The social credit system allows individuals with restricted incomes to afford } \\
\text { quality goods. Individuals who wish to acquire social credits can do so as } \\
\text { payment for either selling a product or service on the exchange platform. }\end{array}$ \\
\hline
\end{tabular}

There is a particular emphasis placed on local making and social enterprise throughout the application, with the principles of sharing, looping and exchange visibly prioritized. Due to the smallness and remoteness of the population, there may be limited solutions for using smart city technology applications. However, applying circular economy principles can be further developed, and may contribute to the Municipality's economic development objectives even further than what is described.

\subsection{Case Study 5: The City of Coquitlam, British Columbia}

\subsubsection{Description}


The City of Coquitlam is located in British Columbia and hosts a population of 139, 284 people. The City of Coquitlam applied for the $\$ 10$ million prize category, however was not selected as a finalist. Coquitlam 's challenge statement focused on becoming a smart city living lab by leveraging technology, data, experimentation, research and public-private-people partnerships to develop waste management solutions that minimize and mitigate human-wildlife conflict and address other emerging environmental and sustainability issues such as waste reduction and diversion, greenhouse gas reduction and use of renewable energies.

Coquitlam has experienced a sharp increase in the frequency of human-wildlife conflicts, due to an increase in unsecured garbage and other similar attractants in residential, commercial and public areas. In 2017, the City received 685 bear-related complaints. The City's application states that with extensive development planned in Coquitlam, new tools are required to better manage its solid waste program. The increased use of technology for smart waste management as well as data collection and analysis associated with wildlife behaviour would enable the City to develop evidence-based solutions that would minimize human-bear conflict and protect both residents and bears.

The City of Coquitlam intends to become a Smart City Living Lab, where it would leverage available technology, such as smart waste management infrastructure, video, environmental sensors and public-facing mobile apps, as well as undertake community engagement initiatives and data collection to inform decisions on planning, service delivery and smart waste-management solutions. The initiative is also intended to provide a template for identifying and addressing emerging issues related to our environment in the future. Coquitlam states the anticipated outcomes to include: reducing the number of incidences of bear attractants in residential, commercial and public areas; using data collected to support evidence-based decision making with regard to waste management (diversion and reduction); 
reduction human-wildlife conflict (by ensuring residential garbage is enclosed and secure); and other emerging issues (GHG reduction, renewable energy sources, etc.); and improving environmental sustainability both in how the City's residents live with wildlife and how to develop the City's growth areas.

Coquitlam's Smart City Living Lab concept is centred on a collaboration between the resident and the City, and integrates technology, innovation, research, and partnerships to design solutions that meet residents' needs and include a continuous service improvement objective. For example, information from various sensors, cameras, live experiences (via public feedback and other stakeholder input) and data-collection tools would inform the development of custom waste management solutions. The collection and analysis of wildlife data on a regional level would provide opportunities for research, information-sharing and the development of collaborative solutions. The City states that the same technology infrastructure concept would also be replicated to address other environmental objectives such as GHG reduction; the use of renewable energy; and climate action, etc.

\subsubsection{Analysis of the City of Coquitlam's Application}

The City of Coquitlam included a few elements of circular economy thinking in its application. The following is an evaluation of the application:

\begin{tabular}{|l|l|}
\hline Principle & Assessment from the Final Application Submission \\
\hline Regenerate & This principle is not used in the application. \\
\hline Share & $\begin{array}{l}\text { Sharing physical assets is not included in the application. However, Coquitlam's } \\
\text { Smart City Living Lab concept is centred on a collaboration between the } \\
\text { resident and the City, and integrates technology, innovation, research, and } \\
\text { partnerships to design solutions that meet residents' needs and include a } \\
\text { continuous service improvement objective. Therefore the concept of sharing } \\
\text { knowledge and resources is utilized in the application. }\end{array}$ \\
\hline Optimize & $\begin{array}{l}\text { The concept of optimization is used in the application, in the context of } \\
\text { Information from various sensors, cameras, live experiences (via public }\end{array}$ \\
\hline
\end{tabular}




\begin{tabular}{|l|l|}
\hline & $\begin{array}{l}\text { feedback and other stakeholder input) and data-collection tools that would } \\
\text { inform the development of custom waste management solutions to optimize } \\
\text { responses to bear-human conflict and waste management goals. The collection } \\
\text { and analysis of wildlife data on a regional level would provide opportunities for } \\
\text { research, information-sharing and the development of collaborative solutions. }\end{array}$ \\
\hline Loop & This principle is not used in the application. \\
\hline Virtualize & This principle is not used in the application. \\
\hline Exchange & This principle is not used in the application. \\
\hline
\end{tabular}

The City of Coquitlam's application has a very specific goal, in solving for bear-human interactions due to current waste management practices. Therefore, Coquitlam's application is light on the use of circular economy principles, with only sharing and optimization included in their proposal. Although the City's application discusses the potential for waste management solutions, they are not explored in detail in the application submission. As such it cannot be commented on, except to state that there is an opportunity for circular economy principles to be further developed, and may contribute to the City's waste management and environmental sustainability objectives even further than what is described.

\subsection{Summary of Analysis}

The following chart summarizes the five responsive applications. The ReSOLVE framework was useful in that it broke down the goals of circular economies into actionable principles that were applied to each responsive application. The sharing principle, which focuses around sharing assets and collaboration was used in every application. It is important to note the SCC application questions focused on identifying collaboration and partnerships, which are a derivative of the sharing principle. Furthermore Looping, Virtualization and Exchange principles showed up in four of the five applications. 
The adoption of smart city technology is a great opportunity to bring circular thinking into municipal decision making, as is demonstrated by the fact that three of the five applications contained all of the circular economy principles, while two had lots of opportunity to weave circular economy thinking into the proposals and smart city solutions. Waste management was a theme throughout all five applications, that connected each application to circular economy thinking.

\begin{tabular}{|l|c|c|c|c|c|}
\hline Principle & Port Alberni & Squamish & $\begin{array}{l}\text { Guelph/ } \\
\text { Wellington }\end{array}$ & Hope Town & Coquitlam \\
\hline Regenerate & $\mathrm{x}$ & $\mathrm{x}$ & $\mathrm{x}$ & & \\
\hline Share & $\mathrm{x}$ & $\mathrm{x}$ & $\mathrm{x}$ & $\mathrm{x}$ & $\mathrm{x}$ \\
\hline Optimize & $\mathrm{x}$ & $\mathrm{x}$ & $\mathrm{x}$ & $\mathrm{x}$ & $\mathrm{x}$ \\
\hline Loop & $\mathrm{x}$ & $\mathrm{x}$ & $\mathrm{x}$ & $\mathrm{x}$ & \\
\hline Virtualize & $\mathrm{x}$ & $\mathrm{x}$ & $\mathrm{x}$ & $\mathrm{x}$ & \\
\hline Exchange & $\mathrm{x}$ & $\mathrm{x}$ & $\mathrm{x}$ & \\
\hline
\end{tabular}

It is interesting to see the themes and similarities among the applications, considering the variety of population sizes, local challenges and smart city priorities. Going forward, there is an opportunity for the Federal government to frame the Challenge questions to better address circular principles. The Federal government could use the ReSOLVE framework to catalyse circular economy thinking in more municipalities.

The following chapter assesses the applications overall as well as the entire SCC process. 


\section{Chapter 5: Conclusion/Recommendations for Practice and Future Research}

The SCC provides an opportunity for local and regional governments to adopt a smart cities approach to improve the lives of their residents through innovation, data and connected technology (Impact Canada, 2017). The goals of the challenge focus on innovation and thinking big, creating opportunities for communities to build new partnerships and networks, and create an opportunity to scale these programs to other communities. It also provides an opportunity to bring circular economy principles to the forefront of city building. The Challenge inspired communities across the country to define their future with the help of their residents through the use of a smart cities approach (ibid). 130 applicants from all 13 Canadian provinces and territories engaged residents about the most pressing issues they face in their communities and submitted impactful, ambitious, and transformative applications to the first competition of the SCC (ibid).

In reviewing the applications, and considering that only five of 130 applications discuss circular economy principles - this highlights that more work needs to be done by the Federal government in shaping the Smart Cities Challenge to encourage circular thinking. This need is compounded by the fact that of the 10 finalists that advanced to the second round of applications, with only one submission relating to circular economy thinking. The Federal Smart Cities Challenge needs to create better opportunities to engage this type of thinking. The Challenge is an important catalyst, enabling municipalities across the country to fund impactful projects, create collaboration spaces, undertake baseline data mapping to guide programs and planning, create a suite of digital tools, and more. The geographic and demographic size of the applicant should not disway circular economy thinking.

The concept of the circular economy is fascinating, and applying it to adoption of smart city technology has potential - but that potential needs to be better integrated/managed/prioritized into the Smart Cities Challenge. One of this paper's recommendations centres around further 
development in smart city thinking centre around future Smart Cities Challenges, and building circular assumptions into the challenge questions would ensuring circular principles are a priority for municipalities as they continue to grow and adapt to smart city technological advances. In evaluating the questions that were asked and what was recieved, one can argue that circular economy principles were not assumed within the questions. A better way encourage circular thinking it to build assumptions into the questions or definitions.

According to its website, the SCC defines a "smart cities approach" as achieving meaningful outcomes for residents by leveraging the fundamental benefits that data and connected technology have to offer, including: openness, integration, transferability and collaboration (Impact Canada, 2017). Openness refers to when communities make their data truly accessible, usable and barrier free, allowing their decision-making processes to become transparent, empowering citizens and strengthening the relationship between residents and public organizations (ibid). Integration refers to data and connected technology empowering communities to break down silos that exist within local governments and public organizations (ibid). Transferability means when tools and technological approaches are open-source, transparent, and standardized, they can be used by communities across the country, no matter their size or capacity (ibid). Lastly, collaboration means connected technology enables communities to bring traditional and non-traditional partners together to collaborate (ibid).

One potential opportunity for the integration of circular economy principles is add to the current definition. Which could take the form of: A smart cities approach achieves meaningful outcomes for residents and the environment by leveraging the fundamental benefits that data and connected technology have to offer, including: openness, integration, transferability and collaboration as well as addressing economic, social development and environmental goals. Disruptive technologies create the potential to rethink, re-engineer and rebalance our cultural and 
social behaviours in such a way that we become more mindful of the value and finite nature of the world's resources.

Another opportunity to implement circular thinking into the SCC, is through the application focus areas. When you look at topics like mobility and local business models, which do not necessarily need to rebuild the infrastructure, it's actually about being smarter and more aware of how we use assets, that's something that any type of city can do (EMF, 2017). Each applicant was to indicate their preferred area of focus for the challenge, based on mobility; healthy environment; healthy lifestyle and recreation; economic opportunity; safety and security; and empowerment and inclusion (Impact Canada, 2017). A maximum of two focus areas was permitted (ibid). Including circular economy as a focus area may encourage more circular thinking - or pairing each focus area with circular thinking (for example: mobility and circular economy; economic opportunity and circular economy) can ensure that circular thinking is a priority among applicants.

In addition, another opportunity to implement circular thinking into the Smart Cities Challenge, is through the application questions. The relevant questions that were asked include:

- Define a challenge statement in a single sentence that guides the preliminary proposal, which describes the outcome(s) that address(es) an important problem in your community and should state the aim to be achieved by implementation of the proposal. The outcomes must be measurable, ambitious, and achievable through the proposed use of data and connected technology.

- A description of the outcome(s) that the proposal seeks to achieve (state specific goals, identify baseline data and evidence to establish metrics, rationale for applying a smart city approach to achieving the identified outcome, and a strategy for measuring progress).

- Describe the community engagement techniques used to shape the challenge statement with residents, businesses, organizations and other stakeholders. The challenge statement should reflect the concerns and needs of the residents, and that the results of the consultations and engagements activities will inform and guide the development of the final proposal going forward. 
- Describe the preliminary proposal and its activities or projects (planned activities or projects to achieve the outcome, clear links from the identified projects to the attainment of the outcome, scope and size of each project, and measures put in place to make the proposal open, interoperable, scalable, and replicable; and enable other uses of the technology, innovation and data in your proposal). The proposal qualifies as a smart city proposal if it achieves positive outcomes for residents by leveraging connected technology and data.

- Describe the ways in which the proposal supports the community's medium and long-term goals, strategies, and plans and your community's readiness and ability to successfully implement your proposal.

- Describe the partners that are or will be involved in the proposal, including private sector, not-for-profit, public utilities, research/academia, civil society, public or national organizations/groups and project incubators.

Looking to future Challenge competitions, the Federal government could use the Smart Cities Challenge questions to catalyse and engage municipalities into thinking about circular economy principles. This could take the form of the following revised questions (the additions are in italics):

- Define a challenge statement in a single sentence that guides the preliminary proposal, which describes the outcome(s) that address(es) an important problem in your community and should state the aim to be achieved by implementation of the proposal. The outcomes must be measurable, ambitious, and achievable through the proposed use of data and connected technology. The proposed solutions can contribute to solving for a larger challenge rather than an end in itself.

- A description of the outcome(s) that the proposal seeks to achieve (state specific goals, identify baseline data and evidence to establish metrics, rationale for applying a smart city approach to achieving the identified outcome, and a strategy for measuring progress). Consider what the economic, social and environmental outcomes of the proposed solutions are, with an emphasis on creating solutions that achieve all three outcomes.

- Disruptive technologies can be used to address larger societal issues that require a system overhaul. Describe the ways in which the proposal supports the community's medium and long-term goals, strategies, and plans and your community's readiness and ability to successfully implement your proposal. 
Another way to spur and encourage circular thinking is through the use of case study examples that can be included in the Challenge application package. Using case study examples as such as the City of Peterborough, Ontario ${ }^{3}$ for instance could be constructive to highlight circular economy principles and encouraging similar ambitions. The City of Peterborough is currently working to engage local business society around the circular economy, and has developed an online platform called "Share Peterborough" with over 100 local business online sharing assets that they are currently under utilising, such as materials, machines sometimes even people, really creating this local ecosystem of businesses that work and benefit together (EMF, 2017). If you go there you might not see it on the street, but you can visit their website to see how sharing platforms in cities can enable interesting business development (ibid). This homegrown solution is a wonderful opportunity to spur further circular thinking in the age of digital advancement.

This analysis begs the question of how far should the Federal Smart Cities Challenge go to promote and prioritize circular economy thinking. What is considered "good enough" and what is possible? To answer this question, we first need to understand that cities of the future are not sustainable without circularity. We have no choice to to change our current consumption habits. All levels of government have a key role to play in building thriving, liveable, resilient communities that are regenerative by design (EMF, 2019). Their proximity to the everyday concerns and needs of citizens gives them this key role. Governments see, experience and often manage the negative consequences of the current "take-make-dispose" linear economy model (ibid). Encouragement must come from all players. In other words, the Federal government has a larger role to play in shaping our future cities to be circular. The Federal government must be a catalyst, to support and encourage both regional and local municipal governments to use circular economy thinking as they modernize and adopt smart city approaches to their governance and operations

\footnotetext{
${ }^{3}$ The City of Peterborough was not an SCC applicant.
} 
In considering the literature reviewed and the assessment of SCC applications, another important takeaway is to consider the policy levers that can be used by federal and local decision makers to enable urban circular economy transitions. Several policy levers apply in the Canadian context and can work to enable that waste and pollution to be designed out of products and urban systems; materials to be kept in use and maintain their value; and for natural systems in and around cities to regenerate.

The following set of recommendations have been created as a conclusion to this paper, and as a call to decision makers to leverage the smart city movement to help transition to a circular economy. Recommendations include:

1. Municipal and regional governments should enable legislation and regulation to stimulate circular economy practices, such as organic waste treatment requirements for large commercial food retailers.

2. The Federal government can utilize its financial support in the form of grants, subsidies, direct and indirect investments and procurements to enable municipal and regional governments to undertake circular city investments within their local communities.

3. Organizations such as Evergreen Canada and other private or not-for-profit partners should be engaged in this conversation as they can help build the capacity needed to undertake training and advisory support programmes for individuals, companies and organizations, to help mainstream circular economy understanding and practices within society. These programmes can take the form of incubator programmers or material-exchange platforms.

4. Convening and partnering with organizations such as Future Cities Canada to facilitate and spur collaboration between public, private and civic leaders. Engaging multiple stakeholders in public policy creation and delivery is particularly valuable when innovating and making system changes for enabling and developing circular opportunities. 
5. Lastly, in addition and outside of the the SCC, the Federal government should establish a Canadian circular economy strategy to set a direction of travel for Canadian municipalities and help orientate other policy levers and offer an invaluable opportunity to raise ambitions and engage stakeholders in undertaking circular economy transitions.

This paper sought to understand whether governments can catalyse circular economy principles as they modernize and adopt smart city approaches to their governance and operations. To conclude, the answer is yes, that all levels of government can catalyse circular economy efforts. There are numerous ways in which circular economy thinking can be further integrated into Smart Cities Challenges going forward as well as decision making in general. 


\section{References}

Ahvenniemi, $\mathrm{H}$ et al. (2017). What are the differences between sustainable and smart cities? Cities. Issue 60, pp. 234-245. Accessed from Science Direct on January 20, 2019 at https://www.sciencedirect.com/science/article/pii/S0264275116302578

Anderson, Chris. (2012). Makers: The New Industrial Revolution. Random House Business Books.

Baker-Brown, Duncan. (2017). The Re-Use Atlas: A Designer's Guide Towards A Circular Economy. RIBA Publishing.

Batty, Michael. (May 2016). Cities as Flows in a Circular Economy Podcast. Circulate News. Accessed January 15, 2019 at https://circulatenews.org/

Bleriot, Joss. (June 2016). Policy Landscape Report on Resource Efficiency \& Circular Economy. Accessed January 14, 2019 at https://circulatenews.org/2016/06/policy-landscape-report-on-resource-efficiency-and-circular-econ omyl

Care, Stella, et al. (2018). Crowdfunding for the development of smart cities. Business Horizons. Issue 61, pp. 501-509. Accessed from Science Direct on January 20, 2019. https://www-sciencedirect-com.ezproxy.lib.ryerson.ca/science/article/pii/S0007681317301908

Code for Canada \& Future Cities Canada. (February 2018). How to be Smart(er) in Mid-Sized Cities in Ontario: Discussion Paper. Accessed on January 15, 2019 at https://www.evergreen.ca/tools-publications/how-to-be-smarter-in-mid-sized-cities-in-ontario/

Desdemoustier, J. et al. (2018). Municipalities understanding of the Smart City concept: An exploratory analysis in Belgium. Technological Forecasting \& Social Change. pp $1-13$. Accessed from Science Direct on January 20, 2019 at https://journals-scholarsportal-info.ezproxy.lib.ryerson.ca/pdf/00401625/unassigned/nfp_muotscca $\underline{\text { eaib.xml }}$

Ellen MacArthur Foundation. (June 2015). Delivering the Circular Economy: A Toolkit for Policymakers. Accessed on January 15, 2019 at https://www.ellenmacarthurfoundation.org/publications/delivering-the-circular-economy-a-toolkit-for -policymakers

Ellen MacArthur Foundation. (August 2017). Cities in the Circular Economy: An Initial Exploration. Accessed on January 15, 2019 at https://www.ellenmacarthurfoundation.org/publications/cities-in-the-circular-economy-an-initial-expl oration

Ellen MacArthur Foundation. (March 2019). City Governments and their Role in Enabling a Circular Economy Transition. Accessed on March 16, 2019 at https://www.ellenmacarthurfoundation.org/assets/downloads/CE-in-Cities Policy-Levers Mar19.pd $\underline{f}$ 
Future Cities Canada and Open North. (October 2018). Getting to the Open Smart City Discussion Paper. Accessed on November 30, 2018 at https://futurecitiescanada.ca/downloads/2018/Getting_to_Open_Smart_City.pdf

Garrigou, Anne-Sophie. (April 2017). Understanding the Principles of the Circular Economy with Alexandre Lemille. The Beam. Accessed on January 15, 2019 at https://medium.com/thebeammagazine/understanding-the-principles-of-the-circular-economy-withalexandre-lemille-86e0c5076eb1

Gauntlett, David. (2011). Making is Connecting: The Social Meaning of Creativity: From DIY and Knitting to YouTube and Web 2.0. Polity Press.

Government of Canada. (2016). National Inventory Report 1990-2014: Greenhouse Gas Sources and Sinks in Canada. Accessed on March 22, 2019 at http://publications.gc.ca/collections/collection_2016/eccc/En81-4-1-2014-eng.pdf

Government of Canada. (2018). Canadian Environmental Sustainability Indicators: Greenhouse Gas Emissions. Accessed on March 22, 2019 at https://www.canada.ca/content/dam/eccc/documents/pdf/cesindicators/greenhouse-gas-emissions/ greenhouse-gas-emissions-en.pdf

Iles, Joe. (September 2017). Get Up to Speed on Circular Economies. Accessed on December 16, 2019 at https://circulatenews.org/2017/09/get-up-to-speed-on-circular-cities/

Infrastructure Canada. (2019). Smart Cities Challenge. Accessed on January 20, 2019 at https://www.infrastructure.gc.ca/cities-villes/index-eng.html

Krosinsky, C and Cort, T. (2018). Sustainable Innovation and Impact. Routledge. New York.

Martin, C. et al. (2019). Smart-sustainability: A new urban fix? Sustainable Cities and Society. Issue 25, pp. 640-648. Accessed from Science Direct on January 20, 2019 at https://www.sciencedirect.com/science/article/pii/S2210670718302191

Nasr, Nabil. (April 2016). Remanufacturing and the Circular Economy Podcast. Circulate News. Accessed January 15, 2019 at https://circulatenews.org/

Nilssen, M. (2018). To the Smart City and Beyond? Developing a Typology of Smart Urban Innovation. Technological Forecasting \& Social Change. Accessed from Science Direct on January 20, 2019 at https://doi.org/10.1016/j.techfore.2018.07.060

Pancholi, S. (2017). Place Making for Innovation and Knowledge-Intensive Activities: The Australian Experience. Technological Forecasting \& Social Change. Accessed from Science Direct on January 20, 2019 at https://www.sciencedirect.com/science/article/pii/S0040162517312106 
Paolo Appio, Francesco, et al. (2018). Understanding Smart Cities: Innovation ecosystems, technological advancements, and societal challenges. Technological Forecasting \& Social Change. pp 1-13. Accessed from Science Direct on January 20, 2019 at https://journals-scholarsportal-info.ezproxy.lib.ryerson.ca/pdf/00401625/unassigned/nfp uscietaasc $\underline{. x m l}$

Prendeville, S et al. (2018). Circular Cities: Mapping Six Cities in Transition. Environmental Innovation and Societal Transitions. Issue 26, pp. 171-194. Accessed through Science Direct on January 20, 2019 at https://www.sciencedirect.com/science/article/pii/S2210422416300788

Prieto-Sandoval, V et al. (2018). Towards a consensus on the Circular Economy. Journal of Cleaner Production. Issue 179, pp 605-615. Accessed from Science Direct on January 19, 2019 at https://www.sciencedirect.com/science/article/pii/S0959652617332146

Ramkumar, Shyaam. (December, 2017). The Fourth Industrial Revolution and the Circular Economy. Circulate News. Accessed on January 15, 2019 at https://circulatenews.org/2017/12/fourth-industrial-revolution-circular-economy/

Impact Canada. (August 2018). Smart Cities Canada Applicant Guide. Accessed on March 7, 2019 at https://impact.canada.ca/en/challenges/smart-cities/applicant-guide

Sukhdev, A et al. (n.d.). Cities in the Circular Economy: The Role of Digital Technology. Google \& the Ellen MacArthur Foundation. Accessed on January 20, 2019 at:

https://www.ellenmacarthurfoundation.org/assets/downloads/Cities-in-the-Circular-Economy-The-R ole-of-Digital-Tech.pdf

Tomalty, Ray. (October 2017). A Systems Approach to Urban Innovation. Future Cities Canada. Accessed November 30, 2018 at https://futurecitiescanada.ca/downloads/2018/FCC Innovation_201808.pdf

United Nations Environmental Programme (UNEP). (2011). Climate Change Press Release. Accessed on February 16, 2019 at https://www.unenvironment.org/news-and-stories/press-release/resource-use-expected-double-20 50-better-natural-resource-use

University of Alberta. (2013). What is Sustainability? Accessed on March 23, 2019 at https://www.mcgill.ca/sustainability/files/sustainability/what-is-sustainability.pdf

Van Ham, Chantal. (January 2018). In the Spirit of Nature, Everything is Connected. The International Union for the Conservation of Nature. Accessed on March 26, 2019 at https://www.iucn.org/news/europe/201801/spirit-nature-everything-connected

Wahl, Daniel Christian. (February 2017). Circular Economy 101: Designing Regeneration into the System. Medium.com. Accessed January 15, 2019 at https://medium.com/@designforsustainability/circular-economy-101-designing-regeneration-into-th e-system-585c912e0886 
Webster, Ken. (2015). The Circular Economy: A Wealth of Flows. Ellen MacArthur Foundation Publishing. First edition.

World Commission on Environment and Development. (1987). The Brundtland Report. Accessed on March 12, 2019 at https://www.are.admin.ch/are/en/home/sustainable-development/international-cooperation/2030ag enda/un- -milestones-in-sustainable-development/1987--brundtland-report.html

World Wildlife Fund. (2016). Living Planet Report 2016. Accessed on March 28, 2019 at https://wwf.panda.org/wwf_news/?282370/Living-Planet-Report-2016

Zainal, Zaidah. (June 2007). Case Study as a Research Method. University of Malaysia. Accessed on March 23 at http://psyking.net/htmlobj-3837/case_study_as_a research_method.pdf. 


\section{Appendices:}

Appendix 1: The Ellen MacArthur Foundation's ReSOLVE Framework

Appendix 2: The City of Port Alberni's SCC Application

Appendix 3: The District of Squamish's SCC Application

Appendix 4: The City of Guelph and Wellington County's SCC Application

Appendix 5: The Municipality of Hope Town's SCC Application

Appendix 6: The City of Coquitlam's SCC Application 


\begin{tabular}{|c|c|c|c|}
\hline Principle & Definition & Top-Down Example & Bottom-Up Example \\
\hline Regenerate & $\begin{array}{l}\text { The shift to renewable energy and } \\
\text { materials - to reclaim, retain, and } \\
\text { restore health of ecosystems and } \\
\text { return recovered biological } \\
\text { resources to the biosphere. }\end{array}$ & $\begin{array}{l}\text { Utilizing rooftops as solar fields, } \\
\text { developing green space for } \\
\text { biodiversity and to improve air } \\
\text { quality. }\end{array}$ & $\begin{array}{l}\text { Personal acquisition of } \\
\text { renewable energy; solar } \\
\text { panels, urban farming, } \\
\text { electric or biogas fuelled } \\
\text { mobility. }\end{array}$ \\
\hline Share & $\begin{array}{l}\text { Sharing assets (e.g. cars, rooms, } \\
\text { appliances), and prolong the life of } \\
\text { materials through maintenance, } \\
\text { design for durability, upgradability } \\
\text { and encouraging reuse/ } \\
\text { second-hand. }\end{array}$ & $\begin{array}{l}\text { Policy innovation to support the } \\
\text { collaborative economy, regulate } \\
\text { sharing, tax and fiscal } \\
\text { measures incentivizing sharing. }\end{array}$ & $\begin{array}{l}\text { Car sharing, appliance } \\
\text { sharing (washing } \\
\text { machines, tools), repair } \\
\text { (repair cafes), reuse } \\
\text { (clothing, furniture, } \\
\text { vehicles, appliances) }\end{array}$ \\
\hline Optimize & $\begin{array}{l}\text { Increase performance/ efficiency of } \\
\text { a product, remove waste in } \\
\text { production and supply chain, and } \\
\text { leverage big data. }\end{array}$ & $\begin{array}{l}\text { By using gathered data on } \\
\text { traffic flows, the efficiency of } \\
\text { cities' major transportation can } \\
\text { be optimized, decreasing } \\
\text { congestion. Installing smart } \\
\text { LED lighting throughout the city } \\
\text { to save energy. Retrofitting old } \\
\text { buildings to increase their } \\
\text { energy efficiency. }\end{array}$ & $\begin{array}{l}\text { Smart citizen labs, Fab } \\
\text { Labs, smart grids, smart } \\
\text { communities. }\end{array}$ \\
\hline Loop & $\begin{array}{l}\text { Remanufacturing products or } \\
\text { components; resources are } \\
\text { processed, looped around and put } \\
\text { back into the economy, rather than } \\
\text { lost in a landfill. }\end{array}$ & $\begin{array}{l}\text { Waste separation and } \\
\text { recycling, district heating, } \\
\text { bio-based economy, reverse } \\
\text { logistics. }\end{array}$ & $\begin{array}{l}\text { Community recycling } \\
\text { initiatives, upcycling } \\
\text { initiatives, community } \\
\text { bio-digesters. }\end{array}$ \\
\hline Virtualize & $\begin{array}{l}\text { Dematerializing directly and } \\
\text { indirectly (for example: e-readers } \\
\text { replacing physical books, or a } \\
\text { Netflix subscription replacing } \\
\text { material DVDs). }\end{array}$ & $\begin{array}{l}\text { Virtual city hall counters. } \\
\text { Autonomous public } \\
\text { transportation and semi- private } \\
\text { transportation like taxis. } \\
\text { Virtualization of public libraries, } \\
\text { archives, legal information. A } \\
\text { paperless municipality. }\end{array}$ & $\begin{array}{l}\text { Community-led digital } \\
\text { platforms, citizen-science } \\
\text { climate monitoring. }\end{array}$ \\
\hline Exchange & $\begin{array}{l}\text { The process of replacing old } \\
\text { technologies with advanced } \\
\text { non-renewable materials, applying } \\
\text { new technologies (such as 3D } \\
\text { printing) and choosing new } \\
\text { products/ services. }\end{array}$ & $\begin{array}{l}\text { Circular construction } \\
\text { /demolition materials and } \\
\text { processes, electric powered } \\
\text { public transportation, } \\
\text { procurement of circular office } \\
\text { furniture. }\end{array}$ & $\begin{array}{l}\text { Electric mobility, organic } \\
\text { and locally- sourced (super) } \\
\text { markets, eco-fashion, } \\
\text { e-readers. }\end{array}$ \\
\hline
\end{tabular}




\section{Applicant information}

\section{Question 1}

Please provide information on the community that is submitting this application. If this application is being submitted by a group of communities, add each community separately using the button. If this application is being submitted by a regional entity, please include the name of the regional entity with each individual community (e.g. City of

Dunn/Smith Region). Do not include the regional entity as a separate, stand-alone community.

\section{Question 2}

Please select a prize category.

\section{Community (City of Port Alberni)}

Name of community City of Port Alberni

Province or Territory British Columbia

Population based on 17678

Indigenous community No

\section{Problem definition}

\section{Question 3}

Please define your Challenge Statement in a single sentence that guides your preliminary proposal. It should describe the outcome (or outcomes) you hope to achieve.

\section{Question 4}

Please describe the outcome (or outcomes) your proposal seeks to achieve by elaborating on your Challenge Statement.

This section should include:

- Specific goals you hope to achieve by implementing
Become a Truly Resourceful Community

With advanced technology, traditional wisdom, and a new consciousness, within five years we will become Canada's first true zero waste community and fully utilize the natural resources in our coastal area, thus also beginning to heal the separation between ourselves and the planet.

\subsection{The Current Situation}

In 2007, the diversion rate of solid waste in our community was $15 \%$, and by 2013 had only increased to $20 \%$. Currently, $740 \mathrm{~kg}$ of waste is disposed of per person per year in Port Alberni. In contrast, the nearby Regional District of Nanaimo has achieved a solid waste diversion rate of $70 \%$.

Port Alberni has been labeled the "Worst Place to Live in Canada" by Money Sense Magazine and consistency ranks high on crime rates and other undesirable social indicators.

These metrics are at first glance unrelated, but the 


\begin{tabular}{|c|c|}
\hline $\begin{array}{l}\text { your proposal, justifying } \\
\text { both the level of ambition } \\
\text { and the achievability of } \\
\text { the outcome (or } \\
\text { outcomes) sought. } \\
\text { Baseline data and } \\
\text { evidence to establish the } \\
\text { current state with respect } \\
\text { to the metrics used in your } \\
\text { Challenge Statement, and } \\
\text { context around the } \\
\text { outcome (or outcomes) } \\
\text { sought. } \\
\text { Evidence to support the } \\
\text { selection of this/these } \\
\text { outcome (or outcomes) } \\
\text { over others, in reference } \\
\text { to the needs of the } \\
\text { community. } \\
\text { Rationale for applying a } \\
\text { smart city approach to } \\
\text { achieving the identified } \\
\text { outcome (or outcomes). } \\
\text { Strategy for measuring } \\
\text { progress toward outcome } \\
\text { (or outcomes) and } \\
\text { achievement of outcome } \\
\text { (or outcomes). }\end{array}$ & 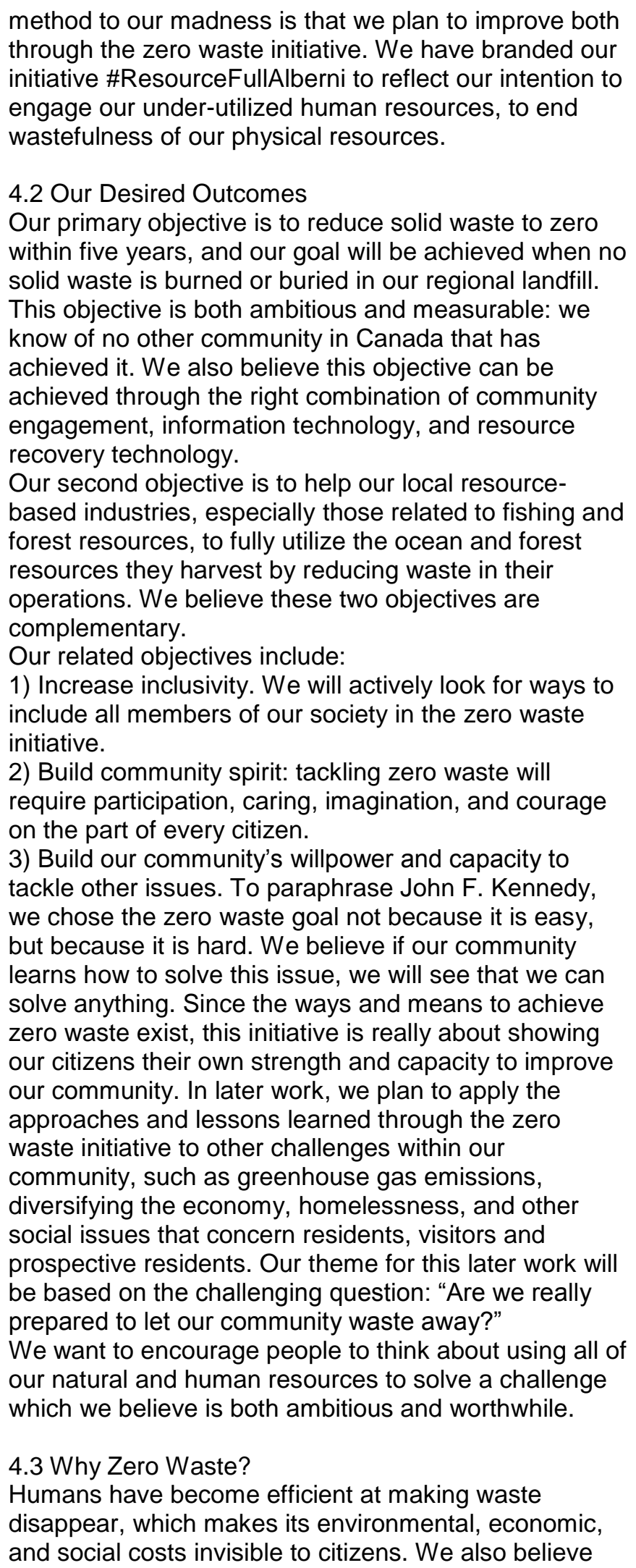 \\
\hline
\end{tabular}




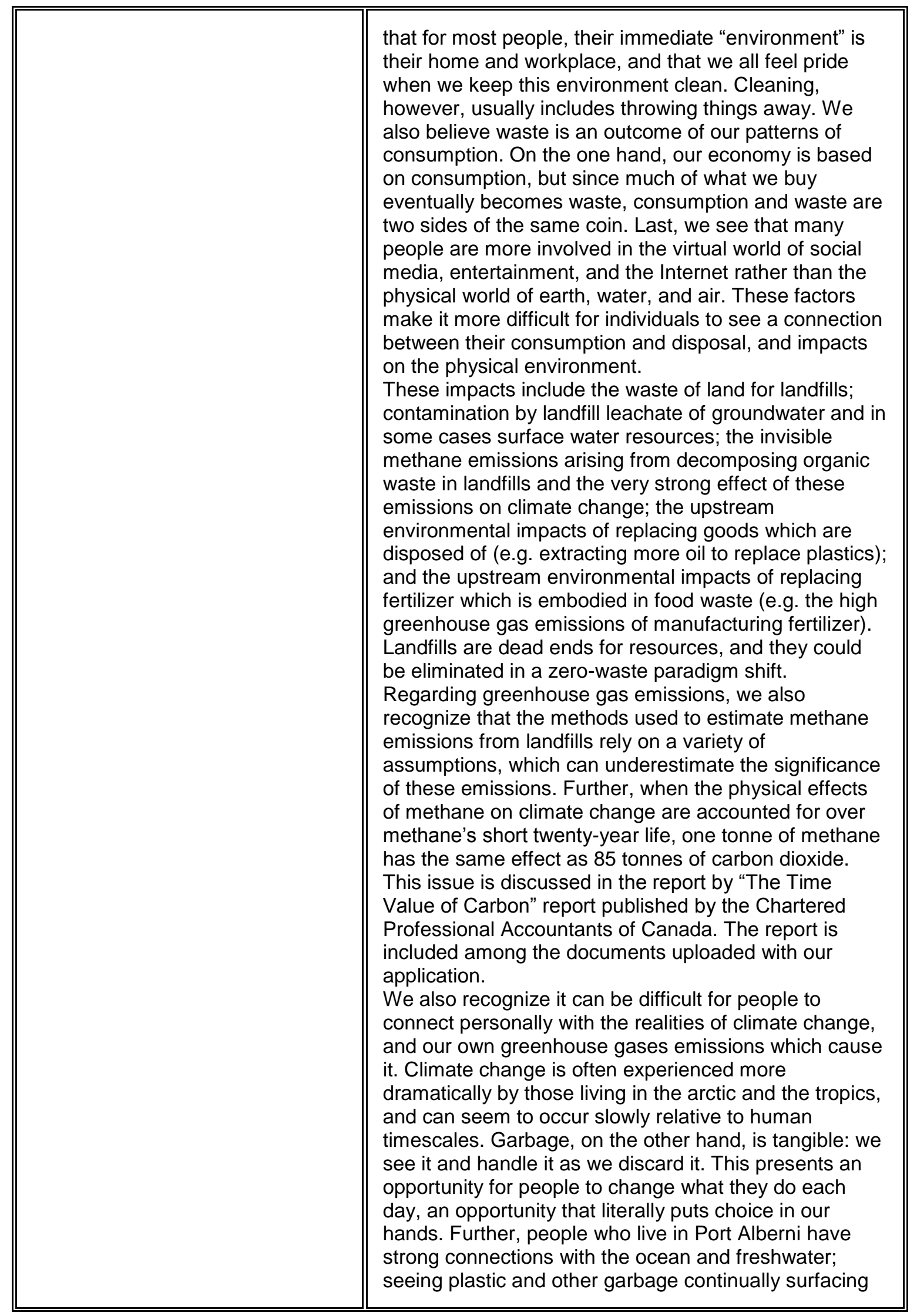




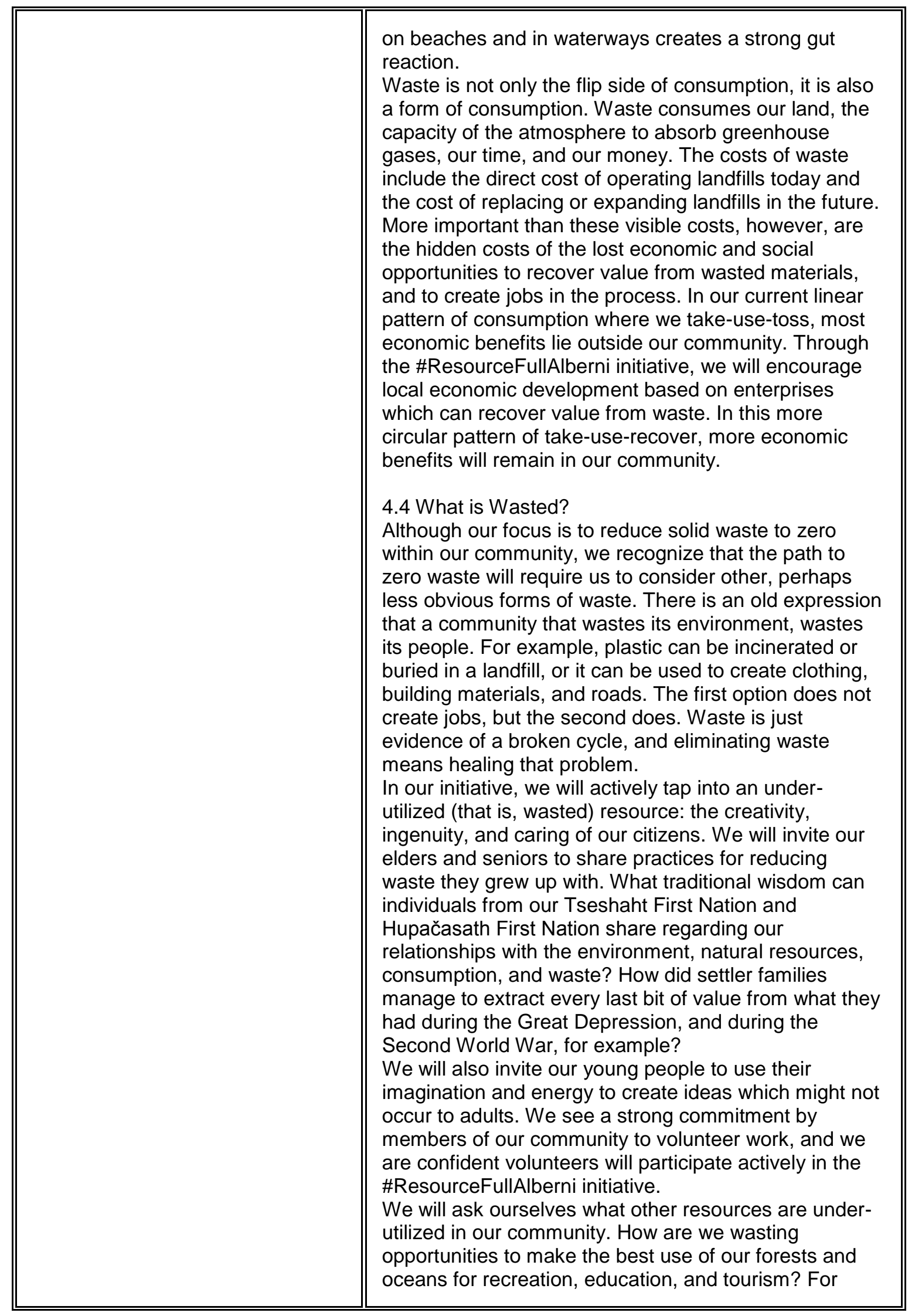




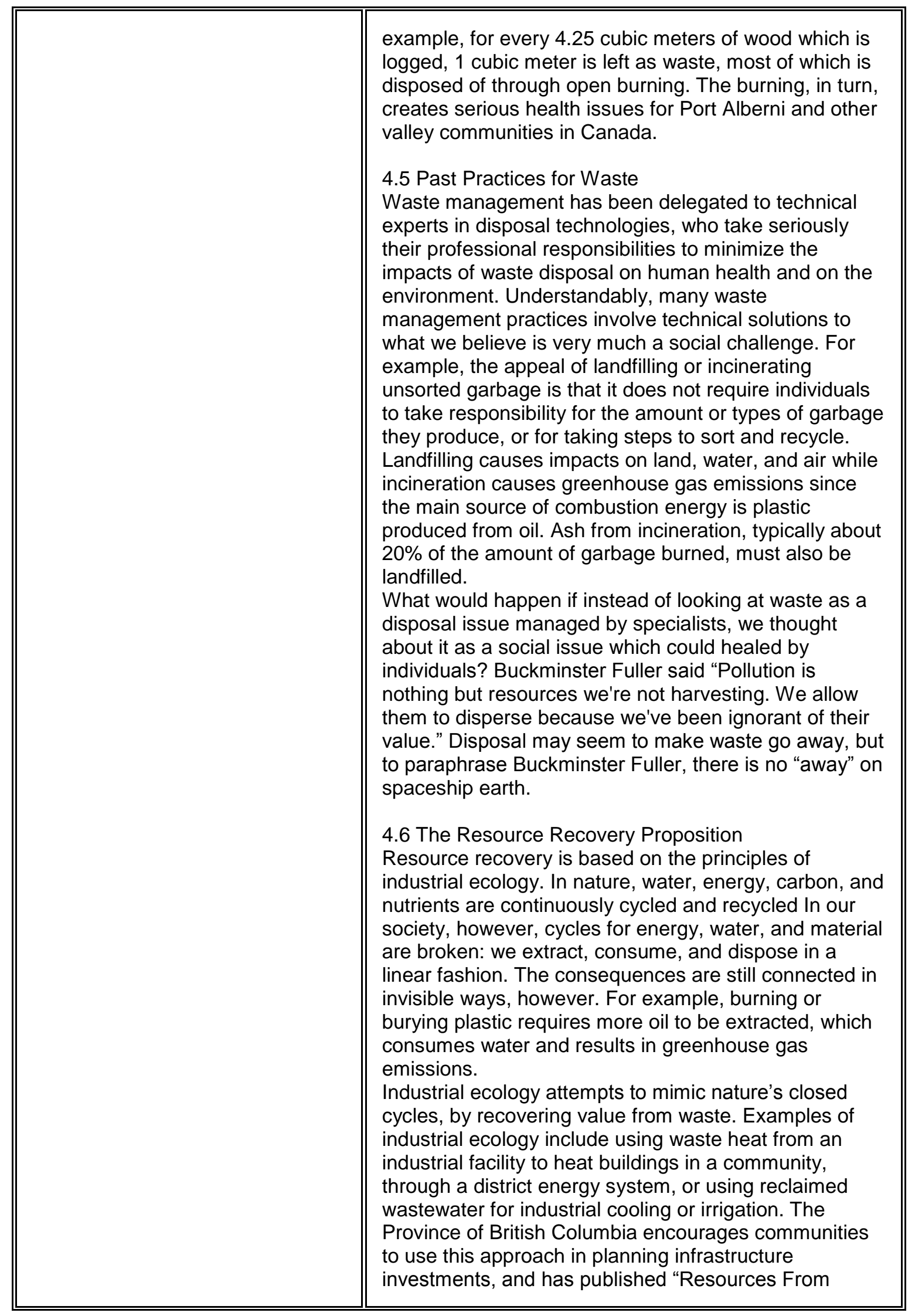




\begin{tabular}{|c|c|}
\hline & 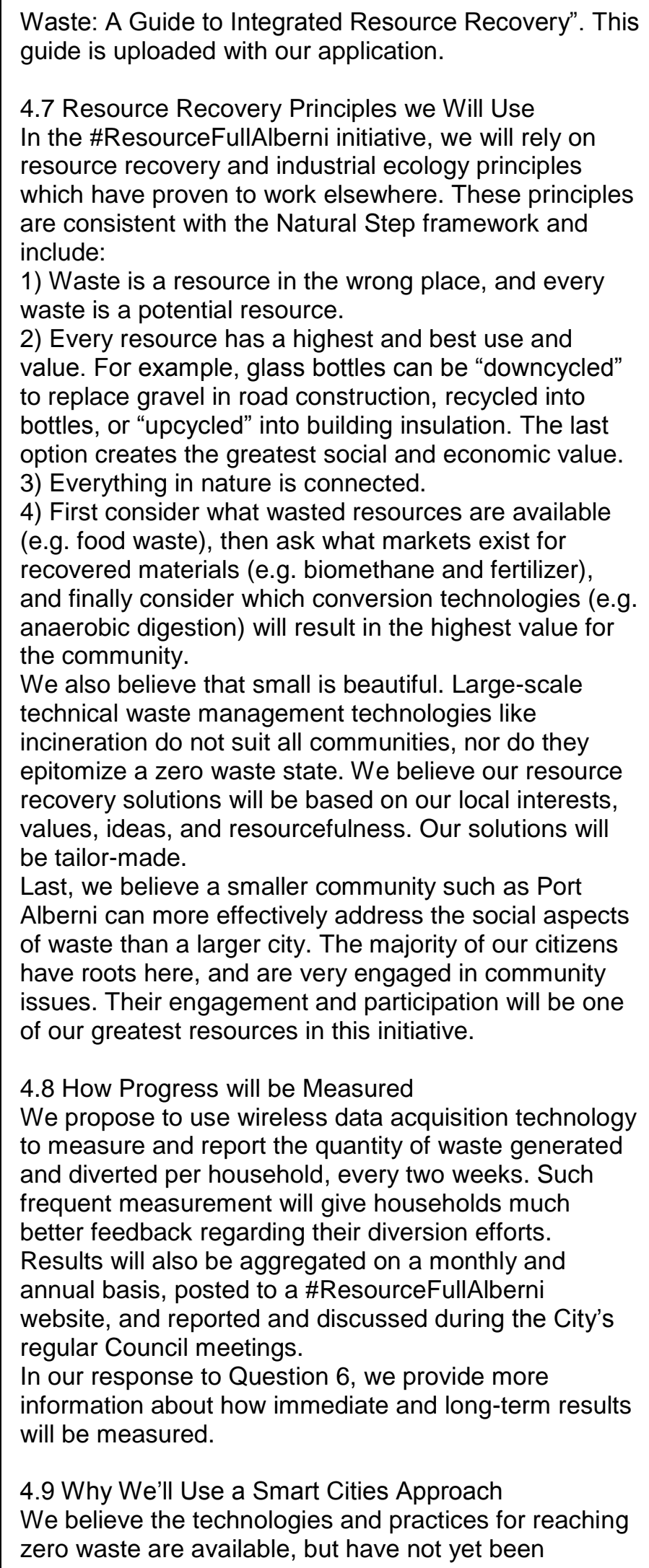 \\
\hline
\end{tabular}




\begin{tabular}{|c|c|}
\hline & $\begin{array}{l}\text { implemented anywhere in Canada with the best } \\
\text { combination of real-time data, information technology, } \\
\text { and extensive community engagement. In our response } \\
\text { to Question } 6 \text {, we outline how we plan to use the Smart } \\
\text { Cities approach. }\end{array}$ \\
\hline $\begin{array}{l}\text { Question } 5 \\
\text { Please describe how your } \\
\text { community residents have shaped } \\
\text { your Challenge Statement. } \\
\text { Describe your plans for continuing } \\
\text { to engage and involve them in } \\
\text { your final proposal going forward. } \\
\text { This section should include: } \\
\text { - Descriptions of previous } \\
\text { engagement with } \\
\text { residents, businesses, } \\
\text { organizations, and other } \\
\text { stakeholders on topics } \\
\text { related to the Challenge } \\
\text { Statement. } \\
\text { Descriptions of feedback } \\
\text { that came to light through } \\
\text { past engagement } \\
\text { processes. } \\
\text { Links between the } \\
\text { Challenge Statement and } \\
\text { engagement feedback. } \\
\text { Evidence of efforts made } \\
\text { to be inclusive and to } \\
\text { represent the community's } \\
\text { diversity. } \\
\text { Plans to sustain } \\
\text { engagement through the } \\
\text { development and } \\
\text { implementation of the final } \\
\text { proposal. }\end{array}$ & 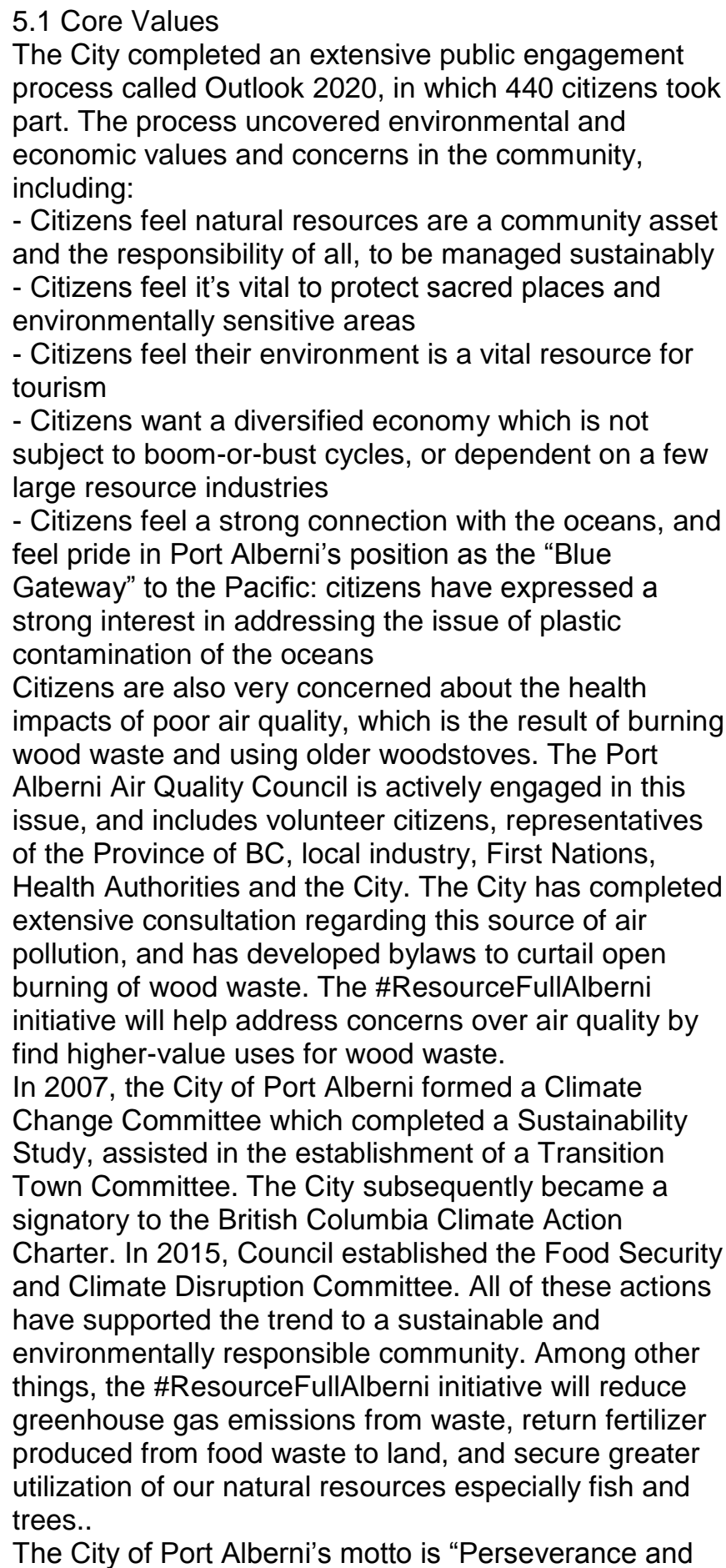 \\
\hline
\end{tabular}




\begin{tabular}{|c|c|}
\hline & 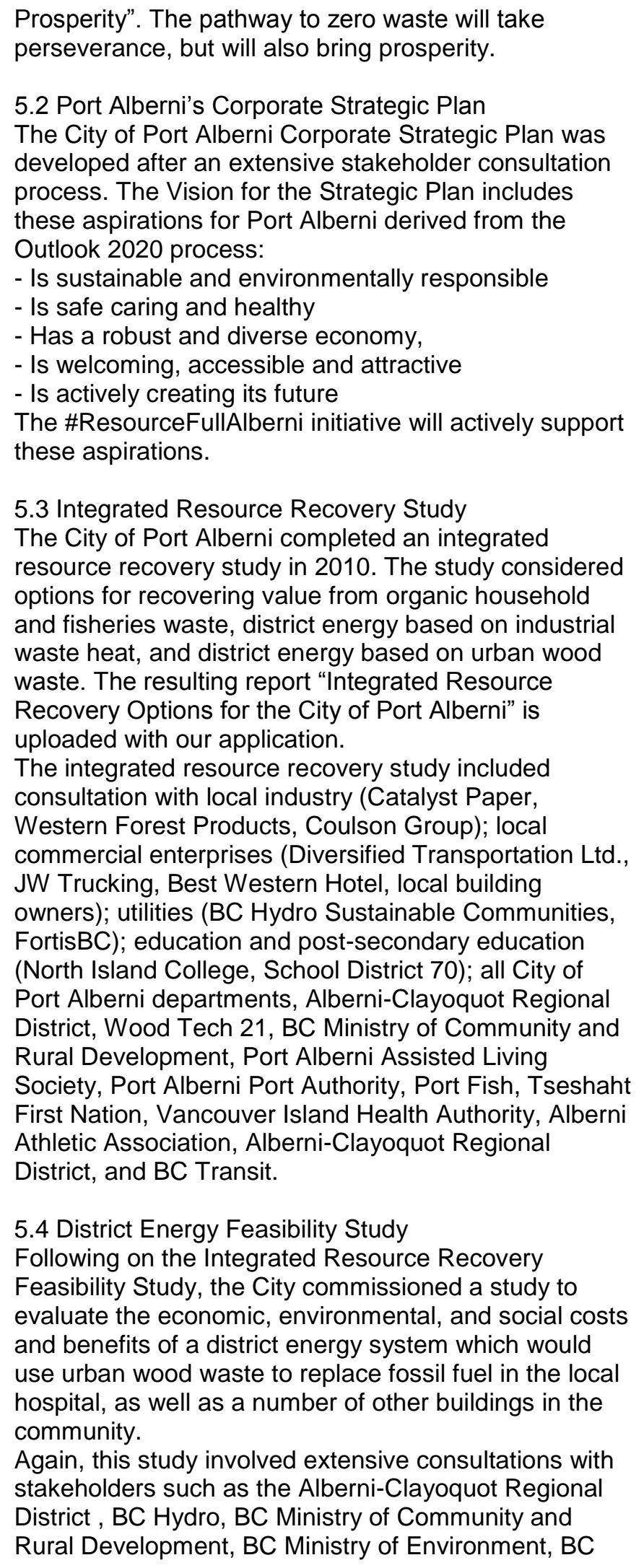 \\
\hline
\end{tabular}




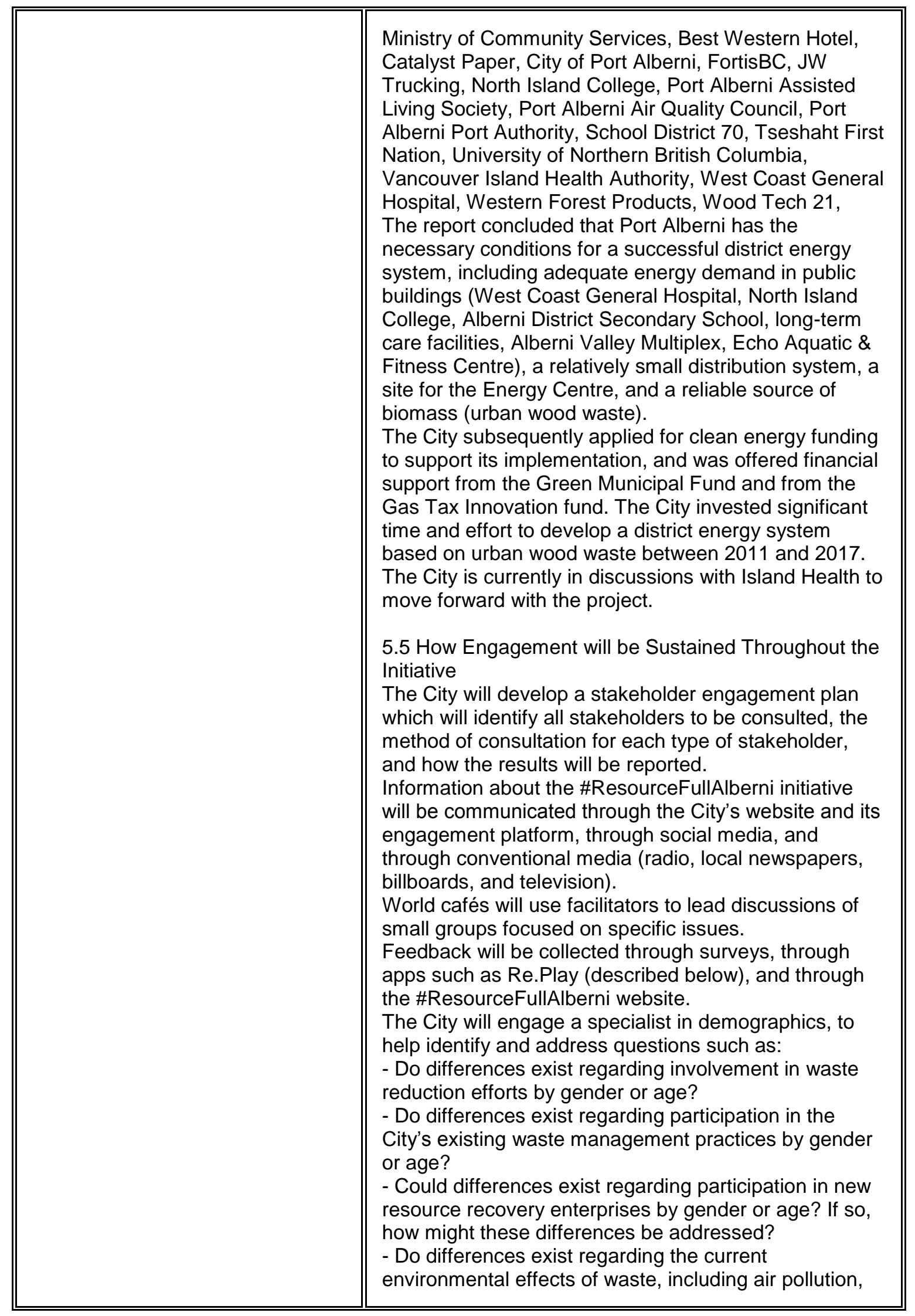




\section{Preliminary proposal details}

\section{Question 6}

Please describe your preliminary proposal and its activities or projects.

This section should include:

- Planned activities or projects to achieve the outcome (or outcomes) set out in the Challenge Statement.

- Clear links from the identified projects to the attainment of the outcome (or outcomes).

- Scope and size of each planned project in your preliminary proposal, describing how it is feasible and suitable for achieving the outcome (or outcomes) in a manner that is impactful for the community, ambitious, and transformative.

- Measures put in place to 1) make the proposal open, interoperable, scalable, and replicable or a description of your plan to do so going forward for the benefit of your own community and other communities in Canada; and 2) enable other uses of the technology, innovation, and data in your proposal.
Our planning will be guided by the adage that "you cannot cross a chasm in two small steps". We cannot achieve zero waste incrementally: radical re-thinking is needed.

\subsection{Information Technologies}

We plan to use the following information and connection technologies, at a minimum:

6.1.1 Smart Data Collection

Garbage bins and green bins will be equipped with RFID tags, which collection trucks will automatically read. Wireless scales on the trucks will record the amount of waste collected. Every two weeks, households will see the amount of waste generated and its cost, either through their City utility account or through a "Re.Pay" app (described below). This technology will provide faster feedback regarding households' waste reduction efforts.

\subsubsection{Mobile and Desktop Apps}

\section{Re.Store App}

Humans have evolved to remember where to find food. We're still good at remembering where to find things we want, but not as good at returning them. The Re.Store app will help people feel as much satisfaction from returning and from buying. Experts in how people change will be consulted in the app's design, but as a starting point, the app will:

- Starting with a regular shopping route, show where hard-to-recycle materials (batteries, Styrofoam, plastic film, and so on) can be dropped off along the way - Allow searches for businesses participating in the \#ResourceFullAlberni initiative, which offer to receive materials for recycling or for return to suppliers, help shoppers reduce packaging they take home, etc. (see for example www.bulkbarn.ca).

- Record the amount of materials dropped off over time

- Offer tips to reduce packaging and food waste

- Offer tips to help consumers buy more durable products

- Provide links to websites showing the full "story of waste", showing ways to minimize waste, etc.

Re.Play App

In the Re.Play game app, recyclables will accumulate in the form of zombies, until the player finds a way to reuse, re-purpose, or recycle them. The game will include different levels, to engage people of all ages. The game will invite individuals and teams to find solutions for 


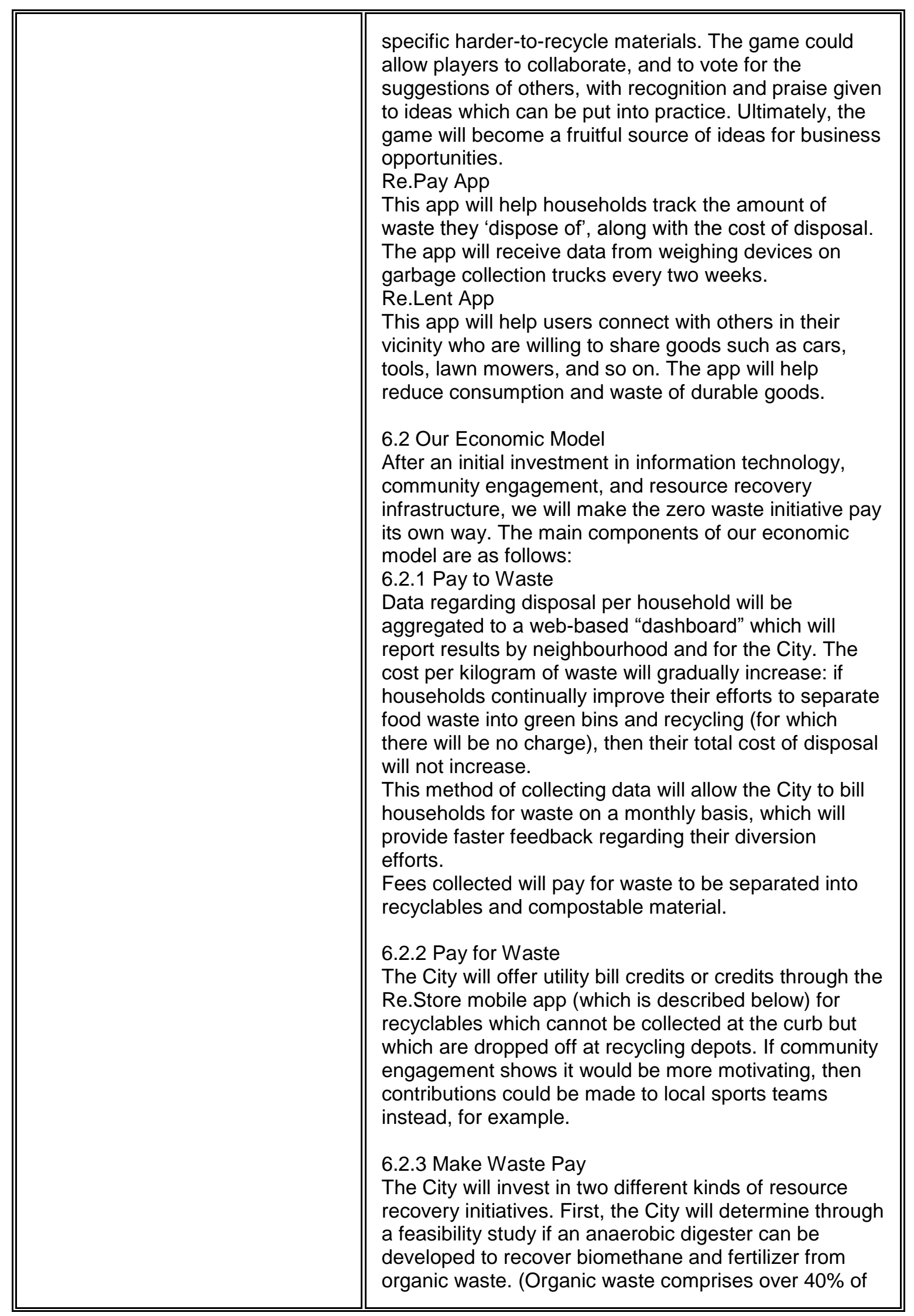




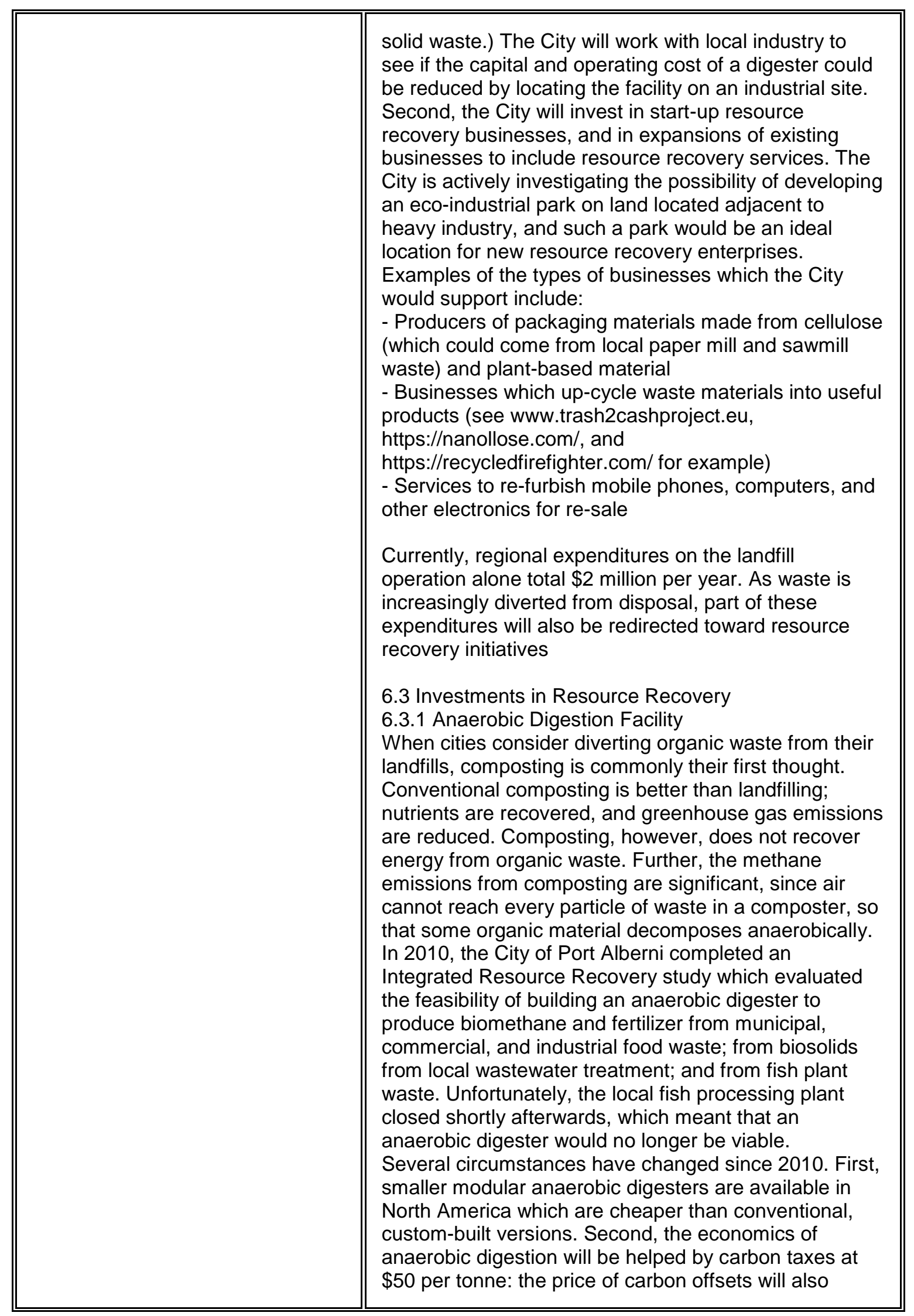




\begin{tabular}{|c|c|}
\hline & 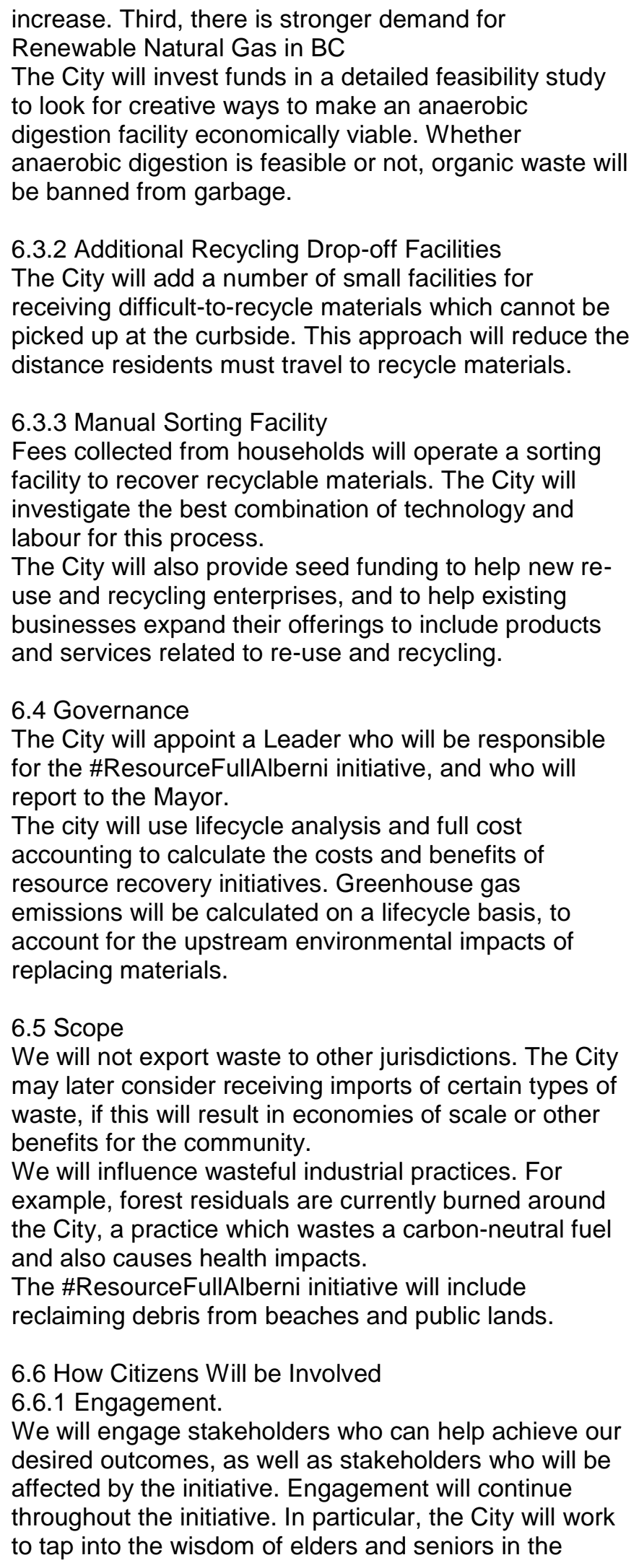 \\
\hline
\end{tabular}




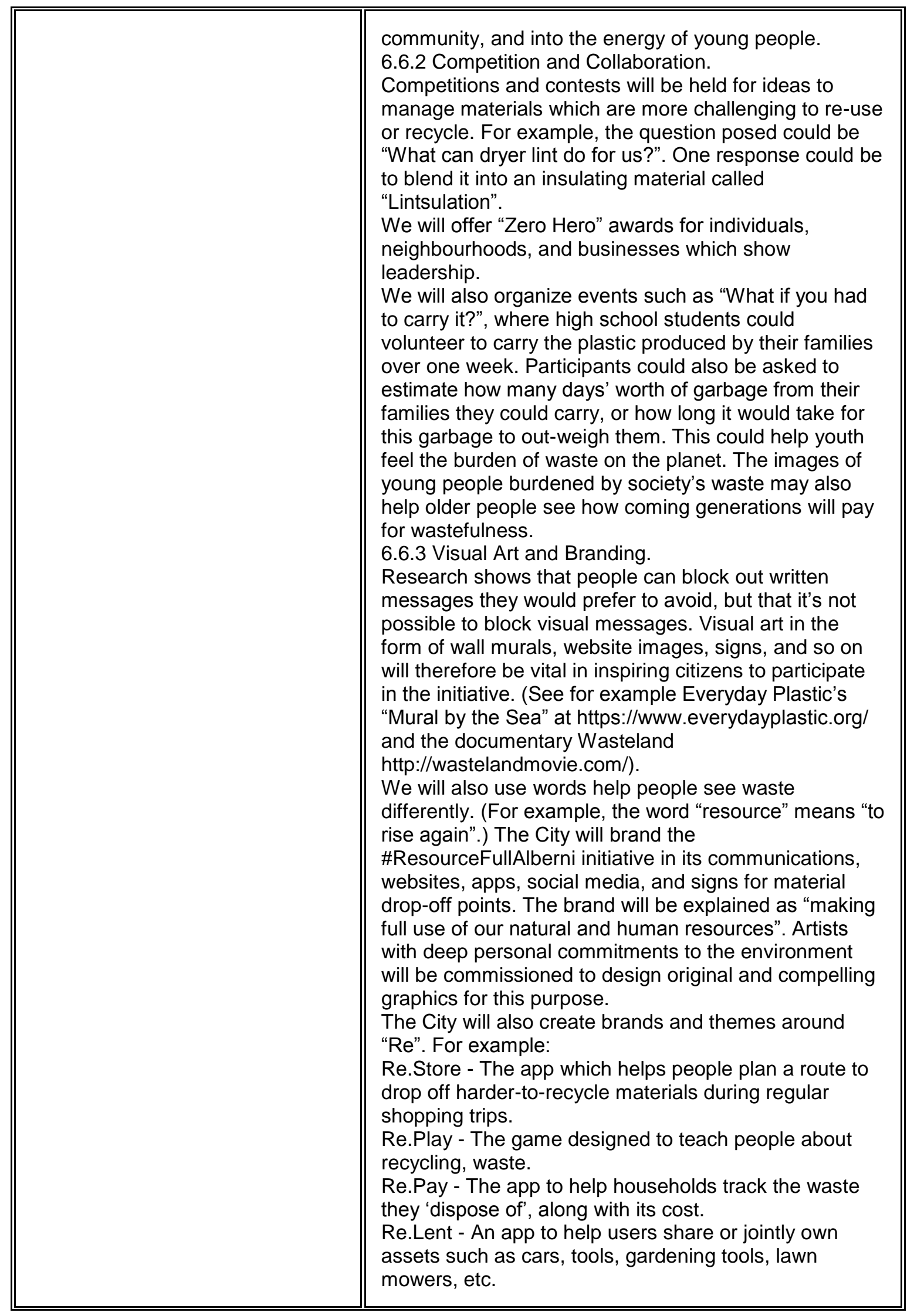




\begin{tabular}{|c|c|}
\hline & $\begin{array}{l}\text { Re.Create - A brand name of a company making art } \\
\text { from waste. } \\
\text { Re.Call - A name for a business which refurbishes } \\
\text { mobile phones. } \\
\text { Re.Volt - A brand name for an enterprise which } \\
\text { refurbishes electronic and electrical goods. } \\
\text { Re.Dress or Re.Cover - A name for an enterprise which } \\
\text { sells used clothing, or recycles clothing into other } \\
\text { products (e.g. insulation). } \\
\text { Re.Move - A brand name for an enterprise which } \\
\text { restores bicycles, skateboards, and so on. } \\
\text { Re.Work - Jobs created by repairing, reusing, or } \\
\text { recycling. } \\
\text { Re.Claim - Removing garbage from land or the ocean. } \\
\text { Re.Consider - Thinking before tossing something away. } \\
\text { Re.Fuse - Saying "no thanks" to excessive packaging } \\
\text { and single-use products. } \\
\text { Re.Cognition, Re.Joice, or Re.Spect - The annual } \\
\text { ceremony to recognize contributions by individuals, } \\
\text { neighbourhoods, businesses, etc.. } \\
\text { Re.Think - Thinking of new uses for old materials. } \\
\text { Re.Solve - Perseverance and problem solving for } \\
\text { waste-reduction challenges. } \\
\text { Re.Group - A problem-solving group. }\end{array}$ \\
\hline $\begin{array}{l}\text { Question } 7 \\
\text { Please describe the ways in which } \\
\text { your preliminary proposal supports } \\
\text { your community's medium and } \\
\text { long-term goals, strategies, and } \\
\text { plans. } \\
\text { To supplement your response, } \\
\text { please upload any relevant } \\
\text { documents and make clear } \\
\text { linkages and references. }\end{array}$ & $\begin{array}{l}\text { 7.1 Core Values } \\
\text { The City completed an extensive public engagement } \\
\text { process called Outlook 2020, in which } 440 \text { citizens took } \\
\text { part. The process uncovered strong environmental } \\
\text { values, as described in the response to Question } 5 . \\
7.2 \text { Official Community Plan } \\
\text { The \#ResourceFullAlberni initiative aligns well with the } \\
\text { following objectives of the Official Community Plan: } \\
\text { - To protect significant natural ecosystems, habitat, } \\
\text { green space linkages, and environmentally sensitive } \\
\text { areas, and promote stewardship of these valuable } \\
\text { resources. } \\
\text { - To encourage diversification and promote } \\
\text { development of the industrial sector in order to achieve } \\
\text { a more stable employment and economic base. } \\
\text { - To promote tourism by capitalizing on existing } \\
\text { amenities in the Northport and Southport areas, and } \\
\text { community recreational infrastructure. } \\
\text { - In order to reduce the amount of solid waste dumped } \\
\text { at the landfill, efforts to compost, recycle and reuse } \\
\text { solid waste shall be encouraged. } \\
7.3 \text { Consolidated Strategic Landfill Diversion Program } \\
\text { The City of Port Alberni is working with the Alberni- } \\
\text { Clayoguot Regional District whose "Consolidated }\end{array}$ \\
\hline
\end{tabular}




\begin{tabular}{|c|c|}
\hline & $\begin{array}{l}\text { Strategic Landfill Diversion Program" has received } \\
\text { federal funding to help divert organic waste from the } \\
\text { regional landfill, in an effort to reduce greenhouse gas } \\
\text { emissions. The timing of this funding is fortunate: as } \\
\text { part of the \#ResourceFullAlberni initiative, we will invest } \\
\text { in a feasibility study to find the highest and best use } \\
\text { and value for diverted organic waste. The funding will } \\
\text { provide leverage to the zero waste initiative, but the } \\
\text { zero waste objective is very ambitious compared with } \\
\text { conventional solid waste planning. } \\
\text { 7.4 Open Burning Bylaws and Woodstove Replacement } \\
\text { Program } \\
\text { Port Alberni experiences significant air pollution during } \\
\text { the Fall and Winter months from open burning of forest } \\
\text { residuals, backyard burning of yard waste, and older } \\
\text { woodstoves. The City operates a woodstove } \\
\text { replacement program in collaboration with the Province, } \\
\text { and has implemented bylaws to restrict open burning } \\
\text { within the community. The \#ResourceFullAlberni } \\
\text { initiative will support these efforts by providing non- } \\
\text { polluting and higher-value uses for wood waste. } \\
\text { 7.5 District Energy From Urban Wood Waste } \\
\text { The City of Port Alberni completed an integrated } \\
\text { resource recovery study in } 2010 \text {. The study considered } \\
\text { options for recovering value from organic household } \\
\text { and fisheries waste, district energy based on industrial } \\
\text { waste heat, and district energy based on urban wood } \\
\text { waste. (The resulting report "Integrated Resource } \\
\text { Recovery Options for the City of Port Alberni" is } \\
\text { uploaded with our application.) The City has invested } \\
\text { significant time and effort to develop the district energy } \\
\text { system, and is currently in discussions with our partner } \\
\text { (Island Health) to move its development forward. } \\
\text { City of Port Alberni Crest.pdf (15.02kb) } \\
\text { Port Alberni } 2015 \text { - } 2018 \text { Strategic Plan Update - } \\
\text { January } 2017 . p d f \text { (3.6mb) } \\
\text { Port Alberni Sustainability Report } 2015 . \text { pdf (2.91mb) } \\
\text { Study, Feasibility of District Energy in Port Alberni.pdf } \\
\text { (1.6mb) } \\
\text { Study, Integrated Resource Recovery Options for Port } \\
\text { Alberni.pdf (1007.3kb) }\end{array}$ \\
\hline $\begin{array}{l}\text { Question } 8 \\
\text { Please describe your community's } \\
\text { readiness and ability to implement } \\
\text { your proposal successfully. }\end{array}$ & $\begin{array}{l}\text { 8.1 Experience with Complex Projects } \\
\text { City of Port Alberni personnel have extensive } \\
\text { experience with large capital projects. When faced with } \\
\text { the need to upgrade its wastewater treatment capacity, } \\
\text { the City negotiated a creative solution with a local } \\
\text { paper mill owned by Catalyst Paper to make use of } \\
\text { existing land and industrial wastewater treatment } \\
\text { infrastructure. This } \$ 22 \text { million project is one of the }\end{array}$ \\
\hline
\end{tabular}


This section should include:

- Experience with implementing complex projects (i.e. multistakeholder, multidimensional) that span multiple business lines and functional units

- Structures, processes, and practices in place or planned for managing and implementing complex projects that span multiple business lines and functional units.

- Organizational strengths and potential weaknesses for managing and implementing a smart city proposal, and plans to address weaknesses to ensure successful proposal management and implementation. largest in the City's history, and required complex engagement with stakeholders in local government, industry, First Nations, the Provincial government, and the Federal government (see https://www.portalberni.ca/news/march-21-2017$648 \mathrm{pm} / \mathrm{news}$-release-city-receives-additional-fundingwastewater-treatment)

\subsection{Project Management Structures and Processes} The City has well-established practices and experienced staff responsible for urban planning, building inspection, engineering, finance, and economic development which serve the city of 17,678 .

\subsection{The City's Strengths}

One of our very significant strengths is the community's ability to mobilize social media on behalf of initiatives people really care about. Over the last seven years we have won a number of contests that were based in large part on the mobilization of online voters. We sent a teacher to Africa twice (in two separate contests), won the World Fishing Network's first Ultimate Fishing Town in Canada contest, sent one of our young and prolific social media users to 'Live at YVR' for 80 days; secured two national prizes for a disabled person who launched a non-profit/social enterprise for very sick and terminally ill people; and won the 2016 Community Futures 'Canada's Most Rider Friendly Community' contest. In every instance we have been up against larger (and sometimes much larger) communities in these challenges.

In addition to its capacity to manage large, complex projects, the City's strengths include excellent relations with its citizens, local industry, commercial businesses, First Nations, the Nuu-chah-Nulth Tribal Council, the Port Alberni Port Authority, the Alberni Clayoquot Regional District, the Provincial government, the Federal government and a multitude of non-profit organizations such as the Alberni Valley Chamber of Commerce, Community Futures Alberni-Clayoquot and West Coast Aquatic. These good relations have resulted in a number of collaborations, such as the City's cooperation with Catalyst Paper to reduce the cost of its expanded wastewater treatment facility, and the City's part ownership in the Hupacasath First Nations Upnit Power Corporation's China Creek MicroHydro Project.

Port Alberni enjoys active engagement by citizens on civic and environmental issues, as shown by our Climate Change Committee and Air Quality Council, with representation by the Province of $\mathrm{BC}$, local industry, the City, and citizens. In community engagement processes such as Outlook 2020, citizens have expressed their strong environmental values, 


\begin{tabular}{|c|c|}
\hline & $\begin{array}{l}\text { including concerns over the health of the oceans, land } \\
\text { use, and air quality. } \\
\text { The City became a PLUS Network member of the } \\
\text { International Center for Sustainable Cities (ICSC) in } \\
2008 \text {. In } 2013 \text {, the City passed Bylaw No. } 4817 \text { - "A } \\
\text { Bylaw to Establish a Reserve Fund for the Purpose of } \\
\text { Reducing Greenhouse Gas Emissions in Port Alberni". } \\
\text { The City actively invests its Carbon Fund in energy } \\
\text { efficiency projects. } \\
\text { Further, Citizens are highly engaged in municipal } \\
\text { matters, and City staff have developed patient and } \\
\text { collaborative ways of ensuring all voices are heard } \\
\text { before decisions are made. } \\
\text { Finally, the size of the community fosters a stronger } \\
\text { sense of connection among citizens, and a stronger } \\
\text { sense that individual actions make a significant } \\
\text { difference to the quality of life in the city. } \\
\text { 8.3 The City's Potential Weaknesses, and Plans to } \\
\text { Address Them } \\
\text { The City is behind other jurisdictions with respect to } \\
\text { solid waste diversion. } \\
\text { The City also recognizes it will need to build capacity in } \\
\text { the areas of resource recovery technology, theory of } \\
\text { change, data collection and visualization, app } \\
\text { development, and the extensive and ongoing } \\
\text { community and stakeholder engagement processes } \\
\text { which will be needed to bring the \#ResourceFullAlberni } \\
\text { initiative to fruition. If the City is awarded a grant to } \\
\text { move forward with the initiative, we will invest funds in } \\
\text { developing these capacities. } \\
8.4 \text { How we Will Build on Current Initiatives } \\
\text { The aforementioned "Consolidated Strategic Landfill } \\
\text { Diversion Program" has received } \$ 6 \text { million in federal } \\
\text { funding to help divert organic waste from the regional } \\
\text { landfill, in an effort to reduce greenhouse gas } \\
\text { emissions. We will invest in a feasibility study to find the } \\
\text { highest and best use and value for diverted organic } \\
\text { waste. } \\
\text { The City is currently in discussions with Island Health } \\
\text { regarding the development of a district energy system } \\
\text { which would use urban wood waste to replace fossil } \\
\text { fuel in the local hospital, as well as a number of other } \\
\text { buildings in the community. }\end{array}$ \\
\hline $\begin{array}{l}\text { Question } 9 \\
\text { Describe your plan for using the } \\
\$ 250,000 \text { grant, should you be } \\
\text { selected as a finalist. Provide a } \\
\text { high-level breakdown of spending } \\
\text { categories and an accompanying }\end{array}$ & $\begin{array}{l}\text { We recognize gaps in our knowledge of stakeholders' } \\
\text { interests, of best practices, and areas where our } \\
\text { capacities need to improve. As we address these } \\
\text { areas, we will not outsource decisions for which we are } \\
\text { responsible, but will engage experts to help build our } \\
\text { own capacity. } \\
\text { 9.1 Stakeholders' Interests }\end{array}$ \\
\hline
\end{tabular}


rationale.

We will use best practices in community engagement to identify stakeholders who can help us achieve results, and stakeholders who will be affected by the process. We expect stakeholders to include the AlberniClayoquot Regional District, the Tseshaht First Nation, the Hupačasath First Nation, our citizens, industry, and commercial businesses. We will identify stakeholders' interests, which we will take into account when developing implementation plans.

\subsection{Best Practices}

Other communities have moved toward zero waste, and resource recovery technologies are mature. We will contact leaders in zero waste to learn from their experiences, including the Regional District of Nanaimo, San Francisco (with a diversion rate of $78 \%$ ), the Brazilian city of Curitiba, the Swedish city of Kristianstad, the Halifax Regional Municipality, and Mountain Equipment Co-op (with a diversion rate of up to $97 \%$ ). As we reach out to leaders in this area, we will ask questions such as:

- How do individuals and communities change? What change management methods worked best?

- What challenges were faced at each stage of the work, and how were they overcome?

- How can we ensure our zero waste initiative improves gender equality?

- How can our zero waste initiative be as inclusive as possible of all members of our community?

- How can we best create employment for those involved in resource recovery?

- How can we ensure the health of those handling waste streams which are normally landfilled?

- How can we ensure that our zero waste initiative does not have unintended consequences, such as the dumping of garbage in our backcountry?

- How can we involve artists, poets, musicians, filmmakers and other creative people in getting the zero waste messages across?

- How can we involve the many trades' people in Port Alberni in designing and making profitable products from waste?

\subsection{Investments in Capacity}

The City will invest grant funds in the following areas: - Research into best practices for resource recovery around the world by communities and corporations - A Business Case to develop the revenue-neutral zero waste model, which will estimate the economic benefits, greenhouse gas reductions, other environmental benefits; the capital and operating costs for required information technologies, data acquisition technologies, resource recovery facilities, public engagement processes; and provide recommendations for 


\begin{tabular}{|c|c|}
\hline & $\begin{array}{l}\text { governance. } \\
\text { - A detailed study of the composition of solid waste from } \\
\text { homes and businesses } \\
\text { - A feasibility study and Business Case for an } \\
\text { anaerobic digestion facility } \\
\text { - A Business Case for an Eco-Industrial Park, building } \\
\text { on work to-date } \\
\text { - Education and training in problem-solving and } \\
\text { continual improvement for teams } \\
\text { - Expertise in the design of engagement and } \\
\text { consultation processes } \\
\text { - Engagement and consultation processes } \\
\text { - Expertise in change management } \\
\text { - The \#ResourceFullAlberni website }\end{array}$ \\
\hline $\begin{array}{l}\text { Question } 10 \\
\text { Describe the partners that are or } \\
\text { will be involved in your proposal. } \\
\text { Where partners are not yet } \\
\text { determined, describe the process } \\
\text { for selecting them. } \\
\text { This section should include: } \\
\text { - A description of existing } \\
\text { partners (what type of } \\
\text { organization, what they } \\
\text { do, etc.), their relevance, } \\
\text { and expected contribution } \\
\text { to the outcome (or } \\
\text { outcomes). } \\
\text { Where partners are not } \\
\text { yet determined or where it } \\
\text { is anticipated that } \\
\text { additional partners are } \\
\text { required, describe the } \\
\text { process for selecting them }\end{array}$ & $\begin{array}{l}\text { The City's partners will include: } \\
\text { 1) The Alberni-Clayoquot Regional District, which } \\
\text { manages the regional landfill. The City will work with } \\
\text { the Alberni-Clayoquot Regional District to form a } \\
\text { subsidiary organization to manage resource recovery } \\
\text { operations. Potentially, First Nations, local businesses, } \\
\text { and citizens could be offered the opportunity to invest in } \\
\text { this organization. Forming such an organization will } \\
\text { make it clear that the community is no longer managing } \\
\text { "garbage" as a disposal issue, but treating waste as a } \\
\text { resource recovery opportunity. } \\
\text { 2) The Tseshaht First Nation and the Hupačasath First } \\
\text { Nation, who will be invited to participate as business } \\
\text { partners in every aspect of the initiative. } \\
\text { 3) Industrial firms such as Catalyst Paper and Western } \\
\text { Forest Products. Often, cities work on issues like solid } \\
\text { waste in isolation. If a city were instead to work with } \\
\text { local industry, the result could be higher value or lower } \\
\text { cost. For example, does local industry have a waste } \\
\text { stream which they are struggling to address? If so, } \\
\text { could a single, jointly-owned resource recovery facility } \\
\text { process waste from the industry and also the } \\
\text { community? Could a resource recovery facility be } \\
\text { located on the industrial site, to reduce capital and } \\
\text { operating costs? Local industrial firms have expressed } \\
\text { interest in reducing their energy costs, and a } \\
\text { willingness to explore the option of locating } \\
\text { infrastructure (such as components of a district energy } \\
\text { system, a wood gasifier, or an anaerobic digester) on } \\
\text { their sites. Locating an anaerobic digester on an } \\
\text { existing industrial site can reduce the capital cost (no } \\
\text { land cost, simpler environmental permitting) and } \\
\text { operating costs (industrial waste heat is available to } \\
\text { maintain the digester temperature; skilled trades and } \\
\text { operators are available to operate the unit efficiently; } \\
\text { and so on). } \\
\text { Further, supplies are delivered to local industry by } \\
\text { truck. We will work with industry to fill otherwise empty } \\
\text { trucks leaving Port Alberni with recyclables. This kind of }\end{array}$ \\
\hline
\end{tabular}




\begin{tabular}{|c|c|}
\hline & $\begin{array}{l}\text { cooperation will reduce the City's costs. } \\
\text { 4) North Island College, Alberni Valley Chamber of } \\
\text { Commerce, Community Futures Alberni-Clayoquot, } \\
\text { Westcoast Aquatic } \\
\text { 5) The Province of British Columbia will support the } \\
\text { zero waste initiative through its Extended Producer } \\
\text { Responsibility programs: } \\
\text { https://www2.gov.bc.ca/gov/content/environment/waste- } \\
\text { management/recycling/product-stewardship for and } \\
\text { support } \\
\text { Other partners will be chosen if they can contribute } \\
\text { knowledge or other resources, including best practices } \\
\text { in the full utilization of resources. For example, the City } \\
\text { will consider forming sister city relationships with } \\
\text { Kristianstad in Sweden and with Curitiba in Brazil. } \\
\text { These cities have demonstrated creative and } \\
\text { collaborative problem solving in their work toward zero } \\
\text { waste. } \\
\text { Technology service-providers will be chosen for their } \\
\text { skill in working collaboratively with communities, and } \\
\text { artists will be chosen from within the community as far } \\
\text { as possible. }\end{array}$ \\
\hline $\begin{array}{l}\text { Question } 11 \text { (confidential } \\
\text { annex) } \\
\text { Please provide, if and only if } \\
\text { required, confidential third party } \\
\text { information. Information provided } \\
\text { in this section will be exempt from } \\
\text { the requirement to be posted } \\
\text { online. } \\
\text { Third party information in this } \\
\text { section should be supplemental to } \\
\text { the information provided } \\
\text { elsewhere in the application and } \\
\text { be limited to those details that are } \\
\text { deemed confidential. Please } \\
\text { clearly indicate to which } \\
\text { question(s) the information } \\
\text { provided in this section relates. }\end{array}$ & \\
\hline Ather ren & \\
\hline $\begin{array}{l}\text { Question } 12 \\
\text { Provide a summary of your } \\
\text { preliminary proposal. This } \\
\text { summary, along with your }\end{array}$ & $\begin{array}{l}\text { The City of Port Alberni's motto is "Perseverance and } \\
\text { Prosperity". We have chosen to become Canada's first } \\
\text { zero waste community not because it will be easy but } \\
\text { because it will be hard, although we also believe we } \\
\text { can achieve that outcome. } \\
\text { Our economic model is to make waste pay its own way. }\end{array}$ \\
\hline
\end{tabular}




\begin{tabular}{|c|c|}
\hline $\begin{array}{l}\text { Challenge Statement, will be } \\
\text { posted online in both official } \\
\text { languages. } \\
\text { You have the option of providing } \\
\text { the summary in both official } \\
\text { languages. If you provide it in one } \\
\text { official language, Infrastructure } \\
\text { Canada will translate it prior to } \\
\text { posting online. }\end{array}$ & $\begin{array}{l}\text { We will invest in resource recovery technologies which } \\
\text { return the highest economic, social, and environmental } \\
\text { value to the community. We will invest in start-up } \\
\text { enterprises to create value from recovered resources. } \\
\text { We will use information technology strategically to } \\
\text { make the cost of waste visible to citizens, and to } \\
\text { empower them to reduce waste. } \\
\text { We realize the zero waste goal can only be achieved } \\
\text { through the full participation of all citizens. To that end, } \\
\text { we will use best practices in community engagement } \\
\text { and the theory of change to design our programs. We } \\
\text { will begin with citizens' environmental values and } \\
\text { personal connections with oceans and forests to tap } \\
\text { into our greatest asset: the traditional wisdom, youthful } \\
\text { ideas, and resourcefulness of our people. } \\
\text { By doing the hard thing, we will discover that if we can } \\
\text { do this, we can overcome the stigma of being the worst } \\
\text { place to live in Canada! }\end{array}$ \\
\hline $\begin{array}{l}\text { Question } 13 \\
\text { Provide the link to the online } \\
\text { location where you will post your } \\
\text { responses to questions } 1 \text { to } 10 . \\
\text { You may also provide your } \\
\text { responses to any other questions. } \\
\text { Your responses must go live on } \\
\text { the URL provided once you have } \\
\text { received confirmation in early to } \\
\text { mid-May that your application is } \\
\text { eligible. }\end{array}$ & https://www.portalberni.ca/smart-cities \\
\hline $\begin{array}{l}\text { Question } 14 \\
\text { In accordance with your } \\
\text { governance structure, provide } \\
\text { evidence of the commitment to } \\
\text { your preliminary proposal from } \\
\text { your community's leadership. This } \\
\text { can be a letter of support with } \\
\text { signatures from your mayor(s), } \\
\text { chief(s), or equivalent or a council } \\
\text { resolution, a band council } \\
\text { resolution, etc. }\end{array}$ & Smart Cities Letter.pdf (433.85kb) \\
\hline $\begin{array}{l}\text { Question } 15 \\
\text { Please identify the point of contact }\end{array}$ & $\begin{array}{l}\text { Contact name: Pat Deakin } \\
\text { Contact title and affiliation: Economic Development } \\
\text { Manager, City of Port Alberni } \\
\text { Contact phone number: (250) } 720-9117 \text { Extension }\end{array}$ \\
\hline
\end{tabular}




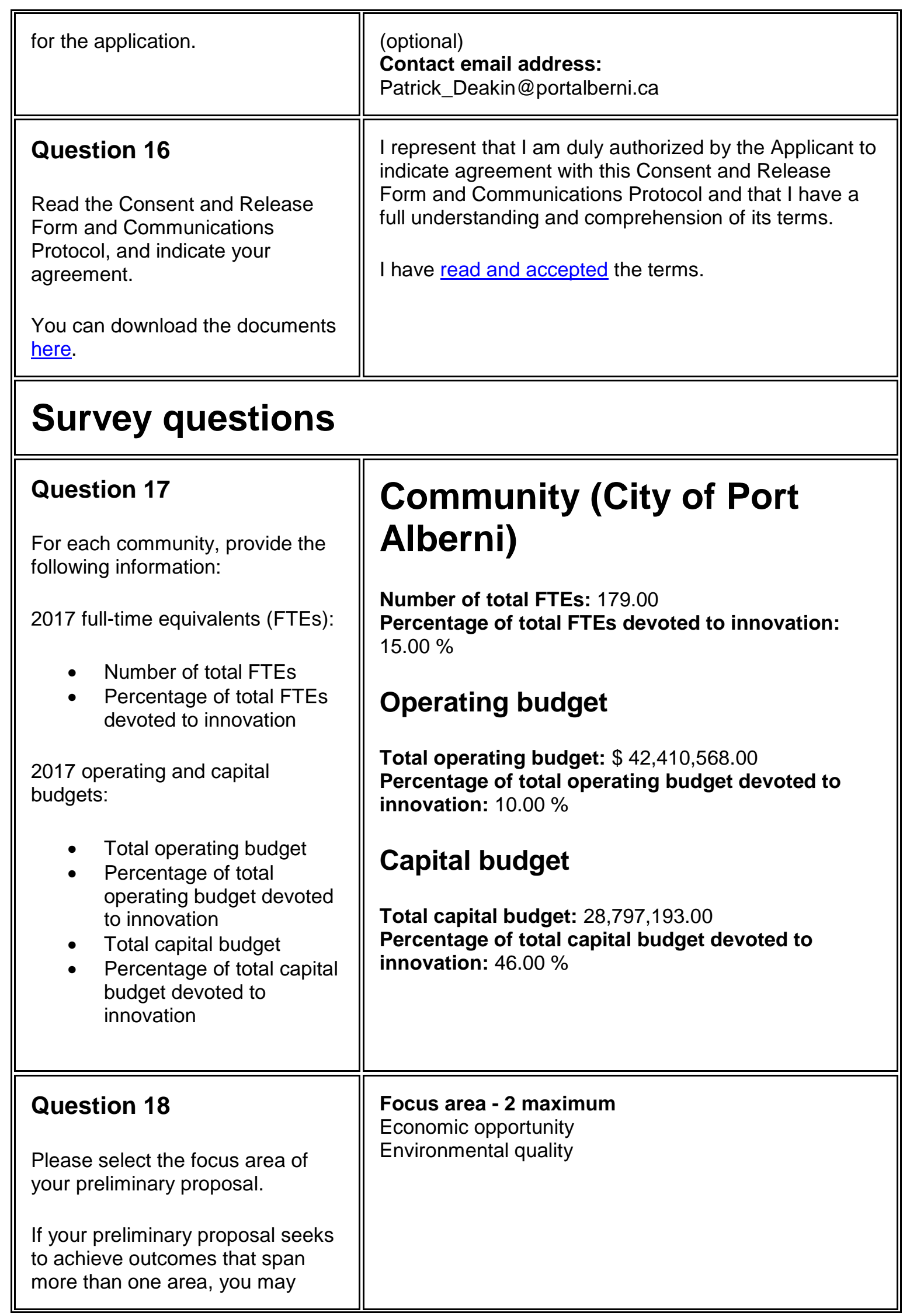




\begin{tabular}{|c|c|}
\hline choose up to two. & \\
\hline $\begin{array}{l}\text { Question } 19 \\
\text { Select all the community } \\
\text { system/service areas expected to } \\
\text { be implicated in your preliminary } \\
\text { proposal. } \\
\text { There is no limit to the number of } \\
\text { community systems/service areas } \\
\text { you may select. }\end{array}$ & $\begin{array}{l}\text { Community system/service } \\
\text { Arts and culture } \\
\text { Economic development } \\
\text { Education and training } \\
\text { Environment } \\
\text { Land use planning and development } \\
\text { Public health } \\
\text { Waste } \\
\text { Water and wastewater } \\
\text { Other }\end{array}$ \\
\hline $\begin{array}{l}\text { Question } 20 \\
\text { Select all the technologies } \\
\text { expected to be implicated in your } \\
\text { preliminary proposal. } \\
\text { There is no limit to the number of } \\
\text { technologies you may select. }\end{array}$ & $\begin{array}{l}\text { Technologies } \\
\text { Augmented reality (AR) or Virtual reality (VR) } \\
\text { Big data analytics } \\
\text { Enterprise solutions } \\
\text { Environmental monitoring } \\
\text { Mobile applications } \\
\text { Open data platforms } \\
\text { Payment platforms } \\
\text { Sensors } \\
\text { Video analytics } \\
\text { Other: Please specify } \\
\text { Other Weightometers on trucks to read RFID chips on } \\
\text { garbage and green bins to provide instant data and } \\
\text { communications }\end{array}$ \\
\hline
\end{tabular}




\section{Squamish Economic Development SQUAMISH SMART CITIES APPLICATION}

Question 1

Please provide information on the community that is

submitting this application.

Name of community: District of Squamish

Province or Territory: British Columbia

Population based on: 19,512

Indigenous community: No

Question 2

Please select a prize category.

$\$ 10$ million (population under 500,000 residents) Question 3 
Please define your Challenge Statement in a single sentence that guides your preliminary proposal. It should describe the outcome (or outcomes) you hope to achieve.

Squamish, one of Canada's fastest-growing municipalities, will engage and empower our community to sustainably grow by reducing overall waste, and by turning waste into assets - clean energy, renewable materials and new products - at once powering our economy, creating future-focused jobs, and exceeding government waste and greenhouse gas emission targets.

Question 4 
Please describe the outcome (or outcomes) your proposal seeks to achieve by elaborating on your Challenge Statement.

As a fast-growing community, the District of Squamish (Squamish) faces the challenge of how to accommodate a rising population while still achieving our ambitious environmental and sustainability targets. By 2036 , the population is projected to nearly double from 20,000 to 36,000 . This rapid growth will increase waste, and, based on current employment data, require a significant and growing number of community members to commute to jobs outside of Squamish, increasing both their cost of living as well as greenhouse gas emissions. While District programs such as recycling and energy reduction are already having a significant impact, they will not be sufficient to meet our community's ambitious Zero-waste action plan.

For these reasons, Squamish has chosen to pursue a path of sustainable growth using the principles of the circular economy, which is restorative and regenerative by design. Relying on system-wide innovation, this type of economy aims to redefine 
products and services to design waste out, while minimizing negative impacts. Underpinned by a transition to renewable energy sources, the circular model builds economic, natural and social capital.

Powered by data and connected technology, Squamish citizens, industry, government and partners will work together to ensure the District not only reduces overall waste, but also turns waste into valuable assets - clean energy, renewable materials and new products. This will in turn power the economy, create future-focused jobs and make us an international leader in exceeding government waste and greenhouse gas emission targets.

Ultimately, we will transform into a thriving community committed to a circular economy and the benefits of its restorative and regenerative paradigm.

Our goal is to exceed provincial waste diversion targets through the transition to a circular economy. Some numbers:

- By 2025, we plan to beat the provincial 2020 waste target by $16 \%$ achieving $292.5 \mathrm{~kg}$ annual per capita waste and a waste diversion rate of $79 \%$. This is to ensure we meet the provincial 2040 zero-waste annual target of $120 \mathrm{~kg}$ per capita and a $95 \%$ diversion rate.

- By 2025, we also plan to reduce greenhouse gas 
emissions $41 \%$ below 2007 levels, en route to meeting or beating the provincial goal of reducing emissions $80 \%$ below 2007 levels by 2050 .

- In working to surpass these two targets, Squamish will aim to reduce the number of commuters by $5 \%$ via the creation of 200 new jobs that will contribute directly to our local economy.

This will be challenging! Waste generation has always been high in Squamish. In 2008, annual per capita waste was more than $1,000 \mathrm{~kg}$. While significant improvements have been made post-2008 thanks to residential recycling (started 2009) and an organics curbside collection (started 2015), the District still faces considerable challenges in meeting our waste-related targets.

Zero Waste Strategy, a report commissioned by the District, suggests that the community will be unable to meet the 2020 provincial and municipal annual targets of $75 \%$ waste diversion and $350 \mathrm{~kg}$ of waste per capita unless further, more aggressive measures are taken to shift consumption and realize new methods of waste diversion. In 2017, annual per capita waste was $610 \mathrm{~kg}$, and the report suggests that the 2020 target will not be achieved before 2032. 
Residents and businesses currently have little incentive to shift attitudes or habits as it relates to waste. The District plans to empower the community and heighten awareness through gamification of waste management. We will provide real-time data insights to users through connected technology that streamlines waste collection and encourages waste minimization. Smart cards, sensors on bins and collection trucks will relay data and incentivize action to "clean up our act." A gamification strategy will be used to measure, monitor and continuously improve the impact of the community's behaviour around waste management.

The District has been spending approximately $\$ 3 \mathrm{M}$ annually ( $8 \%$ of our municipal budget and the equivalent of $\$ 150$ per capita) on solid waste management, funded through waste utility fees, landfill tipping fees and such. The local landfill has now reached capacity and requires a $\$ 5 \mathrm{M}$ vertical landfill expansion. In addition, the District is working to reduce greenhouse gas emissions with the introduction of flare technology valued at $\$ 1 \mathrm{M}$, both of which will increase the cost of landfill operations.

Even more concerning: based on current projections, a horizontal expansion of the landfill will be required in eight years, resulting in further costs 
associated with land acquisition and infrastructure. Beyond reducing and diverting overall waste, capitalizing on technologies that better manage landfill operations will be critical to address increasing capacity requirements due to constant growth. Implementing smart landfill technologies for reverse vending and waste separation, as well as to measure sorting yields, will help optimize waste streams for the District and associated expansion costs.

What's more, multi-family and condominium residences, and local businesses are paying additional hauling fees to private enterprise. In some cases, these companies are also paying to dispose of byproducts generated through their activities, such as grain waste from the beverage industry or wood waste generated through the forest industry.

This is where waste can become an asset - shifting from a cost centre to a revenue stream to supplement important local economic sectors such as forestry and manufacturing.

For example, the regional forest sector supports 470 high-paying jobs (200 in Squamish), which has a direct economic impact of $\$ 44 \mathrm{M}$ annually. At present, local companies are spending in excess of $\$ 400,000$ 
annually to transport or bury wood waste on Districtowned lots or in close proximity to Squamish - a significant cost burden for the regional forest industry. What's more, waste at log sort terminals typically represents $10 \%$ of the timber handled.

These wood biomass volumes could alternatively become a net economic contributor for the industry and our community. With more than $70,000 \mathrm{~m} 3$ of annual waste stock available from active logging operations and related activities, as well several hundred thousand $\mathrm{m} 3$ of buried materials throughout the District, wood waste, as with other byproducts, has the potential to be managed by data and connected technology to power industrial operations, homes and buildings in Squamish - ultimately displacing fossil fuels and reducing greenhouse gas emissions.

Take for instance, The University of British Columbia (UBC). Like Squamish, UBC is striving to meet its energy and power needs while reducing its impact on the environment. Its Bioenergy Research Demonstration Facility has responded to this challenge by developing small-scale power production that's relevant and replicable in other communities. This smart system, the first of its kind in North America, processes renewable biomass to 
generate enough thermal energy to heat $25 \%$ of the campus, eliminating $14 \%$ of campus greenhouse emissions and reducing UBC's reliance on fossil fuels. In addition, a $2 \mathrm{MW}$ cogeneration engine uses renewable natural gas to generate over $5 \%$ of the power for UBC's electrical grid, while waste heat from the electrical generation process is also used to heat campus buildings.

Squamish-based Carbon Engineering is in the business of capturing atmospheric carbon dioxide and turning it into useful products such as vehicle fuel. The company is collaborating with researchers at UBC to examine how to combine hydrogen produced from renewable electricity and water with captured carbon dioxide to create the cleanest fuels on the market.

By applying ideas like these that link innovation with data and connected technology, Squamish will demonstrate on a city-size scale how communities across Canada have the potential to turn waste into assets and reduce the negative consequences of industrial operations. We envision this connected technology creating a new partnership model government, the regional forest industry, Carbon Engineering and academia - to identify, grade and track byproducts to biofuels, and in turn, power 
facilities like Carbon Engineering and use technology to efficiently manage renewable energy operations. This would be a truly circular economy.

With more than 6,600 housing units currently in the District's development stream, and more coming on line every day, Squamish must also address the growing waste generated as a result of construction activity. In 2016, the District experienced an $80 \%$ year-over-year increase in construction, demolition and privately dumped waste at the landfill, equating to 1,881 tonnes. In 2017, the District issued a total of 262 building permits with a construction value of more than $\$ 132 \mathrm{M}$, a number we are on track to surpass by at least $25 \%$ in 2018.

By expanding and promoting our local carbon marketplace, retrofitting smart landfills, enhancing procurement practices to consider how data and technology can save money and reduce environmental impacts, as well as developing platforms to share byproducts, exchange knowledge and encourage participation, Squamish has an opportunity to better manage, monetize and reduce construction debris.

Given the District's anticipated population growth, inaction on waste is not an option. If no 
improvements are made, we will more than double total waste by $2040(27,124$ tonnes versus 13,914 tonnes in 2016), filling the existing and proposed landfills at twice the current rate. Reduction through gamification, technology to streamline landfill operations and the diversion of biomass to renewable energy are all practical and achievable options.

In addition to solid waste, the District is also challenged by greenhouse gas emissions. Indeed, if we view these emissions through the lens of a circular economy, they are a form of waste. As a growing, heavily car-dependent community situated on a highway serving more than eight million vehicles annually, and with a quarter of our workforce commuting to the Lower Mainland or to Whistler for work - most in single-occupancy vehicles - Squamish needs to rethink how to address community greenhouse gas emissions moving forward.

The District adopted the B.C. provincial target to reduce these emissions by $80 \%$ below 2007 levels by 2050 . Like many other communities, we are striving to do so through policies, programs and initiatives that support mobility mode-shifting and increased public transit. Yet this is not enough. 
As usage patterns for automotive transportation are heavily influenced by our community's driving habits and commutes, Squamish must engage and empower the community to measure and monitor the impact of its greenhouse gas emission patterns. We plan to do so by applying data and connected technology to efficiently manage infrastructure, introduce new clean energy sources and encourage more efficient, productive practices - both residential and commercial.

Squamish recently completed a real estate strategy outlining the need for significant investment to retrofit and replace a number of our facilities. Most are at the end of life due to age and overcapacity, or they are no longer providing effective service to the community. The need for an investment in excess of $\$ 100 \mathrm{M}$ has been identified in order to meet future growth. The strategy also identified that the most effective way to generate the greatest possible return on investment in facilities and land is by extending a building's life expectancy. The Internet of Things (IoT) can be the catalyst that helps to realize this, through providing data and connected technology that works to eliminate waste and reduce greenhouse gas emissions. Our partners, Powertech Labs and Stuart Olson, are pioneers in smart 
building technologies and enabling energy efficiency in homes, businesses and plants.

Another of our partners, Philips, already uses loT to great success. The Edge is an innovative, 40,000 $\mathrm{m} 2$, multi-tenant office building in Amsterdam. Philips' main design goal was to create an intuitive environment for workers that could serve as inspiration for sustainable building design around the world. Today, the Edge benefits from a smart lighting system and software applications that use cuttingedge technologies to deliver services that enhance the flexibility of open-plan office space. The system not only allows workers to personalize the lighting and temperature at their workspaces via their smartphones, but also provides building managers with real-time data on operations and activities, enabling them to maximize the facility's operational efficiency, optimize office space and reduce the building's $\mathrm{CO} 2$ footprint.

We have a responsibility to support climate change mitigation and can contribute towards Canada's ambition to meet the goal of a $30 \%$ emission reduction below 2005 levels and to limit global temperature warming to under $2^{\circ}$ Celsius. Working with partners like Powertech Labs, Stuart Olson and Philips to deliberately design waste out of local 
facilities will help Squamish to reduce greenhouse gas emissions. It also makes economic sense for local firms, as it will increase their productivity and profitability.

Driven by an attractive ocean-meets-mountain active-adventure lifestyle, as well as close proximity to the Lower Mainland and Whistler, the District is growing annually by $3 \%$ - a rate nearly three times that of British Columbia and Canada. Moreover, the cost of living has risen significantly in recent years. According to Statistics Canada, in 2016 the average rental rate was 13\% above B.C.'s average. In March 2018, the Real Estate Board of Vancouver reported a $\$ 1 \mathrm{M}$ benchmark property value. With one in every four residents spending more than $30 \%$ of household income on housing, increasing local employment and the number of high-paying jobs, coupled with reducing household costs such as transportation, is a priority for the local government and community. The District's residents are highly attuned to using energy wisely, and a gamification approach, among other initiatives, will help them to achieve their smart energy goals.

While Squamish's close proximity to other municipalities and high cost of living also puts us at risk of becoming a bedroom community, we have no 
intention of becoming one. Our goal is to mitigate impacts from population growth by creating knowledge platforms for innovation focused on remanufacturing, value chains and byproduct sharing. We will use data and connected technology to drive more productive and profitable decisions, improving business processes, community management and personal impact we make en route.

Our Smart Cities partner, UBC's Clean Energy Research Centre (CERC), is working to create safe, widespread and equitable access to sustainable energy. CERC hosts world-leading researchers who see this challenge as an opportunity to help future generations inherit a better world. Imagine a knowledge hub in Squamish, focused on how data and connected technology can be catalysts to a cleaner environment, all powered through collaboration between the community and partners and shared with the rest of Canada.

Most important, as Squamish transitions to a regenerative and restorative economy, we will use data and connected technology to guide our way forward. From conceptual design to implementation, we will continuously measure, make sense of, and be nimble in our approach to build on ideas and 
respond to changing dynamics. As part of our final project design, and relying on our partners, our current expertise in GIS mapping, data analytics and strategic measurement, we will adopt an iterative process that ties progress to outcomes, is transparent, and is easily understood by our community and communities across Canada.

From our design and procurement to our manufacturing processes and logistics, to the products and services we make and use, we will work to reduce our negative impact on the environment while fostering and sharing our innovations, creating local employment, and shifting attitudes and practices around waste and energy.

Question 5

Please describe how your community residents have shaped your Challenge Statement. Describe your plans for continuing to engage and involve them in your final proposal going forward.

The District of Squamish reviewed in detail our community's newly adopted Official Community Plan, 'Squamish2040.' Given the plan's extensive two-year public engagement process, this was an efficient way to understand the challenges our 
community faces, as well as the vision and aspirations of our residents both now and in the future. Participants included children, youth, adults, elders, community organizations, Squamish Nation members, other levels of government, agencies and District partners.

Six key issues emerged through the public engagement process, which we have subsequently considered in relation to the District's Challenge application.

1. Rapid Growth. As a fast-growing community with shifting demographics, carefully managed, sustainable growth is essential to avoid sprawl and environmental degradation. We must plan for efficient infrastructure and create complete, connected neighbourhoods where people can live, work, play and shop.

2. Housing Affordability and Supply. Residents are concerned about being able to afford or find suitable housing in order to remain in the community. Affordable housing supply is also a key factor for employers who need to attract and retain a skilled local workforce. 
3. Economy and Local Jobs. Local jobs and business opportunities are needed to support a diverse and sustainable economy, and improve the quality of life for everyone in the community. This requires preserving critical employment lands; promoting business retention, growth and innovation; and focusing on local skill development and infrastructure needs. Increasing local employment opportunities and job participation rates will also ensure that Squamish does not turn into a bedroom community.

4. Environmental Protection. The District's natural environment is the backbone of the community. It provides habitat for fish and wildlife, plants and ecological communities, and valuable ecosystem services. It also supports the health and wellbeing of residents, and provides world-class recreation and tourism activities vital to our economy. As Squamish grows, so, too, does pressure on natural environments within and surrounding our community. Growth must be managed to avoid or minimize impacts on the natural environment, and to enhance natural areas wherever possible.

5. Local and Regional Transportation. People need safe, convenient and accessible ways to get around Squamish, to get to neighbouring 
communities in the Sea to Sky corridor, and to move easily around the region. Better options for walking, cycling and transit will help reduce the reliance on single-occupancy vehicles and support a more affordable and active community.

6. Community Health and Wellbeing. More than $60 \%$ of our health is determined by the environment where we live, work, learn and play. How Squamish is planned and the way in which our community grows has a significant impact on the health of citizens and generations to come. Though the community is physically active, it is still highly dependent on vehicles, which can have a detrimental impact on air quality and advance sedentary behaviours that can lead to chronic illnesses. Healthy built environments that promote active travel, play and connected, accessible and complete neighbourhoods are needed to support social, physical and mental wellbeing at all ages and stages of life. For Squamish to thrive, basic needs must be adequately met. This includes nutrition, housing, sufficient income, health and support services, public health and safety, accessibility, as well as social connections supporting community cohesion and resiliency. 
The Official Community Plan also formed the basis for our 'Smart Squamish Community Engagement Process,' which took place between Feb. 23 and April 3, 2018. Residents provided feedback both online and during a day-long symposium on how well the chosen areas of focus for the Challenge aligned with community aspirations, as well as potential data, technology and innovative solutions for Squamish.

In addition to requesting feedback on areas of focus for the Challenge, the District engaged potential partners, through a Request for Information process, to provide proposals aligned to our Official Community Plan goals that met the criteria for the Challenge. We received 15 submissions.

Proposals from 13 potential partners were made available for review and feedback on the District's Smart Squamish submission page. Residents were also invited to participate in Smart Squamish, a daylong Smart Cities Symposium held on March 12, 2018. Residents were encouraged to help identify areas for the Challenge and to provide feedback on proposed solutions presented by potential partners.

Online, we asked residents to indicate their preferred area of focus for the Challenge, based on: 
- Mobility

- Healthy Environment

- Healthy Lifestyle and Recreation

- Economic Opportunity

- Safety and Security

- Empowerment and Inclusion

In total, we received 78 responses via a pop-up quiz on our website, www.squamish.ca/smart-citieschallenge, and through social media. Of total respondents, $26 \%$ prioritized a healthy environment, $23 \%$ prioritized healthy lifestyle and recreation, $23 \%$ prioritized economic opportunity, $8 \%$ prioritized mobility, $5 \%$ prioritized safety and security, and $1 \%$ prioritized empowerment and inclusion.

The District's Smart Cities public engagement process was promoted at District public facilities, including our library, community centre, municipal hall and seniors' centre, as well as on the District website, through digital, social and radio promotions targeting local residents, and in the District's weekly newspaper, The Squamish Chief. A full-page ad promoted both the online and town hall engagement process.

Since the launch of the online Smart Cities platform, there have been a total of 910 page views on 
partner proposal pages and 446 page views on the Smart Cities landing page. A total of 70 local residents attended the Smart Squamish symposium, with 25 potential partners and 15 District of Squamish staff.

Themes from our Smart Squamish engagement process included:

- Creating jobs and added productivity in our economy

- Reducing impact on the environment / creating a clean environment

- Enhancing our geographical and social mobility

- Improving community resilience and adaptability

- Seeking new partnerships: private-public, publicpublic, etc.

- Creating learning opportunities for citizens

- Ensuring community values align to our Smart Cities objectives

- Creating opportunities for community participation

Ultimately, residents provided feedback that the theme selected and subsequent application should be focused on reducing our impact on the environment while creating economic opportunity for residents, particularly increasing in local employment. 
The District's Challenge Statement clearly aligns to feedback received as an outcome of the community engagement and Official Community Plan process. Reducing and reusing our waste - whether energy, materials or products - creates significant opportunities in all the aforementioned areas and aligns to critical priorities for our community.

The District adopted the International Association of Public Participation (IAP2) methodology for public engagement in 2015. On issues that affect citizens broadly, we have made a commitment to engage openly and actively so that we create policy and process improvement that incorporates and responds to citizen feedback. As we continue to design and implement our Smart Squamish approach, we will use IAP2 methodology to ensure that, during each step of the process, we are actively engaging and considering feedback. To start, the District will develop both digital and print communication materials that keep our residents up to date on the Smart Squamish process and always allow for public feedback. Beyond this, our Smart Squamish approach will encourage participation from the community both in the form of active participation in technology strategies such as gamification. 
Please describe your preliminary proposal and its activities or projects.

The District of Squamish will transition to a more restorative and regenerative community by design. The following activities are meant to generate outcomes that limit our negative impact on the environment while expanding our economy, resulting in increased productivity for firms and local employment.

\section{Smart Waste Reduction Initiatives}

From design to disposal, the District will work to eliminate waste leakage in our practices. Data and connected technology will play a pivotal role in how we, as a community, understand and respond to the impact we make from the waste we generate. Our focus will be on reducing overall waste by incentivizing behaviour - encouraging smarter, more efficient practices through the following activities:

Smart Waste Collection. Asset-tracking technology such as smart cards and radio-frequency 
identification (RFID) tags on bins will help track waste generation down to the individual level.

Connected technology, such as fill level, composition and foot traffic density sensors will provide real-time and predictive data. Building on this, we will explore how technology such as District bear-proof smart bins can replace existing bins at the end of their lifecycles while retrofitting existing bins to incorporate tagging and sensor technology. This District-wide initiative is meant to shift attitudes and behaviour of residents and businesses, as data will be integrated into the planned Squamish Zero-waste platform and waste management systems. Both realtime and predictive views will be openly available, integrated with gamification and linked to incentives.

Smart Routing. GPS and GIS combined with sensors will drive efficient waste collection. Building on the asset tagging and sensor initiative, the District will work with waste collectors, already GPS equipped, to implement smart routing where practical. A feasibility study will help to determine the smart routing potential for commercial, residential and institutional collection.

Smart Building and Buildings. Using incentives and a policy framework, we will aim to incent residents and businesses to reduce energy 
consumption by integrating Internet of Things (IoT) connected technology, and retrofitting and building more efficiently with renewable, clean energy sources. We will explore how, and implement where possible, loT solutions into existing and planned District facilities to design out waste, maximizing their efficiency. During project design, the District and our partners will explore the use of incentives and policy to develop an open, flexible program at the municipal level, building on and considering provincial and federal initiatives, policy and regulations.

Smart Landfill. From sorting yields and reverse vending to waste separation and environmental impacts, data will provide real-time and predictive insights into landfill waste in order mitigate emissions, as well as to divert and eliminate waste streams. We will work to develop a more effective landfill operation, looking at automation as a way to improve energy efficiency and divert more waste. This operation will serve data through connected technology to form insights for decision making, maximize current capacities and limit the need for expansion.

Smart Procurement. The District will explore the potential to use procurement policies as a way to 
incent suppliers in the area of data, connected technology and innovation, and develop smart tools to weigh the cost/benefit of lifecycle extension, products as a service and increased utilization rates versus traditional models. As the District modernizes our procurement standards, we will work to share best practices and lessons learned with other Canadian municipalities.

Smart Engagement. The District will engage the community and residents to design bylaws and community best practices to help set ambitious yet achievable goals. The District will use gamification technologies to model, monitor and incentivize community members.

\section{Waste to Asset Initiatives}

Almost every human activity results in carbon dioxide (CO2) emissions, the most common greenhouse gas. Working with local business and our partners - The University of British Columbia, BC Institute of Technology, Powertech Labs, Squamish \& District Forestry Association and Carbon Engineering - the District of Squamish will innovate to develop programs, policy and processes to generate energy and new products, turning waste 
into assets. Initiatives include:

Smart tracking. By developing an asset tracking to energy program and working with the local business community, The District will help identify, quantify, grade and value industrial/commercial byproducts through the use of asset-tracking technology for use in clean energy production.

Waste to energy to infrastructure. Connecting the asset tracking to energy program, the District, with partners such as UBC, BCIT and Powertech Labs, will work to generate and store clean energy through energy management systems to power homes, buildings and municipal infrastructure. For instance, local byproducts could power plant operations for local company Carbon Engineering, which is in the business of capturing $\mathrm{CO} 2$ from the air and turning it into useful products such as vehicle fuel. At the finalist stage, the District, with partners and stakeholders from key sectors such as energy, construction, forestry and academia, will work collaboratively in project design to ensure flexibility, scalability and openness.

\section{Squamish Zero-waste Platform.}


Working with our partners, and integrating marketplaces, gamification and knowledge transfer with insights from data and connected technology, the District of Squamish will create

Squamish Zero-waste. This unique and open platform will be used to drive a reduction in waste as well as turn waste into a community asset for local residents and Canadians across the country to benefit from. Assets will include:

Real-time analytics dashboard. Real-time data insights - from air quality to financial impact — will be made easily available to residents via smart phone devices and online through the Zero-waste platform to demonstrate our collective and individual impact on waste production, reduction and diversion.

Gamification. Integrated with real-time analytics, portal and sensor-based data collection, residential and commercial gamification will encourage waste reduction and diversion through incentives schemes, such as badging, community credits and our community carbon marketplace.

Waste-receiver hub. Through the Zero-waste 
platform, residents and businesses will be able to access all collectors through a one-stop-shop approach to encourage waste diversion.

Community carbon marketplace. Expanding our community carbon marketplace, we will encourage more local businesses to join while also driving offsets by residents.

Byproduct marketplace. We will create a platform for residents and local business to share byproducts of what they make to be used for other applications and manufacturing processes.

Knowledge and innovation hub. With our partners and participation from local business sectors such as clean energy, manufacturing and forestry, Squamish residents and the rest of Canada will grow our collective knowledge base, sharing insights from our activities, providing training and education, and encouraging new data and connected technology innovations in waste reduction and diversion. Working with our partners, we will create a best practices guide, sharing our successes and learnings with other communities that share our goals

Question 7 
Please describe the ways in which your preliminary proposal supports your community's medium and long-term goals, strategies, and plans.

The District of Squamish is proactively integrating data and connected technology in our operations, strategies and approaches. Through our Technology Transformation Program, Community Digital Strategy, Community Carbon Marketplace, Open Data Portal and GIS System, the District is working to integrate, transform and innovate in the area of data and connected technology.

As part of our Smart Cities application development, the District analyzed the regenerative and restorative proposal theme and its alignment to District priorities.

The proposal aims to address Official Community Plan (squamish.ca/ocp) objectives, particularly in the areas of:

- Natural environment: air and water quality - Climate change mitigation and adaptation: corporate carbon neutrality and leadership, community greenhouse gas reductions, green 
building design, climate change adaptation

- Municipal infrastructure: clean, safe, efficient and sustainable utility service provision, green infrastructure, solid waste reduction and diversion

- Natural resources: stewardship of forest lands - Economic development: local employment, skills and training, sustainable and diverse business growth

In addition, the proposal aligns with the District's Zero-waste platform adopted in 2016 and the 2016 report commissioned by the District, 'Adapting to Climate Change in Squamish.' The report outlines why and how climate change adaptation should be incorporated into District policies and highlights opportunities for ongoing action.

The regenerative community theme also aligns to Council's strategic priority areas of:

Environment. Council's priorities include minimizing our community's collective impact as we grow, becoming a community that adapts to and mitigates climate change, and future-focused stewardship. The theme also supports Council's goal to ensure municipal bylaws and goals include climate action policies that facilitate climate change adaptation and mitigation actions. 
Economic development. Council's priorities include encouraging diverse and well-paid jobs, reducing the need to commute, growing business opportunities and supporting hubs of entrepreneurship.

Sustainable economic benefits will be realized by employing a city-scale circular economy, driving social, environmental and economic impacts for our local community as well as driving innovation in all areas of our economy. This theme encourages partnerships with university institutions and companies focused on leading-edge energy technologies, which could spawn further opportunities for partnership within Squamish.

Branding ourselves as a regenerative economy will make our community stand apart, allowing us to attract investment, academia and residents sharing similar values.

Healthy community. Council has prioritized a healthy community, as this minimizes impact on the environment and supports Squamish as an adaptable and resilient community incorporating food, agriculture, water, the built environment, employment and citizens into our circular economy.

Open and transparent government. Council's 
priorities of embracing innovation, leading a forwardthinking and responsive municipal government, collaborating with citizens, youth, partners and other levels of government including Squamish Nation, and fostering strategic and financial partnerships complement the regenerative community theme.

Overall, the regenerative community theme addresses our short-, mid- and long-term priorities as a municipality.

\section{Related Documents:}

\section{Squamish Strategic Plan}

Squamish Zero-Waste Strategy

Question 8

Please describe your community's readiness and ability to implement your proposal successfully.

Given our high growth and geographical complexity, the District of Squamish faces many complex issues involving multiple stakeholders. The District, situated between the Greater Vancouver Regional District 
and the world-renowned resort municipality of Whistler, is located on Squamish Nation traditional territory. Intergovernmental affairs play a significant role in the success of District initiatives, whether social, economic or environmental.

Squamish is also employing a forward-looking, strategic approach in managing our growth. With multiple geographic hazards that include floods, fires and steep slopes, the District has put in place complex strategies that involve multiple stakeholders to enhance the safety and security of our residents while also maintaining and creating opportunities for industrial and residential land development.

Overall, our community and District operations benefit from several structures, processes and practices in place or planned for managing and implementing complex activities, including our IAP2 public engagement principles, District-wide GIS and open data systems, new and improved information technology systems, along with countless policy, strategies and action plans to support community wellbeing and increased quality of life.

\section{Recent initiatives:}

\section{Squamish2040, Official Community Plan. The}


District recently completed our Official Community Plan. This two-year process involved many stakeholders, including First Nations, youth, adults, seniors, local business and civil society groups.

Marine Action Strategy. The District's ongoing Marine Action Strategy addresses the interplay of the marine environment and economy across all levels of government, the private sector, as well as residents and visitors.

District Real Estate Strategy. The District recently completed a comprehensive Real Estate Strategy that took inventory of all District-owned land and buildings and considered future needs against projected population growth to determine near-tolong-term requirements and guiding principles for land and building acquisition, disposition and use.

\section{Integrated Flood Hazard Management}

Plan. Following a three-year process, including extensive technical work and community engagement, the Integrated Flood Hazard Management Plan was adopted by District of Squamish Council on Oct. 17, 2017. The District retained a multidisciplinary team of specialists to help prepare the plan. Flood protection improvements include a comprehensive plan to 
address all known deficiencies in the existing dike network, upgrade the existing sea dike to protect against both current and future anticipated sea levels, and adopt a higher standard of protection for the south dikes of the Squamish and Mamquam rivers. Policy updates include recommendations for a new Official Community Plan Hazard Policy, Development Permit Area and new Floodplain Bylaw to ensure that new development is planned and constructed to protect against flooding.

Community Carbon Marketplace. Beginning in 2016, the District set out to develop a community carbon marketplace. This community-based carbon exchange initiative enables local government, businesses and individuals to meet their Climate Action Charter objectives by purchasing carbon offsets from local projects that reduce greenhouse gas emissions and build community resilience. The program is facilitated by the Cowichan Energy Alternatives Society. Following a complex assessment, multiple potential projects have been identified for the marketplace. At present the District is working towards creating our first offsets as part of this marketplace to become carbon neutral.

Technology Transformation Program. A recent, indepth technology review identified many major 
District systems nearing end of life and requiring replacement or significant upgrades. The existing systems fall short due to a lack of integration, outdated underlying technology, functional limitations and significant gap areas that require manual workarounds. With this in mind, the District has invested in and built a network and virtual server infrastructure to support new software acquisitions to replace current systems.

The significant scope of work identified during the internal review brought about the creation of the Systems (Application) Technology Roadmap (SATR), which identified the highest priority areas across District operations and derived a planned approach and sequencing to our IT software overhaul. SATR launched in Spring 2015 and was adopted by Council in November 2015. The District is currently in the implementation phase.

Squamish Oceanfront Development. Through a community visioning process, Squamish created a redevelopment plan for the Oceanfront peninsula acquired by the District in 2004 . When fully developed, these former industrial lands will showcase the best of our community, capitalizing on the oceanfront to create a work-live-learn-play lifestyle that is authentically Squamish. On July 31, 
2014, the District and Squamish Oceanfront Development Corporation signed a purchase and sale agreement, and a limited partnership agreement with Matthews Southwest and Bethel Lands Corporation for the sale of the Oceanfront Lands. After months of intense and complex work, and many Council meetings and community input, the transaction closed on Feb. 3, 2016. The 20-year development plan will see the original community vision become a reality.

In addition, UBC's Clean Energy Research Centre, District of Squamish, Squamish Nation, Carbon Engineering and Newport Beach Developments LP signed a statement of cooperation to create an educational campus on Oceanfront lands focused on the energy economy. The agreement outlines how the organizations are exploring ways to collaborate towards establishing a centre for clean energy research and education as part of the Oceanfront development, located within the traditional territory of the Squamish Nation.

The four Squamish-based organizations - District of Squamish, Squamish Nation, Carbon Engineering and Newport Beach Developments LP — also formed the Squamish Clean Technology Association to seek out leading-edge ventures that will help to 
create an innovation hub focused on clean energy.

The association aspires to position Squamish as a world leader in climate change initiatives, and the Oceanfront campus as an incubator of clean energy innovation

Question 9

Describe your plan for using the $\$ 250,000$ grant, should you be selected as a finalist. Provide a highlevel breakdown of spending categories and an accompanying rationale.

The District of Squamish will proceed with the full development of our final project proposal based on the following expenditures:

- Project Management: $\$ 75,000$

o Funds will be allocated to incremental staffing for the purpose of project management of the final application.

o Related expenditures may include capacity building through training and education. 
- Auditing, research and data collection: $\$ 75,000$ o Taking an integrated approach, the District with partners will audit waste, waste systems, waste leakage, and diversion of residential, industrial/ commercial, institutional and municipal streams. o This will enhance baseline measurement for proposed projects and enable us to prioritize projects and decision making.

o Related expenditures may include the purchase of data and professional fees.

- Project design and development: $\$ 60,000$

o Working with partners, the District will use funds to develop a strategy and design for proposed initiatives informed by evidence-based data and research.

o Partners will supply their skills-based expertise in the development of proposed initiatives.

o Related expenditures may include consulting and other professional fees, software, cloud-based solutions and pilot projects.

- Public Engagement: $\$ 30,000$

o Using IAP2 methodology, the District will continue to engage our citizens about the development of proposed activities.

o Related expenditures may include communication and general promotion of both online and offline 
engagement activities, professional and consulting fees, collateral and cloud-based engagement software.

- Partnership, procurement and contracting services: $\$ 10,000$

o The District will develop final partnership agreements, and undertake initial procurement related to proposed projects.

o Related expenditures may include legal and professional fees

Question 10

Describe the partners that are or will be involved in your proposal. Where partners are not yet determined, describe the process for selecting them.

The District of Squamish engaged potential partners early on through a formal Request for Information Process, also including partners in the application development process. Partners span the academic, private and not-for-profit sectors and clearly align to 
the theme selected.

Should Squamish become a finalist, partners have committed their expertise in auditing systems, in the design of data and connected technology systems, and by informing policy for our final proposal.

Through the discovery phase as finalists, collectively we will determine any gaps that exist in expertise or capacity to implement proposed solutions, determining if additional partnership versus procurement is appropriate.

Participating Partners:

The University of British Columbia, Clean Energy Research Centre: CERC hosts world-leading researchers who consider providing safe, widespread and equitable access to sustainable energy as one of the key challenges and opportunities of our time. Its renowned interdisciplinary program brings together innovators from across UBC and actively seeks local and global collaboration with industry, academia and all levels of government.

British Columbia Institute of Technology Smart Microgrid Applied Research Team (SMART): A leader in renewable energy research, development and demonstration projects, the SMART team has a 
proven track record of delivering innovative solutions that integrate renewable energy generation and storage, electric vehicle charging infrastructure and smart energy management.

Powertech Labs: One of the largest testing and research laboratories in North America, Powertech, a subsidiary of $\mathrm{BC}$ Hydro, is home to a broad range of scientists, engineers, and technical specialists, with capabilities in smart energy, gamification and smart utility services. Powertech brings its Intelligent City Accelerator methodology to this project, which combines smart sensors, communication technologies, data analytics and gamification to enable smart cities.

Carbon Engineering: This world leader in direct air capture of carbon dioxide is using its technology to turn renewable electricity, air and water into synthetic hydrocarbon fuels that emit $90 \%$ less $\mathrm{CO} 2$ than fossil equivalents on a life-cycle basis.

Squamish and District Forestry Association: This local association represents timber rights holders in the Sea to Sky Natural Resources District.

Ecube Labs: Established in 2011, this innovative green technology company is committed to providing 
eco-friendly waste management solutions for the smart and sustainable cities of tomorrow.

Philips Canada: A global leader in lighting products, systems and services, Philips delivers innovations that unlock business value, providing rich user experiences to improve lives. Serving professional and consumer markets, Philips leads the industry in leveraging the loT to transform homes, buildings and urban spaces.

Stuart Olson: An integrated construction and industrial solutions company, Stuart Olson has been empowering Canadian business since 1911. Its rich history demonstrates its reach and diversity as an integrated, full-service organization.

Squamish Nation: Comprised of descendants of the Coast Salish Aboriginal peoples who lived in the present day Greater Vancouver area; Gibson's landing and Squamish River watershed, the Squamish Nation have occupied and governed their territory since beyond recorded history. In addition to the aforementioned partners, Squamish Nation will collaborate to development and implement our final proposal. 



\section{SMART CITIES CHALLENGE ANNOTATED APPLI CATI ON GUI DELINE \\ SECTI ON I : APPLI CANT I NFORMATION}

\section{QUESTI ON 1:}

Please provide the following information on your community.

ANSWER:

- Name of community: City of Guelph and Wellington County

- Province/Territory: Ontario

- Population: 222,726 (2016 census)

- Indigenous community: No

\section{QUESTI ON 2:}

Please select a prize category.

- $\$ 50$ million (all population sizes)

- $\$ 10$ million (population under 500,000 residents)

- $\$ 5$ million (population under 30,000 residents)

ANSWER:

Guelph/Wellington are applying to the $\$ 10$ million prize category.

\section{Section II: Preliminary proposal}

Sub-section 1 - Problem definition (Total of 55/100)

\section{Question 3:}

Please define your Challenge Statement in a single sentence that guides your preliminary proposal. It should describe the outcome (or outcomes) you hope to achieve. ( 50 words max)

\section{ANSWER:}

Guelph/Wellington will become Canada's first technology-enabled Circular Food Economy, reimagining an inclusive food-secure ecosystem that increases access to affordable, nutritious food by $50 \%$, where "waste" becomes a resource, 50 new circular businesses and collaborations are created, and circular economic revenues are increased by $50 \%$ : $50 \times 50 \times 50$ by 2025 . 


\section{QUESTI ON 4:}

Please describe the outcome (or outcomes) your proposal seeks to achieve by elaborating on your Challenge Statement. (2,500 words max) |

Weighting 40/100 (questions 3-4)

\section{ANSWER:}

\section{Summary of outcomes}

1. Cultivating access to nutritious food within our community: by 2025 , Guelph/Wellington will become Canada's first data- and technology-enabled circular food community, better ensuring food security and healthy outcomes by making affordable, nutritious, local food $50 \%$ more accessible.

2. The creation of new circular collaboration partnerships, businesses and jobs: by 2025, Guelph/Wellington will become Canada's first data- and technology-enabled circular food community, creating new opportunities with 50 new circular businesses and collaborations.

3. Valuing waste as a resource: by 2025 , Guelph/Wellington will become Canada's first data- and technology-enabled circular food community, creating new opportunities and sources of revenue by valuing waste as a resource, resulting in a $50 \%$ increase in circular revenue across our diverse community.

\section{Understanding the issue: A complex, interconnected, wicked problem.}

Food is a fundamental requirement of life on this planet. However, the basic structure of food provisioning systems around the world is unsustainable economically, socially and environmentally. Our "linear" economic model of "takemake-dispose" has produced a paradoxical situation of over-abundance and waste, coupled with environmental depletion, poor health outcomes and inequitable distribution.

Globally, we see the impact of this linear model through:

- Environmental degradation. Each year 7.5 million hectares of forests are cut down for unsustainable agriculture production, and 75 billion tonnes of topsoil are lost.

- Inefficient and wasteful food production. On average $30 \%$ of all food produced does not make it to the plate.

- Poor health outcomes. Almost 1 billion people are hungry or undernourished, while at the same time 2.1 billion people are obese or overweight.

In our country and our community, we see many local manifestations of these global food problems. Social impacts include:

- From 2012 to 2014, approximately 14\% of households in Wellington-DufferinGuelph experienced food insecurity (5\% marginal, $6 \%$ moderate and $3 \%$ severe). 
- The number of children living in poverty is too high ( $13 \%$ in Guelph and $17 \%$ in Canada). These numbers are even higher for children of new immigrants, where $47 \%$ live in poverty.

- The cost of food is high and growing: there has been a $27 \%$ increase since 2009 for a family of four.

- The negative health impacts of inadequate access to healthy food are significant, including obesity levels ( $15.1 \%$ in Guelph and $20 \%$ in Canada).

- From 2011 to 2014, 50.7\% of adults in Guelph were overweight or obese; in Wellington County, the number was $60 \%$.

Environmental impacts include:

- In Canada, \$31 billion worth of food is wasted each year. Just under half that waste occurs in households. The rest occurs throughout the supply chain, from production and processing to transportation and sales. To put that in perspective, $\$ 31$ billion is almost equal to the entire annual GDP for New Brunswick. In Ontario, food and organic waste comprise one-third of the province's waste stream.

- When food and organic waste is disposed of in landfills, it creates methane as it breaks down. This powerful greenhouse gas is 25 times more harmful to our environment than carbon dioxide. Increasing Ontario's organic waste diversion by $10 \%$ would reduce $275,000 \mathrm{~T}$ of greenhouse gas emissions (equal to removing 64,000 cars from the road).

The current path is not sustainable - we need to bring food systems and our communities back into healthy balance. And the problem is urgent: if consumption and population growth trends continue, by 2050 the global population will increase to 9 billion, caloric demand will increase by $70 \%$, and crop demand for human consumption and animal feed will increase by $100 \%$.

A global transformation has already begun in the way we think about food, and there are many projects underway in communities around the world to address various aspects of these problems. However, no community to date has implemented a circular food community model.

\section{The solution: A circular food economy}

Guelph/ Wellington will become the "Food Community of the Future": Canada's first data- and technology-enabled circular food community. We will create new opportunities and improve the health and food security of our community by re-imagining and re-inventing our food provisioning system - inspired by nature's own circular system - and provide a practical roadmap for others to follow.

The Ellen MacArthur Foundation describes circularity as being able "to preserve, restore and regenerate natural, social and financial capital." We will achieve this within our local food ecosystem. 
Our vision will transform our community's food ecosystem into a connected "living lab" that supports new collaborations, applying our vast food resources, expertise, social innovation, data analytics, technology and smart citizens to solve food problems.

Catalyzed by a shared purpose and a vision of the many social, environmental and economic benefits of a circular food economy, our community will re-imagine and re-invent how we produce, distribute and consume food. In so doing we will:

- Create new and vibrant economic opportunities within a circular, collaborative ecosystem approach as we re-imagine the conventional linear, waste-producing model.

- Ensure everyone in our community has access to affordable, nutritious food required to live healthy, productive lives.

- Solve food problems with strategies to repurpose and find value in the outputs our current system treats as waste - the by-products of the unsustainable linear food economy.

Our vision for a circular food community will measure success based on the balanced quadruple bottom line outcomes of:

- Prosperity - economic growth

- Planet - environmental sustainability

- People - greater social equity

- Purpose - a clear vision of an inclusive green economy of the future, valuing nutrition, health, diversity, equity and dignity

\section{Guelph/Wellington already has many key elements required to achieve this} vision

The Guelph/Wellington region will leverage an existing cluster of talent, resources, expertise and leadership to solve community — and ultimately global - food problems. Our community has a unique value proposition:

- We represent a partnership - a bridging - between an urban centre (the City of Guelph) and a rural farming/production/local manufacturing/distribution hub (Wellington County).

- We are located in the heart of the "innovation corridor" stretching from Toronto in the east to Kitchener-Waterloo in the west, encompassing seven universities, 15,000 high-tech companies, a critical mass of incubators, a high-quality talent pool and access to significant capital.

- Guelph/Wellington is an established advocate of the food movement, with many community agencies actively addressing social challenges related to food, and a significant concentration of food entrepreneurs.

- The University of Guelph is world-renowned for its work in agriculture and agri-innovation.

- Conestoga College provides food technology and processing programs.

- The Ontario Ministry of Agriculture, Food and Rural Affairs and most provincial agriculture and food organizations are headquartered in the region. 
This project will also make use of collaboration opportunities with national and provincial agri-food industry partners (e.g., Provision Coalition, Bioenterprise, Ontario Federation of Agriculture) who are already leaders in supporting the application and development of technology solutions in the sector.

In addition, we can further leverage our unique value proposition to work with national and international partners to make greater contributions to the circular economy with knowledge, technology development and leadership. The project will collaborate with leading cities (e.g., Glasgow, Amsterdam), foundations (e.g., Ellen MacArthur Foundation, Natural Step Circularity Lab) and think tanks (e.g., Arrell Food Institute) around the world to leverage their knowledge and expertise and contribute to the international body of knowledge and tools for the development of circular economies.

In short, Guelph/ Wellington is uniquely positioned to develop a new circular relationship with our food system, creating positive quadruplebottom-line outcomes to share with communities across the country and around the world.

\section{Leveraging a Smart Cities approach will help us bring those pieces together}

The Smart Cities Challenge is an important catalyst to achieving our vision of establishing a "living lab" - a place where social innovators, farmers and food and technology entrepreneurs collaborate to solve food problems.

A circular food economy requires collaboration and awareness, as well as social and technological innovation. Smart technologies are already helping farmers produce more food with fewer inputs - by optimizing seeding, fertilizer use, herd health and more. But we see the opportunities to use smart technology throughout the food system.

The municipal sector has an important role to play in creating and supporting collaboration, engaging citizens, leveraging existing resources and ensuring processes and policies are in place to support the transition to the new economy. A smart cities approach enables us do that, better coordinating our efforts as we work toward building a circular food economy.

Al, data analytics and visualizations can help us better design urban areas to ensure access to healthy, nutritious food. For example, our Asset \& Behaviour Mapping project (described in Question 6) will provide accessible, evidence-based information to identify gaps and opportunities and better direct public resources. This project will also supply the detailed baseline data we will use to measure progress towards our three outcomes.

Meanwhile, connected technology enables us to measure and track food and other organic material flows with more precision. This information can help with the design of new circular food flows, improving business sustainability and uncovering 
new economic opportunities for creating value from waste. Connected technology also underpins collaboration platforms and spaces that help diverse stakeholders and citizens to identify challenges and effectively work together to solve local and global food system problems.

In Question 6, for example, we discuss how connected technologies will allow us to create tools such as a digital carbon offset marketplace, interactive maps connecting citizens to food resources, transparent agri-food supply chains and more.

With this initiative, Guelph/Wellington will consolidate its reputation as a hub of food innovation and environmental sustainability. Our ambition is nothing less than becoming for food what San Francisco has become for IT.

\section{Strategy for measuring progress}

We believe the following goals lay the foundation for our circular food community. The goals are interrelated and synergistic, leading in the short term to a thriving food innovation ecosystem, which has the power to realize an inclusive green economy and improve health and food security outcomes.

In addition, we will measure transformation to a robust circular food community. Using data and connected technology - including the baseline data from the mapping project described in Question 6 - we will evaluate the progress against our Challenge Statement through metrics that contemplate economic, social and environmental benefits for the community as a result of embracing a circular food economy.

\section{Cultivating access to nutritious food within our community.}

The challenge: by 2025, Guelph/Wellington will become Canada's first data- and technology-enabled circular food community, better ensuring food security and healthy outcomes by making affordable, nutritious, local food $50 \%$ more accessible.

This initiative involves re-imagining a "smart" food system that better ensures food security and healthier outcomes - a system that also implicitly recognizes equity and dignity for all, better manages food resources to serve a diverse and vibrant community and celebrates the importance of good food in our everyday lives.

The metrics we intend to employ to measure success involve using data and connected technology to track:

- The increase in local food production.

- Greater access to nutritional food sources - for example, participation in urban agriculture and new models for circular producer-consumer relationships.

- Expanded access to affordable, nutritious food sources through new initiatives that create equitable distribution. 
- Greater awareness of food and nutrition issues through local programs focused on food education and health.

\section{The creation of new circular collaboration partnerships, businesses and jobs}

The challenge: by 2025, Guelph/Wellington will become Canada's first data- and technology-enabled circular food community, creating new opportunities with 50 new circular businesses and collaborations.

Our ambition is to develop a circular innovation ecosystem that leverages social innovation and technology to advance new business models and collaborations to tackle local and global food problems. This will be accomplished by establishing collision spaces to promote new business collaborations and innovations to solve food system challenges and a collaboration technology-enabled platform to identify challenges and seek solutions. We will combine the existing expertise and institutions with our location in the tech corridor and expand our impact exponentially through the use of data and connected technology. The metrics we intend to employ to measure success involve:

- Tracking the number of food challenges entering Guelph/Wellington technology-enabled collaboration platform, the response rate and the new solutions that move to implementation.

- Tracking the number of new businesses, partnerships and jobs created in the region that align with the circular food economy model.

\section{Valuing waste as a resource.}

The challenge: by 2025, Guelph/Wellington will become Canada's first data- and technology-enabled circular food community, creating new opportunities and sources of revenue by valuing waste as a resource, resulting in a $50 \%$ increase in circular revenue across our diverse community.

Our vision is to re-imagine, re-use and revalue food ecosystem inputs and outputs by maximizing their use, eliminating waste, optimizing economic value and reducing negative environmental impacts. A circular food economy will design waste out of the system, repurposing it to create new inputs that produce both nutrition and energy.

The metrics we intend to employ to measure success involve:

- Tracking the volume of food "waste" that is diverted, where it goes, when it is repurposed and the revenues that are generated by its new use.

- Reporting on new business/economic opportunities and social enterprises created from the revalued resources. 


\section{QUESTION 5:}

Please describe how your community residents have shaped your Challenge Statement. Describe your plans for continuing to engage and involve them in your final proposal going forward. (1,500 words max) |

This section should include:

- Descriptions of previous engagement with residents, businesses, organizations, and other. stakeholders on topics related to the Challenge Statement.

- Descriptions of feedback that came to light through past engagement processes.

- Links between the Challenge Statement and engagement feedback.

- Evidence of efforts made to be inclusive and to represent the community's diversity.

- Plans to sustain engagement through the development and implementation of the final proposal.

Weighting

$15 / 100$

ANSWER:

As the food centre of Canada, Guelph/Wellington is constantly working with our citizens and community partners to understand and overcome food challenges together. Our Challenge Statement articulates how our community wants to take a leap forward by leveraging data and connected technology to become Canada's first circular food community. We arrived at this ambitious goal based, in part, on many years of engaging our citizens, businesses, non-profit organizations and other governments on these issues.

What follows is a review of the most relevant engagement initiatives undertaken in and by our community both prior to and during the development of this application.

\section{A. Highlights of Our Food-Related Community Engagement Story}

In recent years, the Guelph/Wellington community has engaged in several significant visioning projects that either focused on food or included a significant food component.

The Guelph Wellington Food Roundtable

- Description: The Guelph Wellington Food Round Table held a Food Strategy Engagement Series to help determine regional food policy, investment and development priorities with a diverse group of stakeholders-including public officials, community organizations, farmers, restaurateurs, entrepreneurs 
and engaged citizens-to begin the process of developing a community-led Food Strategy for Wellington County and Guelph.

- Outcome: Accomplishments include the Guelph-Wellington Food Charter in late 2011 and the GWFRT Food Charter Toolkit in 2013 for engaging and educating community stakeholders - documents that we drew on in the process of articulating our Challenge Statement.

Community Wellbeing I nitiative

- Description: Guelph's Community Wellbeing I nitiative was initiated in 2011 to help establish a Community Wellbeing Plan that would:

- unite and engage the community around a shared vision of wellbeing

- forge a stronger relationship between the City and the community through a new model of civic engagement

- increase the effectiveness of service delivery

- provide a platform for proactive advocacy with other levels of government

- support innovative partnerships committed to community-wide wellbeing The initiative was guided by a Leadership Group representing multiple community sectors. It was rooted in a Collective Impact approach and aligned with the Canadian Index of Wellbeing.

- Outcomes: Guelph/Wellington made notable strides in the measurement of social indicators, including food security, and printed a 2014 report on local food security that has informed our Challenge Statement.

\section{Toward Common Ground}

- Description: Toward Common Ground is a partnership of social and health service organizations that developed a collective planning model for Guelph and Wellington, focusing in particular on effectively using data to resolve social challenges, including food challenges.

- Outcomes:

o Toward Common Ground has created a data dashboard that tracks indicators and measures of local well-being and has developed strategic planning processes on social challenges that include food security. These significantly influenced our current vision.

Taste Real

- Description: This County of Wellington initiative promotes local food businesses, processors and producers

- Outcomes: Taste Real has fostered learning, partnership opportunities and networking among local food and beverage value chain members.

In addition to the engagements noted above, we drew on material from:

- The Guelph Wellington Poverty Task Force

- The Guelph Chamber of Commerce Food and Agriculture Committee

- Innovation Guelph (offering programs and workshops to food businesses and innovators)

- The Ontario European Agri-Food Forum 


\section{B. Smart Cities Challenge Community Engagement}

The Smart Cities Challenge has been an important catalyst to broaden and deepen our community's engagement, focusing in particular on how we can increase our community's use of data and connected technology so we can become Canada's first circular food economy.

\section{Stakeholder Engagement}

Our community undertook several streams of consultation starting in early 2018 to inform our application. Over the course of several months, we held a series of facilitated sessions that involved a broad diverse representation of stakeholders, including:

- neighbourhood associations

- leaders at the University of Guelph

- business entrepreneurs

- technology experts and start-ups

- ag-tech organizations and businesses

- social sector leaders

- health and well-being experts

- community organizations and other public agencies

- agri-food stakeholders such as primary producers, farm organizations, agribusinesses and commodity organizations

Our approach incorporated continuous validation and dialogue with interested community members, including media entrepreneurs, agriculture and business consultants, foodies and community builders through one-on-one discussions and small group meetings.

We also united more than 50 community leaders to review our vision and approach. This session included "TED talk" presentations by business, social, academic and environmental trailblazers, followed by a facilitated discussion to sharpen our circular food economy concepts.

Over 100 individuals and organizations, including indigenous, Métis and aboriginal community leaders, were contacted to provide input regarding the vision to transform Guelph/Wellington into a leading centre to solve food problems and create a Circular Food economy. These stakeholders included the following:

10 Carden

Ag Energy Co-operative Ltd.

Beef Farmers of Ontario

Bioenterprise Corporation

Chalmers Community Services

Centre

Cisco Systems

Conestoga College

Family and Children's Services of

Guelph/Wellington and Wellington
Family Counselling and Support

Services for Guelph/Wellington-

Wellington

Farm and Food Care Ontario

Grain Farmers of Ontario

Green Table Foods Inc.

Greenbelt Microgreens

Guelph and Wellington Task Force

for Poverty Elimination

Guelph Chamber of Commerce

Guelph Community Foundation 
Guelph Community Health Centre

Guelph Family Health Team

Guelph Neighbourhood Support

Coalition

Innovation Guelph

Katan Kitchens

Lakeside Hope House

LeanDog

Long View

Mann Made Ltd.

Ministry of Agriculture and Rural

Affairs

Ontario Agri-Food Technologies

Ontario Federation of Agriculture

Ontario Fruit \& Vegetable Growers

Association

Ontario Pork

Oreka Solutions

People and Information Network

(PIN)
Provision Coalition

Syngenta Canada Inc

Synthesis Agri-Food Network

Taste Real

The Cornerstone

Toque

Toward Common Ground

TruLeaf Sustainable Agriculture United Way Community Services of Guelph and Wellington

University of Guelph

Upper Grand District School Board

WDG Public Health

Wellington County

Wellington-Dufferin-Guelph Public

Health

Welo

Workforce Planning Board

YMCA-YWCA of Guelph

We are also engaging our residents through a website focused on our Smart Cities Challenge application, where they are invited to provide input on specific ideas for achieving each goal. City and county council were both involved throughout the process to ensure that the views of their constituents were reflected in the application, while Guelph MP Lloyd Longfield held a public meeting to discuss food security as part of the Government of Canada's plan to develop a national food policy.

We also brought together an advisory group of core partners including the University of Guelph, public health experts, agriculture organizations and community leaders to refine the vision and application details.

\section{Engagement moving forward}

To this point, we have focused our outreach efforts on working with stakeholders and citizens to define a broad vision for our Circular Food Economy initiative.

With our partners, citizens, entrepreneurs, and businesses, we will enhance our engagement efforts by further developing and refining our plan. During the summer, we will raise awareness of our goal to become a Circular Food Economy and solicit input on how to achieve the three key goals we have defined. Activities include media outreach, an expanded web presence to share information and solicit community input, social media campaigns, fact sheets, events and promotional videos. 
SUB-SECTI ON 2 - PRELI MI NARY PROPOSAL DETAI LS (Total of 45/100)

\section{QUESTI ON 6:}

Please describe your preliminary proposal and its activities or projects. $(2,000$ words max) |

Weighting 15/100

ANSWER:

For each of the three outcomes we have established to make Guelph/Wellington the Food Community of the Future, we have planned several projects.

Outcome 1. Cultivate access to nutritious food within our community

Target: Affordable, nutritious, local food is $50 \%$ more accessible in Guelph/Wellington by 2025

This initiative involves re-imagining a "smart" food system that better ensures food security and healthier outcomes. Such a system will also implicitly recognize equity and dignity for all, better manage food resources to serve a diverse and vibrant community and celebrate the importance of good food in our everyday lives.

The following projects will support Outcome \#2 by:

- Identifying opportunities for collaborators to work together to solve challenges related to food access, nutrition and affordability

- Better directing public resources (community gardens, kitchens, etc.) to areas of need

- Developing an Urban Agriculture plan and supporting policies and bylaws

- Better connecting citizens with farms, markets, retailers, restaurants, breweries, and other businesses that feature food grown in Guelph/Wellington through an interactive, online map and supporting programs

\section{Project 1A: Asset \& Behaviour Mapping}

This critical project will provide baseline data mapping of the state of access to nutritious food and community food assets to calibrate what we have and where the gaps lie. As a result, it will allow us to identify geographic and demographic priorities within the community. The analysis of multiple layers of data, including behaviour, will also provide new insights for public health interventions and a platform for community-wide evidence-based decision-making. The mapping process will entail:

- undertaking a Public Health Study to map the availability, access, utilization and stability of nutritious food within our community.

- overlaying existing data from partner sources to gain new insights. These sources include:

o City/County economic and planning data 
o the University of Guelph Family Health Study longitudinal data

- Greater Golden Horseshoe Food and Farming Alliance Asset Mapping

- Taste Real Local Food Map data of locations where local food can be purchased (farmers, farmers' markets, restaurants and retail outlets)

o 2018 Social Determinants of Health report

- StatsCan data

o The Canadian Council on Social Development's Community Data Program

o New agri-food assets to be developed as local food program/collaboration space hubs (e.g., community kitchens planned for 10 Carden in Guelph and the Hillsburgh Library in Wellington County)

Feasibility: As indicated above, a wealth of data already exists that we can tap into. Additionally, the University of Guelph has the capacity to support the application of big data analytics to this project.

Impact/Scalability: This project can serve as a model for other communities.

\section{Project 1B: Circular Action Plan}

Once the mapping is complete, we will apply big data analysis and use the resulting insights to develop a Food Security \& Health Action Plan. The Action Plan will combine the data, knowledge, expertise of diverse collaborators to develop new intervention models and evidence-based policy development and decision-making regarding asset and resource distribution and program development.

Feasibility: As described in Questions 6 and 8, we can tap the expertise of several well-established agencies in Guelph/Wellington to craft well-informed collaborative programs and interventions.

Impact/Scalability: Significant local impact, thanks to highly targeted interventions informed by granular data.

\section{Data/ Technology Enablers}

- Big data analytics - data from multiple sources will be combined and analyzed to better understand the complex relationship between health, assets and access to nutritious food.

- Open data portal technology - all data will be made available through an open data portal with open APIs to encourage use by researchers and entrepreneurs.

- Geographic Information System (GIS) technology, spatial data analytics technology - interactive maps and visualizations will be developed to make the information accessible to the public and support decision-making and strategy development.

Outcome 2. Create new circular collaboration partnerships, businesses and jobs

Target: 50 new circular businesses and collaborations are created by 2025 
How might we better collaborate to solve food system challenges to create a circular food economy? How can we identify outcomes and measure progress based on the quadruple bottom line of people, prosperity, planet and purpose? How do we create new circular collaborations, businesses, jobs and social enterprises? How might we educate and train people (particularly women, youth and marginalized population) to work in the new food economy?

Our approach is to establish a technology-enabled collaboration ecosystem and create collision spaces that bring together diverse expertise, talent and resources. The resulting community-driven solutions would be replicable in other communities nationally and globally.

The following projects will support Outcome \#1 by:

- Building a living lab ecosystem for ongoing circular innovation and implementation.

- Creating an inclusive green economy.

- Facilitating repeatable projects built out of our community's unique food problem-solving environment.

- Delivering community-driven solutions to broad-based linear food problems.

\section{Project 2A: Circular Food Economy Lab}

We plan to establish a Circular Food Economy Lab of partnerships and collaborations that applies data, technology and social innovation to re-invent local food systems and solve local food problems that are globally relevant.

This project will be anchored by one or more "collision" spaces, creating hubs for collaborators in the agri-food, clean tech, social innovation and other sectors to address circular food challenges and drive quadruple bottom line outcomes. It will include a "food project concierge" responsible for shepherding problem-solvers through the development process, identifying potential collaborators and connecting them with local resources.

Feasibility: We have already identified a number of potential spaces with our partners. Elements of the supporting virtual collaboration platform are also well scoped.

Impact/Scalability: Model can be replicated in other communities.

\section{Project 2B: I mpact Fund}

This project will bring together, better coordinate and promote existing funding programs and funders. By offering a comprehensive array of grants, loans, prizes and/or venture capital, it will enable new partnerships, support start-ups and facilitate innovations that apply circular ideas to identified food challenges. It will also identify gaps in funding needs in this sector. 
At the same time, we will utilize the successful Guelph Civic Accelerator model (http://open.quelph.ca/accelerator/) to identify citizen and stakeholder challenges and broadcast food-related challenges through the collaboration platform. The solutions proposed by collaborators would in turn attract funding to develop prototypes and accelerate implementation.

Impact/Scalability: Collaborative funding program models and challenge approaches can be scaled up and/or replicated in other communities.

\section{Project 2C: New Food Economy Skills and Training}

Leveraging the institutional resources, skills and talent in our community, we will provide food innovation education and training, as well as public learning labs to promote and innovate on food policy and ideas. This investment will help ensure the ongoing development of circular innovation thinkers and doers.

Feasibility: The University of Guelph is prepared to build on programs such as the Feeding 9 Billion Challenge, the I deas Congress, the Food from Thought Initiative, the Centre for Business and Student Enterprise, the Accelerator Program and the Community Engaged Scholarship Institute. Together, this suite of initiatives is poised to develop and offer a holistic set of programming opportunities to ensure that the skills of social innovation and entrepreneurship unlock the potential of the circular food economy.

Impact/Scalability: Training approaches, including community-based learning opportunities, can be adapted and used in other communities.

\section{Data/ Technology Enablers:}

- Connection platform involving collaboration technologies.

- Online learning delivery tools.

Outcome 3: Value food waste as a resource

Target: $50 \%$ in new circular revenue across our diverse community is generated by 2025 by valuing waste as a resource.

How might we better:

- Design waste out of the food system?

- Reduce the environmental impact of food waste?

- Revalue "waste" as energy, nutritious food and other resources?

- Discover new business and economic value from "waste"?

Our vision is to re-imagine, re-use and revalue food ecosystem inputs and outputs by maximizing their use, eliminating waste, optimizing economic value and reducing negative environmental impacts.

The following projects will support Outcome \#3 by:

- Reducing waste.

- Creating new revenue streams from what used to be considered waste. 
- Producing fewer negative environmental externalities: GHGs, water depletion and other ecological issues.

\section{Project 3A: Business Tools and Services}

We will develop, curate and share a suite of tools, business diagnostics and services to help public organizations and businesses reinvent their processes and business models. This project will support the creation of value from "waste" by-products that are currently under-used or discarded, recovering chemicals, nutrition, medicinal compounds and energy.

Feasibility: This project will involve Guelph's Provision Coalition, an organization that works with food and beverage manufacturers to assess their sustainability challenges and implement solutions to increase efficiencies and minimize food waste. The intent is to leverage the Provision Coalition's pre-competitive data platform (and potentially other mapping/diagnostics/system design platforms) for redesigning business processes to either reduce/eliminate waste or divert waste to new inputs or revenues. The project would involve applying blockchain technology to the agri-food supply chain to increase transparency and reduce waste, developing new tools and business models that can be shared with others.

In doing so, we would draw on the experience gleaned through the Coalition's CASI initiative, a collaboration of farm organizations and food/beverage processors, manufacturers and retailers working together to create a transparent and sustainable agri-food supply chain.

Impact/Scalability: Business models, tools and services can be used in other communities across Canada and globally.

\section{Project 3B: “Re-imagine Food" Awareness Campaign}

By educating consumers on the importance of revaluing waste, we will boost demand for the products of a circular economy and build stronger relationships between food producers and consumers. As a result, we will support the outcomes of reducing the waste associated with transport, creating local jobs and strengthening resilience as well as urban-rural links.

Feasibility: We have extensive experience educating residents on sustainability issues. Furthermore, we can draw on the resources of a number of organizations (noted in Question 8) to amplify our message.

Impact/Scalability: Public education materials can be adapted and used by other communities and awareness campaign can be replicated.

\section{Project 3C: Circular Carbon Credits}

For the past seven years, the City of Guelph has been selling greenhouse gas offsets produced by its Eastview Landfill Site and Organics Waste Processing Facility on the voluntary market to BMO. To help other local businesses buy and sell their own carbon offsets, Guelph is exploring the potential of developing a secure, open and accessible digital marketplace powered by blockchain technology. Having 
access to this system will encourage more companies to reduce their carbon footprint by buying offsets generated from food waste. Meanwhile, companies that generate carbon offsets can find local buyers for those credits, keeping the monetary and social value circulating in the Guelph/Wellington community. This project will both reduce waste and create new revenue streams out of wasted resources. In addition, it will create new circular businesses in the community.

Feasibility: This project builds on an existing initiative and experience in carbon offset credits.

Impact/Scalability: The model and results of applying fintech and increasing the value and benefits of carbon offset credits can be shared with other communities, as can the technology.

\section{Project 3D: Value Mapping}

This project will identify and map the food cycle for selected undervalued food items that have the potential for greater usage and a current high degree of waste. The City of Guelph currently employs residential waste collection carts equipped with RFID technology capable of providing key insights into community waste dynamics and opportunities related to food waste reduction, distribution and accessibility. Approximately 48,000,000 data points are generated annually, offering a wealth of information that can be analyzed to develop metrics and identify key intervention points to help drive a circular food economy.

Feasibility: This project leverages existing technology and data and draws on the expertise of the Provision Coalition (mentioned in Project 3A, above).

Impact/Scalability: Learnings can be shared with other communities, and the project can serve as a model for other communities.

\section{Data/ Technology Enablers}

- Sensors/blockchain technology for verification/traceability.

- Business diagnostic and analytics technology - providing a platform to evaluate current business models and processes in food production and identify opportunities to reduce systemic waste.

- City of Guelph residential waste carts equipped with RFID transponders. 


\section{QUESTION 7:}

Please describe the ways in which your preliminary proposal supports your community's medium and long-term goals, strategies, and plans. (500 words max)

To supplement your response, please provide any relevant documents and make clear linkages and references. Weighting 5/100

\section{ANSWER:}

Guelph/Wellington and key stakeholders have identified agri-food as a strategic priority for the region. Over the years, several strategies and plans have been developed that build on this priority, including:

\section{Guelph on the Corridor, 2018}

(https://guelph.ca/wp-content/uploads/info items_031618.pdf\#page=15)

The City of Guelph, Wellington County, the University of Guelph, the Chamber of Commerce and other key stakeholders identify agri-food and clean technology innovations as Guelph's differentiating factor on the Toronto-Waterloo Innovation Corridor.

\section{Vital Signs, 2017/ 2018}

(http://www. guelphcf.ca/LinkClick.aspx?fileticket =0xM6x3HX8Hw\% 3d\&tabid=100) Vital Signs provides a meaningful, high-level snapshot of strengths and challenges in Guelph and Wellington County, including employment, income, food, and housing.

\section{The Green Energy and Technology (GRE\&T) Centre, 2017}

The GRE\&T Centre is envisioned as an accelerator site to evaluate and develop emerging, green and customer-friendly energy solutions, supporting businesses in bringing green technologies to market.

Solid Waste Management Master Plan, 2014

(http://guelph.ca/wp-content/uploads/2014SWMMPFinalReport.pdf)

Guelph's 25-year strategy sets a path to achieve ambitious waste minimization, diversion and disposal targets.

\section{Guelph as Location for Agri-Food and Agri-Tech Headquarters and Knowledge-Oriented Offices, 2014}

This report concludes that Guelph is uniquely suited as a premiere agri-food and agri-tech cluster in North America.

\section{Guelph Innovation District Secondary Plan, 2014}

(http://guelph.ca/wpcontent/uploads/OPA54_GuelphInnovationDistrict_08102017.pdf)

Designed to guide and regulate the sustainable development of the Guelph Innovation District, this planning framework includes the need to reduce foodrelated waste and carbon emissions. 
Guelph Community Wellbeing I nitiative, 2011- 2014

(https://guelph.ca/plans-and-strategies/guelph-community-wellbeing-initiative(wi/)

This extensive, three-year community engagement initiative identifies food security as a core priority for Guelph.

Wellington County Economic Development Strategic Plan, 2012

(https://www.wellington.ca/en/business/resources/2016EcDev/MeansBusiness/Well ington_County_Economic Development_Strategy.pdf)

Food and agriculture are identified as major priorities for Wellington County's economic plans, including supporting a sustainable agriculture sector and promoting local food networks.

Guelph-Wellington Food Charter, 2011

(http://www.cog.ca/pww/documents/GuelphWellingtonFoodCharter.pdf)

Endorsed by Council, this document identifies the key priorities for creating a just and sustainable food system for all.

Strategic Plan for the Guelph Agri-I nnovation Cluster, 2010

(http://guelph.ca/wp-content/uploads/Strategic_Plan_for_the_Guelph_AgriInnovation_Cluster.pdf)

Prepared by the Chamber of Commerce, the University of Guelph, Guelph Partnership for Innovation, the City of Guelph and other stakeholders, this strategic plan guides the growth and development of Guelph's food and agri-business sectors.

Prosperity 2020, 2009

(http://guelph.ca/wp-content/uploads/Prosperity_2020_Phase1-

Economic Base_Analysis Report.pdf)

The City of Guelph's economic development strategic plan identifies "Agri-food and Innovation" as one of its three key sectors for adding value to the local economy and a strategic advantage to Guelph.

\section{Wellington County BR+E Project, Business I nterview Findings and Action} Plan, 2014

(http://www.centrewellington.ca/dobusiness/Documents/FINAL\%20Centre\%20Welli ngton\% 20BR+E\% 20Report.pdf)

Drawing on insights gained from a Business Retention and Expansion retreat, the Wellington Economic Development Group prepared an action plan based on a number of identified strategic opportunities, including developing the local food sector.

This proposal also aligns with the Sustainable Development Goals and Canada's emerging Food Policy, the themes of which mirror the pillars or our application:

- increasing access to affordable food

- improving health and food safety

- conserving our soil, water, and air

- growing more high-quality food 
Finally, we are collaborating with the Ellen MacArthur Foundation as participants in their Cities in the Circular Economy project, exploring how to leverage digital technology to unlock the potential of circular food systems (https://www.ellenmacarthurfoundation.org/assets/downloads/Cities-in-theCircular-Economy-The-Role-of-Digital-Tech.pdf).

\section{QUESTI ON 8:}

Please describe your community's readiness and ability to successfully implement your proposal. (1,000 words max)

This section should include:

- Experience with implementing complex projects (i.e. multi-stakeholder, multi-dimensional) that span multiple business lines and functional units.

- Structures, processes, and practices in place or planned for managing and implementing complex projects that span multiple business lines and functional units.

- Organizational strengths and potential weaknesses for managing and implementing a smart city proposal, and plans to address weaknesses to ensure successful proposal management and implementation.

Weighting

$10 / 100$

ANSWER:

\section{Current readiness}

This project will draw on the expertise of a broad range of organizations based in Guelph/Wellington. These include:

- a university recognized as a global leader in agriculture and food issues, with initiatives that include:

o The Food From Thought program, which aims to exponentially increase the ability to leverage big data for the benefit of food production and biodiversity

o The Guelph Food Waste Research Group - a group of experts from the University of Guelph who are advancing groundbreaking research to reduce the environmental impact of our food systems and improve food security

- the provincial Ministry of Agriculture, Food and Rural Affairs

- a successful municipal Civic Accelerator model that enables collaborations between the City of Guelph and innovative startups, entrepreneurs, student teams and companies to solve complex problems in the community

- a strategic location in the middle of the Ontario Innovation Corridor, a technology and innovation supercluster

- many agricultural industry associations and organizations 
- a large community of entrepreneurs in the areas of bio-tech, clean-tech, agri-tech and food processing

- countless innovative community partners tackling food security challenges, including

- Toward Common Ground - an action-focussed group of social and health service organizations

- Guelph Wellington Poverty Taskforce - a collaboration of diverse partners addressing poverty in our community

- Guelph Community SEED Hub - a Guelph Community Health Centre project aiming to overcome food insecurity

- Taste Real, a County of Wellington initiative that has brought together local businesses, farms and producers to create one of Ontario's most vibrant food economies and food tourism destinations

The City of Guelph is a leader in environmental stewardship, already implementing food waste diversion and reduction strategies. Our Solid Waste Management Master Plan includes the establishment of a food waste reduction campaign to avoid unnecessary waste and preserve resources associated with food production, packaging and transport.

Our Community Energy Initiative, developed in 2007 as one of Canada's first community energy plans, focuses on reducing local greenhouse gas emissions. The plan has a baseline emissions inventory - essential data that will be incorporated into our food data mapping, fintech carbon credits and circular flow mapping projects. Meanwhile, the City's Climate Change Office and Sustainability Board were created to prioritize environmental sustainability and climate adaptation and resilience.

Finally, we have the connectivity base required for a Smart Cities initiative. Wellington County is part of the SouthWestern Integrated Fibre Technology (SWIFT) Network - an initiative to bring reliable internet to rural communities. In 2018, SWIFT will begin investing nearly $\$ 300$ million to connect almost 3.5 million people across Southwestern Ontario.

\section{Experience implementing complex projects}

Over the years, the City of Guelph has brought a number of complex projects to successful conclusion, working with numerous stakeholders and managing significant budgets.

A recent example is the Victoria Road Recreation Centre Renovation. This $\$ 15.1 \mathrm{M}$, tier 1 capital project transformed an aging and outdated recreation centre to an updated, more inclusive and accessible community centre that meets all building code and legislated requirements. It was completed last J une on time and on budget, thanks in part to an internal governance structure that included a project manager, technical project team and steering committee.

Additionally, the City-led Guelph Wellbeing project showcases our ability to collaborate with numerous community stakeholders. The project, which ran from 
2011 to 2014, identified food security, physical connectivity, affordable housing and social connectivity as important Guelph issues. The initiative engaged the community in the development of vision and goals, garnering 3,000+ inputs and an ongoing stakeholder list of 400 collaborators. It resulted in enhancement in strategies and programs (e.g., community grants, Older Adult and Youth strategies, Cycling and Transportation master plans, Community Garden and Community Paramedicine programs, and the Affordable Housing Strategy).

Our community's Smart Cities Challenge initiative will be implemented, as many other important and complex initiatives have been, by working closely with the University of Guelph. The University has extensive experience managing major initiatives, including partnering with the Ontario Ministry of Agriculture, Food and Rural Affairs on Food from Thought. This initiative, funded through the federal government's Canada First Research Excellence Fund, is designed to apply the tools of big data to create a more sustainable food system.

\section{Plans to address potential weaknesses}

To ensure we have both the bandwidth and the necessary expertise to ensure the smooth running of this initiative, we will work with our partners to create a project secretariat, as described below. Additionally, we have reached out to create collaborations with national and international experts in the circular economy field.

\section{Project management structure}

Building on the assets and experience described above, and backed by strong political support (see Question 14), we will create the structures and accountability required to succeed.

Specifically, the City will create a Circular Food Economy Secretariat with the mandate to build on community expertise and support the implementation and growth of the Guelph/Wellington Smart Cities initiative to achieve $50 \times 50 \times 50$ by 2025.

Because of its scale, complexity, and community impact, we will take a multidisciplinary approach to managing this project, including collaboration of staff from the following areas: Infrastructure, Development and Enterprise, Finance, Risk Management, Legal, Procurement, Community Services, Intergovernmental Affairs, Community Investment, Community Energy, and Information Technology.

The City of Guelph, working closely with Wellington County and the University of Guelph, will implement a project management system that extends the rigour and risk analysis that is part of our normal operating procedures. This structure includes public communications, financial analysis, risk analysis and stakeholder analysis.

In doing so, we will draw heavily on the expertise of the Project Management Office. This City of Guelph office is utilized as a regular governance and operating structure for all complex City projects and offers rigorous best practices in risk analysis, reporting and transparency. 
To provide strategic direction for the initiative as a whole, we will establish an Advisory Council. A seat on this Council will be reserved for a County of Wellington representative, ensuring smooth communications between the City and the County.

\section{QUESTI ON 9:}

Describe your plan for using the $\$ 250,000$ grant, should you be selected as a finalist. Provide a high-level breakdown of spending categories and an accompanying rationale. (500 words max) |

Weighting $5 / 100$

\section{ANSWER:}

Guelph/Wellington is well situated to hit the ground running, having, as we do, a number of expert partners, committed to achieving the outcomes described above. However, an initiative of this scope and ambition will require detailed planning, significant human resources and good baseline data. To that end, here is an overview of the approach we will take to maximize our community's use of the $\$ 250,000$ grant:

1. Formalize a Secretariat and an advisory council

- Based at the City of Guelph, a Circular Food Economy Secretariat will be created and led by an official in the City government.

- An Application Advisory Group was established in Q1 2018 as an oversight group for the development of the Smart Cities application. Moving forward, an Advisory Council will be established with representation from the partner organizations listed in Question 10. We recognize that the complexity of this initiative and the breadth of the anticipated outcomes will require all of these voices.

- Agreements for long-term commitments with partner organizations will be completed, including determining in-kind contributions and staffing.

2. Plan and execute a public engagement strategy

- We will finalize the details of a comprehensive public communications and engagement plan to ensure broad awareness of the Smart Cities Challenge in Guelph/Wellington, building more momentum for our circular food economy and inviting more good ideas and potential collaborations.

3. Establish project charters and a performance measurement management strategy

- We will work with our partners, , to develop clear and robust systems to measure our performance. This will require comprehensive definitions of the three goals that are specific, measurable, actionable and realistic and that have clear time frames attached to them. 
- Working with data experts across our community, we will develop a rigorous approach to collecting and using data so that we can measure our progress towards our goals of cultivating nutritious food, valuing waste and creating circular economy jobs.

- Comprehensive strategic and operational plans will be developed to define the scope of work and milestones for Q2 to Q4 2018.

4. Initiate Asset and Behaviour Mapping project

- Because this project will provide the baseline data that will inform all the other projects we have described in Question 6, we envision launching this project during the business case phase of this initiative.

\section{Spending categories}

- Project development (development of project charters, metrics etc.): $\$ 75,000$

- Communications and engagement: $\$ 50,000$

- Create a data management plan (to establish baseline and support performance tracking): $\$ 75,000$

- Initiate critical components of Asset and Behaviour Mapping project: $\$ 50,000$

\section{QUESTION 10:}

Describe the partners that are or will be involved in your proposal. Where partners are not yet determined, describe the process for selecting them. (500 words max) |

This section should include:

- A description of existing partners (what type of organization, what they do, etc.), their relevance, and expected contribution to the outcome (or outcomes).

- Where partners are not yet determined or where it is anticipated that additional partners are required, describe the process for selecting them.

Weighting

$10 / 100$

ANSWER:

Our community has engaged extensively with our residents and stakeholders of all kinds (see Question 5). However, there is a core group of partners, outlined here, that have been the creative and intellectual force behind our application.

Core Partners

o City of Guelph (municipality)

- Contributions: Overall project management, project identification, subject matter expertise 
Wellington County (municipality)

- Contributions: Strategic counsel, subject matter expertise

o University of Guelph (post-secondary institution)

- World-renowned university in the fields of agriculture and agri-innovation

- Contributions: Strategic counsel, project management support, data expertise, subject matter expertise (cultivating nutritious food; valuing food waste)

o Conestoga College (post-secondary institution)

- Leading Canadian Institute of Technology and Advanced Learning

- Contributions: Subject matter expertise (cultivating nutritious food; valuing food waste; food production and processing)

o The SEED Community Hub (not-for-profit)

- Community food project that aims to help overcome food insecurity through programs and services that tackle the root causes of poverty

- Contributions: Strategic counsel, subject matter expertise (cultivating nutritious food)

o Oreka Solutions (business)

- Insect producer that uses surplus foods from grocery stores, beverage and food manufacturers to feed black soldier flies, which are then used as a feed product for livestock

- Contributions: Strategic counsel, subject matter expertise (valuing food waste; creating circular jobs)

o Mann Made Ltd. (business)

- A design and construction firm with expertise in vertical farming

- Contributions: Strategic counsel, subject matter expertise (cultivating nutritious food; valuing food waste; creating circular jobs), data expertise

o Innovation Guelph (business accelerator)

- Offers programs and workshops to help food businesses and innovators thrive

- Contributions: Subject matter expertise (creating circular jobs)

o Ontario Federation of Agriculture (industry association)

- Farmer-led organization that advocates for sustainable agriculture and food 
- Contributions: Subject matter expertise (cultivating nutritious food; creating circular jobs)

o Sygenta (business)

- Agriculture company that offers crop services and advice to help Canadian growers maximize yields and make better use of resources

- Contributions: Subject matter expertise (valuing food waste; creating circular jobs)

o Wellington-Dufferin-Guelph Public Health (public sector)

- Delivers programs and services to promote healthy behaviours and protect the health of individuals, families and communities

- Contributions: Subject matter expertise (cultivating nutritious food)

o Guelph Community Health Centre (public sector)

- Provides health-related services and community programs

- Contributions: Subject matter expertise (cultivating nutritious food)

o Guelph Neighbourhood Support Coalition (not-for-profit)

- A network of neighbourhood groups and program partners working to meet the needs of children, youth and families in Guelph

- Contributions: Subject matter expertise (cultivating nutritious food)

o Michael Keegan \& Associates (consulting firm)

- Guelph-based public affairs and strategy consultants

- Contributions: Strategic counsel, project management

\section{Future Partners}

As the initiative grows, our Core Partners will identify additional collaborators to ensure our community is maximizing our use of data and connected technology. Specifically, we will add partners who are able to create and track data to measure progress and innovators who will find solutions to our identified challenges.

\section{QUESTION 11 (CONFIDENTIAL ANNEX):}

Please provide, if and only if required, confidential third party information. Information provided in this section will be exempt from the requirement to be posted online. (500 words max)

Third party information in this section should be supplemental to the information provided elsewhere in the application and be limited to those details that are 
deemed confidential. Please clearly indicate which question(s) the information provided in this section relates to.

- INFC said this refers to whether an applicant wants to include proprietary information, but they are encouraging all applicants to provide as much information as possible that can be shared publicly. This will provide a more accurate public representation of the applications and, related, more transparency in how they are evaluated.

\section{SECTI ON III : OTHER REQUI REMENTS}

This section has no bearing on the evaluation, but is required to complete the application. This section is not required to be posted online with the exception of questions 12 and 13.

\section{QUESTI ON 12:}

Provide a 200-word summary of your preliminary proposal. You may also provide an image that represents your preliminary proposal.

This summary, along with your Challenge Statement, will be posted online in both official languages.

You have the option of providing the summary in both official languages. If you provide it in one official language, Infrastructure Canada will translate it prior to posting online.

\section{ANSWER:}

Food is a fundamental requirement of life on this planet. However, the basic structure of today's linear "take-make-dispose" food system is unsustainable economically, socially and environmentally.

Guelph-Wellington aims to become Canada's first circular food economy, bringing our food system and communities back into healthy balance. Through our ruralurban partnership, we will enhance access to nutritious food, turn "waste" into valuable resources and create new economic opportunities.

Situated in the heart of Ontario's Innovation Corridor, Guelph/Wellington is a hub of food innovation and environmental sustainability, making us uniquely positioned to achieve this vision. Leveraging local expertise, big data and the latest technology, we will transform our food ecosystem into a connected "living lab" where researchers, social innovators, farmers, entrepreneurs and other community partners collaborate to solve complex food problems.

The Smart Cities Challenge is an important catalyst, enabling us to fund impactful circular food projects, create collaboration spaces, undertake baseline data mapping to guide programs and planning, create a suite of digital tools, and more. 
Together, we will build the "Circular Food Community of the Future," creating positive quadruple bottom line outcomes - prosperity, planet, people and purpose - and share the roadmap with the communities across the country and around the world.

\section{QUESTION 13:}

Provide a link to the online location where you will post the full version of your application.

\section{ANSWER:}

https://guelph.ca/city-hall/city-administrators-office/smart-cities-challenge/

\section{QUESTION 14:}

In accordance with your governance structure, provide evidence of the commitment to your preliminary proposal from your community's leadership. This can be a letter of support with signatures from your mayor(s), chief(s), or equivalent or a council resolution, a band council resolution, etc.

ANSWER:

Provided INFC with supplementary information via link - ck

\section{QUESTION 15:}

Please identify the point of contact for the application.

\section{ANSWER:}

- Name: Cathy Kennedy

- Title and affiliation: Manager, Policy and Intergovernmental Relations, City of Guelph

- Phone number: 519-822-1260 X 2255

- Email address: cathy.kennedy@Guelph.ca

\section{QUESTION 16:}

Read the Privacy Notification, Consent and Release form, and Communications Protocol and indicate your agreement.

\section{ANSWER:}

- This is just a box to tick on the application. 


\section{SECTI ON IV: SURVEY QUESTI ONS}

This section has no bearing on the evaluation, but is required to complete the application. This section is not required to be posted online. This information is meant to help Infrastructure Canada better understand the profile of applicants, collect baseline data about communities, and improve and adjust the Smart Cities Challenge process in the future. This information may be publicized for statistical analysis and reporting purposes, but only aggregates will be used (i.e. communities will not be identified). You may provide estimates wherever information is approximate or unavailable.

\section{QUESTION 17:}

Please provide the following information about your organization.

- 2017 full-time equivalents (FTEs):

o Number of total FTEs

o Percentage of total FTEs devoted to innovation

- 2017 operating and capital budgets:

o Total operating budget

- Percentage of total operating budget devoted to innovation

- Total capital budget

o Percentage of total capital budget devoted to innovation

ANSWER:

- 2017 full-time equivalents (FTEs):

o Number of total FTEs

City of Guelph: 1,211

Wellington County: 639

Total: 1850

o Percentage of total FTEs devoted to innovation

City of Guelph $2.7 \%$

Wellington County: $0.9 \%$

Total: $2.1 \%$

- 2017 operating and capital budgets:

o Total operating budget

City: $\$ 306,397,590$

Wellington County: $\$ 200,063,100$

Total: $\$ 506,460,690$

- Percentage of total operating budget devoted to innovation

City: $1.72 \%$

Wellington County: $1 \%$

Total: $1.4 \%$

- Total capital budget

City: $\$ 90,308,062$

Wellington: $\$ 96,390,200$ 
Total: $\$ 186,698,262$

- Percentage of total capital budget devoted to innovation

City: $5.42 \%$

Wellington: $32 \%$

Total: $23 \%$

\section{QUESTION 18:}

Please select the focus area of your preliminary proposal.

If your preliminary proposal seeks to achieve outcomes that span more than one area, you may choose up to two.

ANSWER:

- Economic opportunity

- Empowerment and inclusion

- Environmental quality

- Healthy living and recreation

- Mobility

- Safety and security

\section{QUESTI ON 19:}

Select all the community system/service areas expected to be implicated in your preliminary proposal.

There is no limit to the number of community systems/service areas you may select.

ANSWER:

- Arts and culture

- Economic development

- Education and training

- Emergency services and enforcement

- Environment

- Land use planning and development

- Public health

- Recreation and parks

- Roads and transportation

- Social services

- Waste

- Water and wastewater

- Other: please specify 


\section{QUESTION 20:}

Select all the technologies expected to be implicated in your preliminary proposal.

There is no limit to the number of technologies you may select.

ANSWER:

- Artificial intelligence (AI)

- Assistive technology

- Augmented reality (AR) or Virtual reality (VR)

- Autonomous and connected vehicles

- Big data analytics

- Cloud computing

- Enterprise solutions

- Environmental monitoring

- Geospatial

- Health or Medical technology

- Internet of Things (IOT)

- Mobile applications

- Networks

- Open data platforms

- Payment platforms

- Sensors

- Video analytics

- Wearables

- Other: please specify 
The municipality of Hope Town is pleased to have submitted an application to Infrastructure Canada's Smart Cities Challenge. This contest challenged local and regional governments across Canada to envision innovative ways to utilize modern technologies to respond to existing community challenges. The municipality of Hope Town submitted the following Smart Cities application to reinforce that given the right tools, even the smallest communities can be leaders in innovation.

\section{Question 1}

Please provide information on the community that is submitting this application. If this application is being submitted by a group of communities, add each community separately using the button. If this application is being submitted by a regional entity, please include the name of the regional entity with each individual community (e.g. City of Dunn/Smith Region). Do not include the regional entity as a separate, stand-alone community.

Community (Municipality of Hope Town)

Name of community Municipality of Hope Town

Province or Territory Quebec

Population based on 339

Indigenous community No

\section{Question 2}

Please select a prize category.

$\$ 5$ million (population under 30,000 residents)

\section{Question 3}

Please define your Challenge Statement in a single sentence that guides your preliminary proposal. It should describe the outcome (or outcomes) you hope to achieve. 
Couple existing community infrastructure and mobile technologies to reengineer the "thrift shop" model of reusing consumer goods to create a trendy and convenient platform which engages all socio-economic segments of citizenry, thereby: combating poverty and social exclusion, encouraging sustainable consumer goods consumption / waste reduction, ultimately reinvigorating a devitalized rural community.

\section{Question 4}

Please describe the outcome (or outcomes) your proposal seeks to achieve by elaborating on your Challenge Statement.

This section should include:

- Specific goals you hope to achieve by implementing your proposal, justifying both the level of ambition and the achievability of the outcome (or outcomes) sought.

- Baseline data and evidence to establish the current state with respect to the metrics used in your Challenge Statement, and context around the outcome (or outcomes) sought.

- Evidence to support the selection of this/these outcome (or outcomes) over others, in reference to the needs of the community.

- Rationale for applying a smart city approach to achieving the identified outcome (or outcomes).

Strategy for measuring progress toward outcome (or outcomes) and achievement of outcome (or outcomes).

The Hope Town Resource Center project will use mobile and web based technology in conjunction with existing core community infrastructure, to create a consumer goods and community resource exchange platform; you may think of it as thrift shop 2.0. This project upon its completion, will:

1) Offer a physical location to store and distribute consumer goods fit to be reused or repurposed,

2) Create a digital platform where consumers can conveniently participate in this exchange either peer to peer or using the Hope Town Resource Center as an intermediary. 
3) Create a social capital exchange, where users can buy or sell consumer goods and services in exchange for social capital rather than currency.

Specific outcomes

Empower a devitalized community by:

- encouraging a responsible consumer lifestyle while building community resilience -improving the living conditions of individuals living with poverty and social exclusion - supporting the sustainable use and development of a core community infrastructure - equipping community organizations to become partners in community development

Responsible community lifestyle and consumer resilience - The Hope Town Resource Center project is rooted in two community realities. The first reality is material opportunity; there is an abundance of consumer goods which rather than being destined for landfill, can be redirected to individuals who can reuse or repurpose these materials. This is an idea whose time has come; the negative stigma that in previous years would have been attached to this venture (the terms flea market, goodwill, or thrift shop come to mind) is now gone. In 2017 Sweden opened the first mall dedicated to the sale of repaired and upcycled goods. Becoming a conscientious consumer has become trendy.

Modern society is trending towards a circular economy (production, distribution, consumption, reuse/repair/upcycle, return to production) rather than a linear economy (resource extraction, production, distribution, consumption, waste). The project's directors are confident that this mindset momentum can be capitalized on to not only engage citizens to participate in the project, but to have them attach a personal pride and value to their active participation. Community resilience will be the ultimate result of this inward reflex to source goods and services. As individuals and community organizations engage in this model, the result will be a community networking dynamic which fosters the free exchange of ideas, sharing of resources and collaboration towards common development goals. 
The digital platform element of this project will provide the ease of use which will ensure that consumer intentions to reuse / repurpose / upcycle are actually followed through with. It is essential that making the sustainable option of directing a consumer good which is no longer wanted to the Hope Town Resource Center project, is simpler and more timely than throwing the object in the refuse.

Improving living conditions - The second community reality that this project will address is the proportion of the community who face the daily challenges associated with poverty and social exclusion. According to the 2016 census, the prevalence of low income based on the low income measure after tax is $21 \%$ of individuals in Hope Town and $16 \%$ of individuals in the MRC of Bonaventure. This proposed project has the potential to place valuable consumer goods (which could be anything from clothing, appliances, mobile tech, construction materials etc.) directly in the hands of an individual who has immediate or pressing need for that good, rather than simply stored on a dusty shelf at a thrift store in the hopes that somebody who needs it, can actually find it and afford it.

The social credit element of this project will be instrumental in allowing individuals with restricted incomes to be able to afford quality goods. The principle is basic - individuals who wish to acquire social credits can do so as payment for either selling a product or service on the exchange platform. Products and services could possibly include excess garden produce, seamstress services, volunteer hours with local community organizations, repaired, refurbished or upcycled goods, handpicked wild berries, handicrafts and other hand made items, etc. There is no limit to the innovative ways that an individual may use their particular talents to offer a desired good or service to the community at large. In addition to acquiring the social credits which can in turn be redeemed on the exchange, in this manner individuals living with social exclusion can find their way to interact in a meaningful and productive way with the community at large. There is solid evidence that the population in Gaspesie are open to the notion of social credits. In fact, members of the Gaspesian community have created their own social credit exchange called the "demi" which is actually a legal tender $10 \$$ or $20 \$$ bill cut in half, and accepted by certain groups within the community as payment for goods and services. Clearly the notion of social capital in lieu of cash currency is an idea which will find traction in this region. 
Core community infrastructure - While there is great potential that individuals offering goods and services can seamlessly be paired up with individuals seeking these same products and services via the digital platform, the physical location of the Hope Town Resource Center is an indispensable element. This physical locale will offer: personal support for individuals who for a variety of reasons cannot access the online platform independently, a convenient and secure pick up and drop off location for consumer goods so that items can be traded in security, a convenient storage location for items which are not immediately purchased when offered for sale, the potential locale for community development projects which draw inspiration from the project. One can imagine a wide variety of minor repair services as well as training programs that could be offered in such a milieu, or a tool library, where users can borrow necessary tools rather than purchasing for small projects.

This community structure has long been at the center of community concern, as community members have considerable attachment to the structure. The municipality has explored a variety of avenues to revive and reuse the old school structure for community benefit, and this building application would answer multiple needs for citizens throughout the region. A resource center, or Ressourcerie is central to the MRC of Bonaventure strategic plans regarding poverty, further lending support to the municipality in their planned development.

Equipping community organizations - Community not for profit organizations are key elements in healthy and mobilized communities. In the municipality of Hope Town and surrounding communities, not for profit organizations provide essential community leadership, maintain infrastructures and animate those infrastructures for all community members. This community service role is essential for small devitalized municipalities who simply do not have the resources to take the place of these organizations.

This being said, many community not for profit groups are facing a critical juncture; the traditional volunteer base model simply does not work any longer, which has put increasing pressure on a core group of tireless volunteers, who are now spread too thin across multiple organizations. This project has the exciting potential to revive community organizations though introducing mobile technology which instantly engages youth. Younger generations are motivated by sharing their experiences across the wide social media audience, their community is global, not municipal. The digital platform can be designed to include a means of easily "sharing" community volunteer activity across social media networks. 
An simple example can illustrate this simple but effective relationship. Imagine a youth who has spotted a video game system on the exchange platform that they would like to purchase, but requires social credits to do so. Also on the platform will be community service offers from not for profit groups. The sports club is looking for teens willing to help children lace up skates at the local rink on Saturdays, the church is looking for people willing to shovel the steps prior to Sunday service, the Golden Age club is looking for people to help serve at a community supper. The youth picks the service that meets their interests and abilities, renders the service, collects their social credits, and purchases the video game system. The exchange platform has the power to instantly pair the youth with a community service that interests them, and adds value for both the individual and the community group in the process.

Promotion of community groups could be built right into the platform, which would continuously generate awareness of community groups and the work that they do for the community at large. There will inevitably be individuals who collect social credits through frequently selling consumer goods, who have no intention of redeeming those credits to purchase items themselves. These credits could be donated to a community organization of choice, who in turn can engage a new generation of volunteers with these credits.

Baseline data

The municipality of Hope Town (population 339) is located in the MRC of Bonaventure (population 17,660) on Quebec's Gaspe Peninsula.

Geography: rural coastal community, low population density, relative geographic isolation with limited transportation options

Cultural/linguistic: The MRC of Bonaventure is majority francophone, punctuated with pockets of Anglophone communities. According to 2016 census data on first official language spoken, The MRC of Bonaventure is $85 \%$ French speaking, and 15\% English speaking. Hope Town constitutes one of these Anglophone communities. The 2016 first official language spoken data indicates $45 \%$ of residents in Hope Town are French speaking and $55 \%$ are English speaking. There is one Indigenous community (Gesgapegiag, Mi'kmaq nation) in the MRC of Avignon, immediately bordering the MRC 
of Bonaventure. However, many individuals who identify as indigenous or having indigenous roots live throughout the communities of the MRC.

Socio Economic: historically, primary industries dominated the region, with considerable secondary industries related in particular to forestry and the fishery. This dynamic has shifted over recent years however, and there is growing opportunity in new fields relating to wind power, communications and information technologies. Unemployment in the region is high, education levels are comparatively low, median individual and household incomes are also comparatively low. The MAMOT's most recent indice de vitalité économique (2014) indicates Hope Town's economic vitality index as devitalized at -10.70522 . These regional socio economic trends are amplified within the Anglophone community which can be generally stated to be lagging behind their French speaking counterparts in most socio-economic indicators.

The Smart Cities approach has the power to amplify the impact of the Hope Town Resource Center project, not only on a regional, but national scale. In the absence of the Smart Cities approach, the municipality will still pursue its project to create a resource center for reusable consumer goods in its infrastructure. At a minimum the municipality will be able to offer the service to its community and perhaps the immediately surrounding communities. If the municipality can't secure partner funding to improve the energy efficiency of their structure, they will have to limit operation periods to the time of the year when heating is not required.

With a Smart Cities approach, a volunteer charitable service blossoms into a full business plan, with potential to create jobs and become an economically viable project, with a reach that can extend across an entire geographic region, and actively engage community actors across this same region. One can imagine the potential of additional physical resource center sites opening in distant communities, however still using the same digital exchange platform. Furthermore, goods can move quickly and efficiently from the seller to the purchaser, and limit storage and waste of items that never find their way into the hands of individuals who can use them.

Lastly the exchange platform can become self promoting using savvy social media strategies, and engage a broad population base regardless of geographic location, language or age. The one very real constraint which may exist is the limited access to smart phones or computers that individuals living with poverty may experience. With the assistance of community organizations and the physical location of the Hope Town 
Resource center, these individuals can actually be directly reached and provided a reused smart phone to get them started, and a location to access Wi-Fi for free; imagine the possible impacts. The possible social development initiatives that can grow from this ambitious but simple project are limitless with a Smart Cities approach.

Measuring success

Measuring performance will need a two prong approach, relying both on raw data collected by the exchange platform, and the collection of qualitative data and subsequent interpretation of that data by community actors in social development.

The platform will be designed to track basic data sets (always respecting privacy of users) including but not limited to the movement of consumer goods (by type, by volume, by region, by asking price, by peer to peer vs. physical storage at the Hope Town Resource Center site), a general portrait of individual users (by geographic provenance, by activity level on the platform, by average credits traded) and a general portrait of community organization users (by geographic territory, by activity sector, by credits exchanged). Additionally, the same key data will be collected at the Hope Town Resource Center site, as well as relevant qualitative data.

The combination of these two methods will allow project directors to effectively measure the reach of their project, regularly set performance targets, identify communities which have yet been unreached and identify community groups who can be engaged to assist in reaching new communities.

\section{Question 5}

Please describe how your community residents have shaped your Challenge Statement. Describe your plans for continuing to engage and involve them in your final proposal going forward.

This section should include:

- Descriptions of previous engagement with residents, businesses, organizations, and other stakeholders on topics related to the Challenge Statement.

- $\quad$ Descriptions of feedback that came to light through past engagement processes. 
- $\quad$ Links between the Challenge Statement and engagement feedback.

- $\quad$ Evidence of efforts made to be inclusive and to represent the community's diversity.

- $\quad$ Plans to sustain engagement through the development and implementation of the final proposal.

The appropriateness of this project's outcomes and activities is well supported in the local and regional development context. The community of Hope Town has been actively attempting to revive and reopen the old school building since acquiring it from the school board in 2009. A feasibility study was undertaken by the municipality in 2011, and while the community need and opportunity to operate the school as a community center was well founded, the annual operational costs of maintaining a structure with inefficient heating and repair needs was not properly considered in this plan.

The old school structure appears multiple times in the community family policy and senior citizens policy and action plans elaborated in 2013, both in terms of the need to support the structure, but also in terms of planning activities and services to take place within the structure. Also evidenced within the family and senior citizens action plan is a concern regarding less fortunate citizens as a need for affordable housing and support for a clothing donation program are in the action plan.

The current council is preparing to undertake renewed community development plans in 2018, and as such has been engaged in the preliminary work of laying out its course of action to ensure that a maximum number of citizens are implied in this planning, and that their priorities and concerns are captured in the subsequent action plans. Based on preliminary discussion with community groups and community members, it is fully expected that a revival of the old school building will remain a priority for citizens, as will a continued duty of care for individuals living in conditions of poverty and social exclusion.

The priority of supporting the needs of individuals living with poverty is clearly elaborated in the MRC of Bonaventure's 2013 - 2015 Plan d'action pour la solidarité et I'inclusion sociale. Furthermore, the creation of a resource center within the MRC was specifically identified as an action: "2.4.1 Explorer la faisabilité de la mise en place d'une " ressourcerie » s'adressant aux clientèles défavorisées au plan de l'emploi... ". The MRC is in the process of elaborating its updated plan, and it will likely include this priority again as it was not achieved during the previous action plan period. 
Individuals who are key project drivers in Hope Town were pleased to participate this past March 2018, in an MRC of Bonaventure strategic planning forum for the social development plan for the MRC. Key directing principles were elaborated at this forum that are consistent and supportive of the Hope Town Resource Center project. The directing principles elaborated at this forum were as follows: social inclusion, quality of life, vitality of communities, accessibility to services and resources, mutual recognition of the three linguistic groups present in the region, and a call for the engagement of all regional partners to collaborate to this end. This project is consistent with the MRC's strategic social development planning, and as such will solicit the support of multiple regional partners as the project progresses on a regional level.

At the provincial level we can find further support in the ministère des Affaires municipales et de l'Occupation du territoire publication, STRATÉGIE GOUVERNEMENTALE POUR ASSURER L'OCCUPATION ET LA VITALITÉ DES TERRITOIRES 2018-2022. Priority 2 elaborates the support for initiatives that combat poverty and social exclusion, and priority 6 calls for the assurance of reliable and efficient transmission of information and transportation across the entire region. We find within these two priorities a validation of both a proposed outcome (improve living conditions of individuals living with poverty and social exclusion), and the selected course of action (creating a digital platform to communicate and make the exchange platform available across the entire region) to achieve that outcome.

Finally, at the national level, messaging has been sustainably clear that citizens need to take meaningful actions to address green house gas emissions. Encouraging consumers to be conscientious about how they choose to dispose of unwanted consumer goods has a direct impact on transportation, product packaging (particularly plastic), and landfill use. The more that consumers opt to reuse or upcycle their unwanted consumer goods, green house gas emissions will be directly impacted, giving consumers the power to effect meaningful climate action in their own lives. To this end the community Hope Town applied to the Federation of Canadian Municipalities Climate Innovation Program in 2017 seeking support for the infrastructure renovation phase of this project. A response is still pending.

\section{Question 6}

Please describe your preliminary proposal and its activities or projects. 
This section should include:

- $\quad$ Planned activities or projects to achieve the outcome (or outcomes) set out in the Challenge Statement.

- $\quad$ Clear links from the identified projects to the attainment of the outcome (or outcomes).

- $\quad$ Scope and size of each planned project in your preliminary proposal, describing how it is feasible and suitable for achieving the outcome (or outcomes) in a manner that is impactful for the community, ambitious, and transformative.

- Measures put in place to 1) make the proposal open, interoperable, scalable, and replicable or a description of your plan to do so going forward for the benefit of your own community and other communities in Canada; and 2) enable other uses of the technology, innovation, and data in your proposal.

The physical location of this project will be the Hope Town Resource Center, which is an old elementary school located centrally in the community, and also centrally located along the southern coastline of the Gaspe Peninsula. This infrastructure is the property of the Municipality of Hope Town and is structurally sound and in a state of good repair, however, work must be undertaken to improve the structure's energy efficiency rating in order to make it economically feasible for the municipality to operate year round. This will imply engaging consultants who specialize in environmental retrofits of infrastructure, architects and engineers, and for the construction phase a contractor professional. The municipality has already begun the process of seeking funding partners to achieve this work. In 2017 an application was made to the Federation of Canadian Municipalities under their Municipalities for Climate Innovation Program to undertake a feasibility study to retrofit this structure. The MRC of Bonaventure has engaged to invest in this phase of the project as soon as a major funding partner can be secured, as well as the Municipality of Hope Town and Association Sportive et Loisir de la Municipalité de Hope Town.

Rooting this project in a physical location is a key element to achieving outcomes. While the digital exchange platform provides broad and uniform access, a physical location is required to bring the deliverables directly to the people, and to root the project within the community. The physical location will offer essential support to those individuals who do not have, or are not at ease with online access or mobile technologies. It will also offer a secure third party location for goods exchange, as many individuals may prefer for a variety of privacy and security reasons not to pick up or deliver items to and from private residences. The old school structure also offers the exciting potential to house social development initiatives that may evolve as a result of this project. 
Digital platform: The digital platform portion of this project would need to be developed by professionals in the field of web and mobile solutions development. Most certainly some digital platforms already exist which include the basic elements that our platform would require (Kijiji or e-bay). The platform would need to be easy to use, prioritize privacy and security of users, be easily navigated by users in any language, and have built in reporting and tracking mechanisms so the project can effectively measure the success or shortfalls of the project. For example, the number of transactions of material goods, the geographic areas where transactions are most or least concentrated, the type of goods or services most frequently exchanged, the associated values of materials exchanged, etc. The project directors will need to engage with actors in regional social development to ensure that the sensitivities and needs of citizens who live with poverty or social exclusion not only have access to the project, but can extract maximum benefit from the project. Specialists in online privacy and security will also need to be consulted to ensure that the platform developed meets the community expectations regarding both digital and physical privacy and security.

Social capital exchange: This portion of the project is the most innovative element, and is what defines this project as more than a basic thrift shop or more than a simple peer to peer goods exchange platform. With this element, the project has the potential to engage those citizens in the region who are both at the leading edge of social and economic empowerment trends, while simultaneously including citizens who live on the social periphery in conditions of poverty and social exclusion. The vision here is to create a credit exchange for users of the platform, so that rather than buying and selling goods and services for Canadian dollars, they would do so by a system of social credits created and maintained by the project directors. In this manner this project also has the potential to revolutionize community mobilization and reinvigorate community organizations. We can imagine a credit system where community organizations can offer social credits as a meaningful reward for community volunteers, these credits can then be redeemed to purchase goods and services on the exchange. Likewise, individuals who find themselves with an abundance of social credits which they don't intend to use, could donate them back to community organizations. Regional actors in social development would be engaged in the development of this element to address issues of inclusion, dignity for all users and fairness. Additionally, consultation would be required from experts regarding the safeguarding against fraudulent and unintended use of social credits. Finally, experts in economic development would need to be engaged to ensure the project creates an effective revenue model which would allow fluid operation of the project and the ability to engage all resources required annually. 
The entire design process of this project is with the intention that it can be replicated in any community in Canada. The digital exchange platform will prioritize a design that is understandable in both official languages, and could possibly be used in multiple regions across the country. Users would simply identify which region they reside in and the platform would automatically populate the available offers. Furthermore, an option could be added where users who wish to use the platform, but their region has not yet spearheaded their own similar project, could generate an introductory email to send to their own regional elected officials or community development actors.

This project implies three distinct investment streams. Investment in a physical home base infrastructure, investment in creating the digital platform and credit exchange system, and an investment in human resources to manage the project once it is launched. However, the development investment in the digital platform and the credit exchange should be a one time expenditure unique to this project development. After this initial investment, upgrading and personalizing the platform to meet specific community needs can be undertaken punctually as needed. In this manner additional communities could undertake the project in the future and have access to the digital platform and credit exchange system at minimal cost to their community.

The operations model can also be shared with future project adopters, so they can have a reasonable expectation of the resources that will be required to successfully operate the project.

\section{Question 7}

Please describe the ways in which your preliminary proposal supports your community's medium and long-term goals, strategies, and plans.

To supplement your response, please upload any relevant documents and make clear linkages and references.

The municipality of Hope Town's family and senior citizen policy (PFM MADA in Quebec) specifically names the old school structure and references the need to address issues surrounding poverty and social exclusion (in the action plan referencing affordable housing and charitable church work). See file HTown-PA.pdf 
The municipality also submitted a funding request to the FCM in 2017 to undertake a feasibility study to retrofit the old school structure, with the specific goal to create a community resource center in this structure. See file MCIP project proposal.pdf which clearly explains and illustrates the community commitment to this development strategy, pre-existing the Smart Cities challenge.

The MRC of Bonaventure has confirmed its financial support for the above mentioned project application to the FCM. see uploaded files FDT2017-096_lettreconfirmation.pdf and FDT2017-097_lettreconfirmation.pdf

Also, both the municipality of Hope Town and the ASLH confirmed their support of the above mentioned project in the form of the attached resolutions ASLH resolution.pdf and municipality resolution.pdf

The MRC of Bonaventure within the framework of its action plan to fight poverty and social exclusion specifically identified the development of a resource center, or Ressourcerie, in its last round of action plans. The current plan is in development but communications with the agents responsible for that plan confirms it will likely be retained again as a priority action. Thus affirming that this project is pertinent on a regional level. See page 32 plan d'action 2013-2015 ATI MRC de Bonaventure.pdf http://www.mrcbonaventure.com/fr/documentation-fr/documents/category/plan-daction-2013-2015.html

Community representatives took part in the recent strategic planning forum for the MRC of Bonaventure's social development plan. The directing principles of MRC's plan are very closely echoed in the desired outcomes of this Smart Cities project proposal see attached cadre de référence résuméV2.docx.pdf

The economic vitality index produced by the MAMOT support the pressing social development need in this region, see the economic vitality index https://www.mamot.gouv.qc.ca/fileadmin/publications/developpement_territorial/indi ce_developpement/DR_11_localites.pdf , where Hope Town is grouped with three neighbouring devitalized municipalities 
CASA (the Committee for Anglo Social Action) also support the generalized impoverished position of the Anglophone community relative to their regional French speaking counterparts. http://casa-gaspe.com/images/Regional-Profile-

ENGLISH_23fev.compressed.pdf

The MAMOT ministère des Affaires municipales et de l'Occupation du territoire publication, STRATÉGIE GOUVERNEMENTALE POUR ASSURER L'OCCUPATION ET LA VITALITÉ DES TERRITOIRES 2018-2022. Priority 2 elaborates the support for initiatives that combat poverty and social exclusion, and priority 6 calls for the assurance of reliable and efficient transmission of information and transportation across the entire region.

https://www.mamot.gouv.qc.ca/fileadmin/publications/occupation_territoire/strategie _ovt_2018-2022.pdf, pages 53 to 57.

The notion of creating a social credit exchange has already taken root within the Gaspésie region and suggests a digital version will be well received http://www.macleans.ca/news/canada/demi-why-some-people-in-quebec-are-cuttingup-their-cash/

Local community organizations and not for profit groups have already been actively seeking solutions to their long term survival and success in engaging younger generations. This indicates they will be willing and active participants in a Smart Cities project see attached CAP tool kit final report.pdf

\section{Question 8}

Please describe your community's readiness and ability to implement your proposal successfully.

This section should include:

- $\quad$ Experience with implementing complex projects (i.e. multi-stakeholder, multidimensional) that span multiple business lines and functional units.

- $\quad$ Structures, processes, and practices in place or planned for managing and implementing complex projects that span multiple business lines and functional units. 
- $\quad$ Organizational strengths and potential weaknesses for managing and implementing a smart city proposal, and plans to address weaknesses to ensure successful proposal management and implementation.

Despite the small size of the community, the Municipality of Hope Town has considerable experience developing and managing major infrastructure projects to meet the community's needs. Since 2013 the municipality has successfully overseen two major renovation phases completed at the municipal offices, creating a multifunctional community center. The project phases were organized and executed in a manner that the municipality could employ the limited resources at its disposal to maximum effect.

- Renovations grouped into 2 distinct phases to break the project up into manageable portions for the human and financial resources available

- Total project cost of both phases approximately $\$ 400,000$, of which just over $50 \%$ was successfully leveraged from regional, provincial and federal stakeholders as well as private partners.

- Community portion of this investment achieved through careful management of municipal funds and successful community based fund raising.

- Resulting structure houses municipal offices, community center, open air amusement park, outdoor seasonal skating rink with indoor rink change/locker area, office space for inter-municipal sports and recreation coordinator.

The municipality employs several strategies in all of its project undertakings (infrastructure and social development) to ensure the conditions for successful project outcomes.

1) Community support - the greatest asset of the municipality of Hope Town is an engaged and active community volunteer base. Small municipalities must rely on community groups to provide essential community outreach. A thriving community takes a healthy partnership between the council and community groups to both build and maintain community infrastructure, and to provide animation and community mobilization around these structures once they are in place. The ability of community groups to successfully fundraise for community projects is a key indicator in the success of this relationship

2) Professional architect and engineering plans - decisions of the community and the council are based on professional plans with realistic representations of what the project will entail in terms of human and financial resources, and time.

3) Secure project partners - once a project is prioritized by the community, the community commits to a reasonable proportion of the total project investment that the 
community can afford. The remainder of project funding must be secured through additional project partners before call for tenders and project work can begin.

\section{Project management}

Linda MacWhirter - Mayor of Hope Town since 2013, was councillor prior from 2009. Experienced community volunteer; Hope Town Sports Club, Home and School Association, High School Governing Board, Hayes Bursary Fund for Continuing Education, Intermunicipal Sports and recreation committee, Family and Senior Citizen policy committee, Hope Town United Church volunteer and organizer.

In all municipal projects the Mayor actively manages the entire project from its conception to completion. Additionally, she will call on the punctual participation of councillors, community members, municipal employees, regional partners to assist as needed through the project process. Tasks which are managed on a punctual basis by support members include (but are not limited to) fund raising, materials procurement, transportation, reporting, partnership and funding leveraging.

While the infrastructure component of this Smart Cities project lies entirely within the experience and competence of the municipality to complete unilaterally, the creating of a digital platform and social credit exchange lay outside the scope of the municipality to undertake without a strategic partner such as infrastructure Canada. The municipality concedes that this thinking on a grand scale will require resources (human and financial) and accompaniment that are not currently at their disposal.

However, it is entirely within the capacity of the project directors to formulate an action plan and seek professional services to supplement the project development process. The project directors have already identified that professionals in web based and mobile design, cybersecurity, cyberfraud and business development will need to be engaged. This is over and above the typical partner engagement with design professionals (architects and engineers), funding partners, regional development stakeholders and community organizations that must be undertaken with any project.

The municipality is prepared to plan accordingly and engage the partnerships and professionals required should their project be selected as a Smart Cities finalist. 


\section{Question 9}

Describe your plan for using the $\$ 250,000$ grant, should you be selected as a finalist. Provide a high-level breakdown of spending categories and an accompanying rationale.

If this project is selected as a finalist, the $\$ 250,000$ grant will be used to move the municipality into a position of preparedness to launch the project either as a whole or in part depending on the determination of operation costs of each of the project activities.

The municipality of Hope Town is committed to ensuring that plans to retrofit the resource center infrastructure respond to the community's expectations of climate responsibility and operational efficiency.

Feasibility study regarding climate sensitive retrofits of infrastructure $\$ 10,000$

Informed decisions regarding infrastructure investments must be based on well elaborated professional plans, which include building elements that meet all codes and regulations and provide robust budgetary expectations.

Professional services, full architect and engineer plans for infrastructure $\$ 70,000$

The municipality intends to responsibly and efficiently operate the Hope Town Resource Center, within its financial and human resource means. A business plan is therefore required

Professional services, full business development plan $\$ 6,000$

The municipality does not possess the expertise required to launch and manage a digital platform for mobile and computer devices. A feasibility study will identify all components required and detail costs.

Feasibility study regarding digital platform design $\$ 6,000$

Privacy and security are primary concerns in this project, particularly where online applications and the collection of data are implied. Furthermore, the creation of a social capital exchange will require special consideration to ensure this is tightly managed so that no unintended uses or risks are not anticipated. 
Consultants fees regarding cyber security and cyber fraud $\$ 12,000$

This project's elaboration will surpass the current human resource capacity at the municipality of Hope Town. Additional staff will be required to meet all of the planning and organizational requirements.

Capacity building, 2 full time, 1 part time project coordination positions $\$ 120,000$

Participation of stakeholders is essential to the success of this project. The region here covers a large surface area, and it must be considered that in order to engage quality participants, remuneration in the form of per diems or honorariums should be provided to defray the very real costs to dedicate the required time.

Community engagement, steering committee honorariums, per diems $\$ 8,000$ Community engagement, hospitality and travel $\$ 8,000$

\section{Question 10}

Describe the partners that are or will be involved in your proposal. Where partners are not yet determined, describe the process for selecting them.

This section should include:

- A description of existing partners (what type of organization, what they do, etc.), their relevance, and expected contribution to the outcome (or outcomes).

- $\quad W h e r e$ partners are not yet determined or where it is anticipated that additional partners are required, describe the process for selecting them.

Municipality of Hope Town - project leader

Association Sportive et Loisir de la Municipalité de Hope Town - community organization leader for the project, providing critical outreach and community animation. The ASLH are already officially partnered with the municipality for the infrastructure phase of the project, having committed funds and sweat equity to the project. The ASLH are adept at planning and animating community based activities and mobilizing community members around common goals, as well as grass roots fund raising. 
$\mathrm{MRC}$ of Bonaventure - Revitalization Agent. A strategic resource in the employ of the $M R C$ in conjunction with six devitalized municipalities in the MRC, including the municipality of Hope Town. The revitalization agent identifies key project stakeholders, and organizes partnerships around community projects. The agent in turn uses invested partner funds to leverage funding from a variety of funding programs. The agent views each project from a macro level, and ensures that essential plans and elements are in place to maximize the project's probability of success. The agent also calls to the attention of project leaders weaknesses or pitfalls that may place a project at risk, and suggests strategies to mitigate for that risk.

MRC of Bonaventure - Rural and social development agent. This specialized agent has profound networks throughout the MRC and the entire Gaspesie region in the fields related to social development such as health, employment, youth services, senior citizen services, English language services, services for the disabled, etc. This agent offers effective communication and liaison with social development stakeholders. CASA future partner. The Committee for Anglo Social Action is actively engaged in the Gaspesian community, offering services to the anglo community through punctual projects and undertaking regular studies and reporting on the status of the health of the community at large.

CASA will be a key partner in assuring that appropriate social stakeholders are involved and that key considerations when dealing with the anglo community are addressed.

CEDEC-future partner. Community Economic Development and Employability Corporation specialize in business development and revitalization for OLMCs in Quebec. Instrumental in both networking with appropriate business development professionals, offers services in complete business development planning.

Kwatroe - construction consultants based in Gaspe Quebec who have been solicited to submit an estimate for feasibility and professional plans for the retrofit of the infrastructure. In addition to specializing in environmentally friendly retrofit projects, this organization is well aware of the particular challenges that construction projects can present here in the Gaspe region.

Jolyfish-future partner. Web and mobile tech designers based in Gaspesie. 
Community organizations - future partners. It will be essential to engage these organizations to ensure they both understand the project, and are ready to adopt the platform once it is launched.

Undetermined partners - experts in the area of cyber security, fraud, and cyber credit design must be sought. This networking will be undertaken if the project is identified as a finalist. The revitalization agent will make preliminary enquiries to build a network in this field. 


\section{Applicant information}

\section{Question 1}

Please provide information on the community that is submitting this application. If this application is being submitted by a group of communities, add each community separately using the button. If this application is being submitted by a regional entity, please include the name of the regional entity with each individual community (e.g. City of Dunn/Smith Region). Do not include the regional entity as a separate, stand-alone community.

\section{Question 2}

Please select a prize category.

\section{Community (City of Coquitlam)}

Name of community City of Coquitlam Province or Territory British Columbia Population based on 139284 Indigenous community No
$\$ 10$ million (population under 500,000 residents)

\section{Problem definition}

\section{Question 3}

Please define your Challenge Statement in a single sentence that guides your preliminary proposal. It should describe the outcome (or outcomes) you hope to achieve.
Coquitlam will become a Smart City Living

Lab by leveraging technology, data, experimentation, research and publicprivate-people partnerships to develop waste management solutions that minimize and mitigate human-wildlife conflict and address other emerging environmental and sustainability issues such as waste reduction and diversion, greenhouse gas reduction and use of renewable energies.

IMPROVING HOW WE LIVE WITH WILDLIFE BY BECOMING A SMART CITY LIVING LAB

Coquitlam is a vibrant and rapidly growing community of more than 140,000 people within Metro Vancouver, British Columbia and is expected to grow to 240,000 by 2046. The community includes both new and established residential, commercial and industrial areas, with significant growth taking place now and over the next 30 years in greenfield areas of the city, such as Burke Mountain. The development of 


\begin{tabular}{|c|c|}
\hline $\begin{array}{l}\text { and the achievability of the } \\
\text { outcome (or outcomes) sought. } \\
\text { Baseline data and evidence to } \\
\text { establish the current state with } \\
\text { respect to the metrics used in your } \\
\text { Challenge Statement, and context } \\
\text { around the outcome (or outcomes) } \\
\text { sought. } \\
\text { - Evidence to support the selection } \\
\text { of this/these outcome (or } \\
\text { outcomes) over others, in } \\
\text { reference to the needs of the } \\
\text { community. } \\
\text { Rationale for applying a smart city } \\
\text { approach to achieving the } \\
\text { identified outcome (or outcomes). } \\
\text { Strategy for measuring progress } \\
\text { toward outcome (or outcomes) } \\
\text { and achievement of outcome (or } \\
\text { outcomes). }\end{array}$ & $\begin{array}{l}\text { northeast Coquitlam and adjacent } \\
\text { northwest Burke Mountain are currently the } \\
\text { largest greenfield residential development } \\
\text { areas in Metro Vancouver. } \\
\text { As a result of its valued urban setting and } \\
\text { variety of public parks among forests and } \\
\text { natural areas, Coquitlam consistently } \\
\text { generates the highest call volume of bear } \\
\text { sightings provincially each year to the BC } \\
\text { Conservation Officer Service. In addition, } \\
\text { the city is home to a wide variety of other } \\
\text { wildlife typical of a coastal mountain } \\
\text { community (e.g. cougars, bobcats, coyotes, } \\
\text { deer, raccoon, skunks, etc.). } \\
\text { Due to the rapid growth of the community } \\
\text { and an influx of new residents to the area, } \\
\text { Coquitlam has experienced a sharp } \\
\text { increase in the frequency of human-wildlife } \\
\text { conflicts; notably due to an increase in } \\
\text { unsecured garbage and other similar } \\
\text { attractants. For example, the City received } \\
685 \text { bear-related complaints in } 2017 \text { (303 } \\
\text { related to general bear issues/sightings } \\
\text { and } 382 \text { related to unsecured garbage. } \\
\text { Unfortunately the number of bears } \\
\text { destroyed by the BC Conservation Officer } \\
\text { Service has also increased, from two in } \\
2015 \text { to } 15 \text { in } 2016 \text {. In many cases these } \\
\text { bears had become garbage habituated and } \\
\text { relocation was not deemed a viable } \\
\text { alternative. } \\
\text { The City of Coquitlam takes pride in its } \\
\text { proactive and innovative approach to waste } \\
\text { management solutions that mitigate } \\
\text { human-wildlife conflict. Support for a Smart } \\
\text { City Living Lab would allow the City to build } \\
\text { on the momentum of the successes } \\
\text { achieved to date while also fostering } \\
\text { solutions to address emerging issues in } \\
\text { this area. } \\
\text { For example, Coquitlam's dedicated bear } \\
\text { education earned the City an official Bear } \\
\text { Smart community designation from the } \\
\text { provincial government in } 2017 \text {, and a } \\
\text { focused solid waste enforcement program } \\
\text { in } 2017 \text { resulted in a reduction in } \\
\text { unsecured garbage complaints. However, } \\
\text { with extensive development planned on } \\
\text { Burke Mountain and other areas in } \\
\text { Coquitlam over the next decades, new } \\
\text { tools are required to better manage the } \\
\text { City's solid waste program. The increased } \\
\text { use of technology for smart waste } \\
\text { management as well as data collection and }\end{array}$ \\
\hline
\end{tabular}




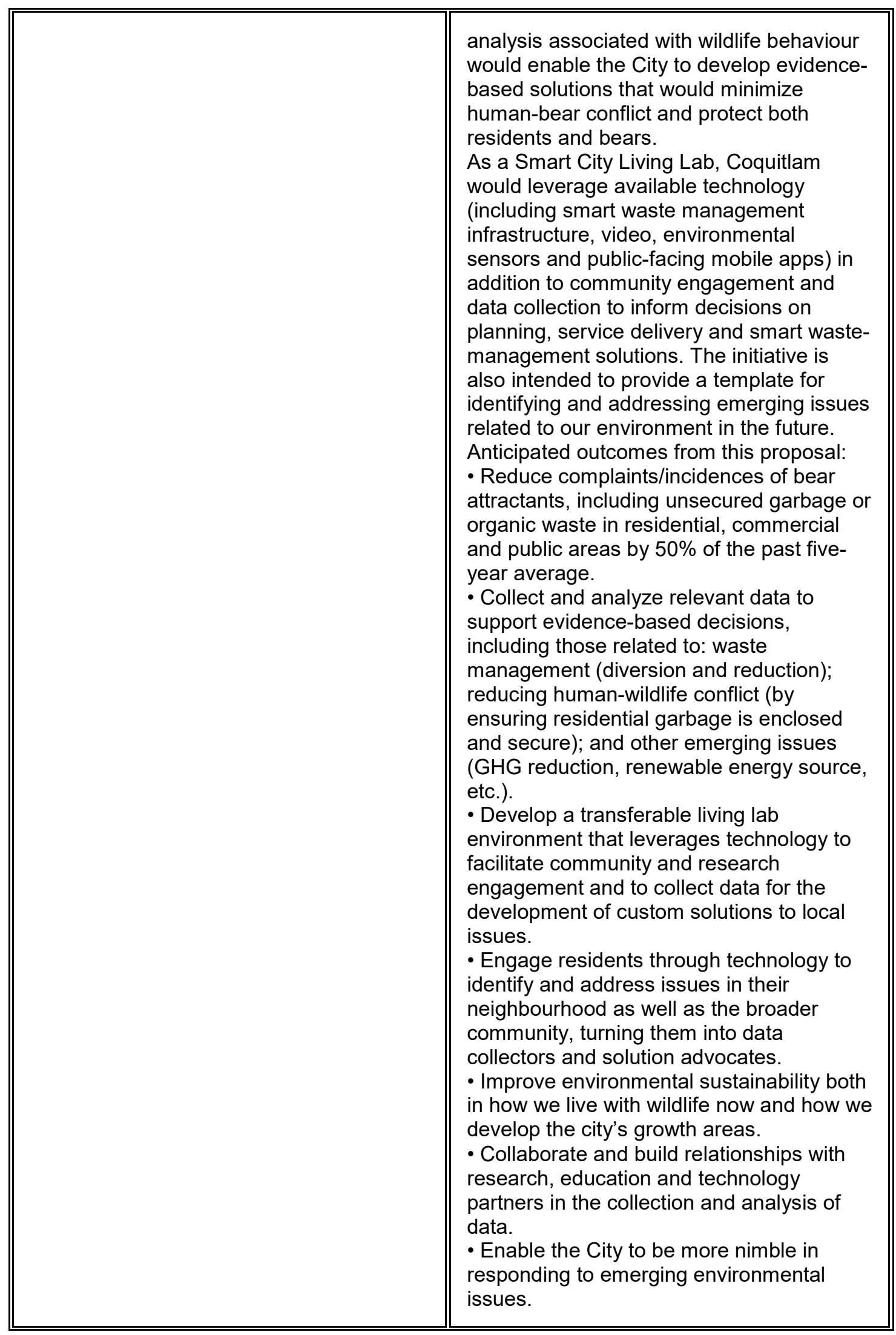




\section{Question 5}

Please describe how your community residents have shaped your Challenge Statement. Describe your plans for continuing to engage and involve them in your final proposal going forward.

This section should include:

- Descriptions of previous engagement with residents, businesses, organizations, and other stakeholders on topics related to the Challenge Statement.

- Descriptions of feedback that came to light through past engagement processes.

- Links between the Challenge Statement and engagement feedback.

- Evidence of efforts made to be inclusive and to represent the community's diversity.

- Plans to sustain engagement through the development and implementation of the final proposal.
PUBLIC CONCERN REGARDING BEAR AND WILDLIFE INTERACTIONS

Coquitlam's challenge statement directly addresses community concern regarding human-wildlife conflict by identifying the need for a secure, wildlife-proof, "smart" waste management system that will minimize the likelihood of attracting bears and other wildlife into residential

neighbourhoods and mitigate the potential for human-wildlife conflicts.

Coquitlam is a provincial hotspot for bear complaints, which have increased significantly in recent years (see Question 4) despite ongoing enhancements to the City's human-wildlife conflict management efforts. These complaints are an indicator of resident concern.

Without changes to the City's approach to solid waste management, these incidents will continue to rise as growth continues in greenfield areas in the northeast portion of Coquitlam (Burke Mountain), which borders forests.

\section{PUBLIC INPUT}

The City conducted a public survey from October 2017 to January 2018 to collect community input on possible themes for Coquitlam's submission for the Smart Cities Challenge. About 250 responses were received. Results showed:

- Public safety, water and wastewater, public engagement and

telecommunications were among the highest overall priorities (ranked as top or significant priorities by more than $74 \%$ of respondents). Other priority areas included waste management and environmental protection, including wildlife management. - In terms of benefits, respondents gave high marks to safety and security improvements $(84 \%)$, enhanced services to residents $(83 \%)$ and environmental sustainability $(79 \%)$ benefits. Other important benefits included improved quality of life, and a stronger sense of community and connectedness.

- Many of the suggested ideas submitted by respondents aligned with this proposal. These included: expanded $\mathrm{Wi}-\mathrm{Fi}$ throughout the City, a City services mobile app with problem reporting and community dialogue functions, and increased use of 


\begin{tabular}{|c|c|}
\hline & $\begin{array}{l}\text { CCTV. } \\
\text { Coquitlam's challenge statement directly } \\
\text { addresses these responses by targeting a } \\
\text { reduction in human-wildlife conflicts, } \\
\text { improving environmental sustainability, and } \\
\text { using technology to engage the community } \\
\text { in finding solutions, including promoting } \\
\text { dialogue and connectedness. } \\
\text { ONGOING ENGAGEMENT } \\
\text { Citizens will play an important role in } \\
\text { generating the data used to create } \\
\text { solutions, including real-time problem } \\
\text { reporting through a mobile app, and } \\
\text { feedback and dialogue through City-hosted } \\
\text { online discussion groups and a Smart City } \\
\text { Living Lab working group. }\end{array}$ \\
\hline \multicolumn{2}{|c|}{ Preliminary proposal details } \\
\hline $\begin{array}{l}\text { Question } 6 \\
\text { Please describe your preliminary proposal } \\
\text { and its activities or projects. } \\
\text { This section should include: } \\
\text { - Planned activities or projects to } \\
\text { achieve the outcome (or } \\
\text { outcomes) set out in the } \\
\text { Challenge Statement. } \\
\text { Clear links from the identified } \\
\text { projects to the attainment of the } \\
\text { outcome (or outcomes). } \\
\text { Scope and size of each planned } \\
\text { project in your preliminary } \\
\text { proposal, describing how it is } \\
\text { feasible and suitable for achieving } \\
\text { the outcome (or outcomes) in a } \\
\text { manner that is impactful for the } \\
\text { community, ambitious, and } \\
\text { transformative. } \\
\text { Measures put in place to 1) make } \\
\text { the proposal open, interoperable, } \\
\text { scalable, and replicable or a } \\
\text { description of your plan to do so } \\
\text { going forward for the benefit of } \\
\text { your own community and other } \\
\text { communities in Canada; and 2) } \\
\text { enable other uses of the }\end{array}$ & $\begin{array}{l}\text { WHAT IS A SMART CITY LIVING LAB? } \\
\text { The Smart City Living Lab concept would } \\
\text { respond to a growing issue facing } \\
\text { Coquitlam and other communities in Metro } \\
\text { Vancouver: waste management and } \\
\text { human-wildlife conflict. } \\
\text { As a means of identifying solutions, the } \\
\text { Living Lab concept is centred on a } \\
\text { collaboration between the resident and the } \\
\text { City, and it integrates technology, } \\
\text { innovation, research, and partnerships to } \\
\text { design solutions that meet residents' needs } \\
\text { but with a continuous service improvement } \\
\text { objective. For example, information from } \\
\text { various sensors, cameras, live experience } \\
\text { (via public feedback and other stakeholder } \\
\text { input) and data-collection tools would } \\
\text { inform the development of custom waste } \\
\text { management solutions, their assessment } \\
\text { and their refinement. } \\
\text { After the test case in Coquitlam, the } \\
\text { concept could be scaled to involve } \\
\text { neighbouring cities and eventually any } \\
\text { municipal or provincial land within Metro } \\
\text { Vancouver, creating one of the largest } \\
\text { living labs in the world. The collection and } \\
\text { analysis of wildlife data on a regional level } \\
\text { would provide unprecedented opportunities } \\
\text { for research, information-sharing and the } \\
\text { development of collaborative solutions. } \\
\text { Within Coquitlam, using the same } \\
\text { technology infrastructure the concept could } \\
\text { also be replicated to address other }\end{array}$ \\
\hline
\end{tabular}




\begin{tabular}{|c|c|}
\hline $\begin{array}{l}\text { technology, innovation, and data } \\
\text { in your proposal. }\end{array}$ & $\begin{array}{l}\text { environmental objectives such as GHG } \\
\text { reduction; the use of renewable energy; } \\
\text { and climate action, etc.. } \\
\text { In order to ensure a strategic approach and } \\
\text { focus on the concept objectives, a Smart } \\
\text { City Living Lab working group would be } \\
\text { created to engage the community and } \\
\text { relevant stakeholder groups for idea } \\
\text { generation and feedback purposes. } \\
\text { DATA COLLECTION AND ANALYSIS } \\
\text { New technology would help the City gather } \\
\text { data to inform decisions about } \\
\text { development and municipal services. } \\
\text { Elements of the proposal include the } \\
\text { following: } \\
\text { - Environmental sensors throughout the } \\
\text { City would measure data in real time for } \\
\text { conditions such as wildlife movements and } \\
\text { activities, air quality, noise, odour, water } \\
\text { quality, temperature and carbon monoxide } \\
\text { levels. Feedback from the sensors could } \\
\text { help improve livability and help the City } \\
\text { identify trends and respond in a timely way } \\
\text { to circumstances that could negatively } \\
\text { affect both humans and wildlife. For } \\
\text { example, CCTV systems with video } \\
\text { analytics could be installed to help identify } \\
\text { wildlife corridors in new development areas } \\
\text { and to pinpoint problem areas in } \\
\text { neighbourhoods with high bear activity. } \\
\text { - Collected data would be stored in both } \\
\text { structured (e.g. databases) and } \\
\text { unstructured formats (e.g. data lakes). This } \\
\text { would enable the use of artificial } \\
\text { intelligence engines to mine raw data for } \\
\text { relationships that might be missed through } \\
\text { traditional analysis methods. For example, } \\
\text { a proposed garbage truck route in a } \\
\text { particular area might conflict with a typical } \\
\text { bear migration route, identifying the need to } \\
\text { develop a solution before it becomes a } \\
\text { significant issue. } \\
\text { - Both traditional and next-generation } \\
\text { methods would be used to review data, } \\
\text { develop actionable solutions and gauge } \\
\text { success. } \\
\text { - Partnerships with scientists, researchers, } \\
\text { educational institutions and others would } \\
\text { assist with data analysis and co-creation of } \\
\text { solutions. } \\
\text { POTENTIAL SOLUTIONS } \\
\text { as retractable garbage cans in public areas } \\
\text { and receptacle sensors that indicate when }\end{array}$ \\
\hline
\end{tabular}




\begin{tabular}{|c|c|}
\hline & $\begin{array}{l}\text { public waste receptacles are full would } \\
\text { reduce accessible garbage, a significant } \\
\text { bear attractant. } \\
\text { - Wildlife reporting and alert mechanisms to } \\
\text { be added to the City services mobile app } \\
\text { currently in development. These functions } \\
\text { would enable citizens to report wildlife } \\
\text { interactions in real time with geo-tagging } \\
\text { and to sign up to receive relevant alerts } \\
\text { based on their location (e.g. a bear sighting } \\
\text { at the park they are visiting or in their } \\
\text { neighbourhood). } \\
\text { - A "living with wildlife" discussion group to } \\
\text { be enabled through the City services } \\
\text { mobile app to provide a forum for the public } \\
\text { - particularly those in new development } \\
\text { areas - to share ideas, discuss issues and } \\
\text { engage in two-way dialogue with the City. } \\
\text { - Deployment of Wi-Fi in all parks and } \\
\text { public spaces would: } \\
\text { o Enable broader public access to the } \\
\text { mobile app, encouraging real-time } \\
\text { reporting and alerts. } \\
\text { o Support wireless communication with } \\
\text { sensors, CCTV cameras and video } \\
\text { analytics and other data-collection and } \\
\text { analysis technology. }\end{array}$ \\
\hline $\begin{array}{l}\text { Question } 7 \\
\text { Please describe the ways in which your } \\
\text { preliminary proposal supports your } \\
\text { community's medium and long-term goals, } \\
\text { strategies, and plans. } \\
\text { To supplement your response, please } \\
\text { upload any relevant documents and make } \\
\text { clear linkages and references. }\end{array}$ & $\begin{array}{l}\text { LAND USE AND DEVELOPMENT } \\
\text { Development of Coquitlam's northeast area } \\
\text { has been planned for decades and will help } \\
\text { the City fulfill its obligation to the Regional } \\
\text { Growth Strategy adopted by all Metro } \\
\text { Vancouver cities. The proposed use of } \\
\text { technology to reduce human-wildlife } \\
\text { conflict will help ensure environmentally } \\
\text { sustainable development in this growth } \\
\text { area. } \\
\text { TECHNOLOGY PLAN } \\
\text { The project will support the roll-out of the } \\
\text { City's Technology Roadmap, adopted in } \\
2018 \text { to guide how the City chooses and } \\
\text { uses technology over the next five years. } \\
\text { The roadmap identifies a number of Smart } \\
\text { City initiatives. } \\
\text { CITY STRATEGIC PLAN } \\
\text { The project aligns with the following } \\
\text { corporate Strategic Goals: } \\
\text { Strengthen neighbourhoods: A community } \\
\text { comprised of clean, safe, green and } \\
\text { inclusive neighbourhoods that are } \\
\text { connected to a convenient and affordable } \\
\text { transportation network and vibrant } \\
\text { commercial centres where residents can }\end{array}$ \\
\hline
\end{tabular}




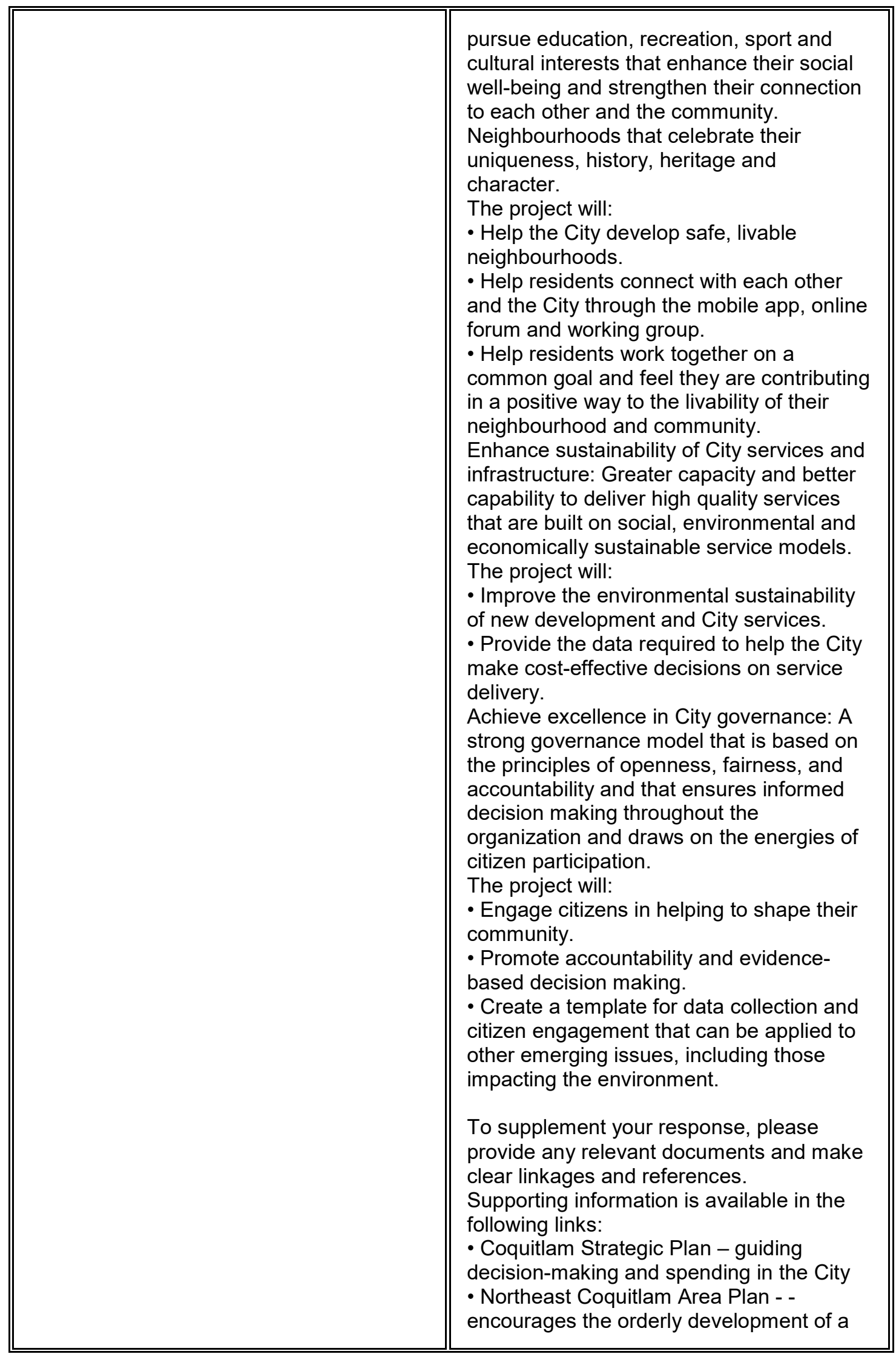




\begin{tabular}{|c|c|}
\hline & $\begin{array}{l}\text { community that accommodates a future } \\
\text { population of approximately } 35,000 \\
\text { persons on Burke Mountain. } \\
\text { - Northwest Burke Vision - development } \\
\text { plans for undeveloped areas of Burke } \\
\text { Mountain in northeast Coquitlam } \\
\text { - Technology Roadmap - guiding the City's } \\
\text { technology growth over the next five years } \\
\text { - Bear Smart Program - public education } \\
\text { program that focuses on tips for living } \\
\text { smart with urban wildlife, including bears }\end{array}$ \\
\hline $\begin{array}{l}\text { Question } 8 \\
\text { Please describe your community's } \\
\text { readiness and ability to implement your } \\
\text { proposal successfully. } \\
\text { This section should include: } \\
\text { - Experience with implementing } \\
\text { complex projects (i.e. multi- } \\
\text { stakeholder, multi-dimensional) } \\
\text { that span multiple business lines } \\
\text { and functional units. } \\
\text { Structures, processes, and } \\
\text { practices in place or planned for } \\
\text { managing and implementing } \\
\text { complex projects that span } \\
\text { multiple business lines and } \\
\text { functional units. } \\
\text { Organizational strengths and } \\
\text { potential weaknesses for } \\
\text { managing and implementing a } \\
\text { smart city proposal, and plans to } \\
\text { address weaknesses to ensure } \\
\text { successful proposal management } \\
\text { and implementation. }\end{array}$ & 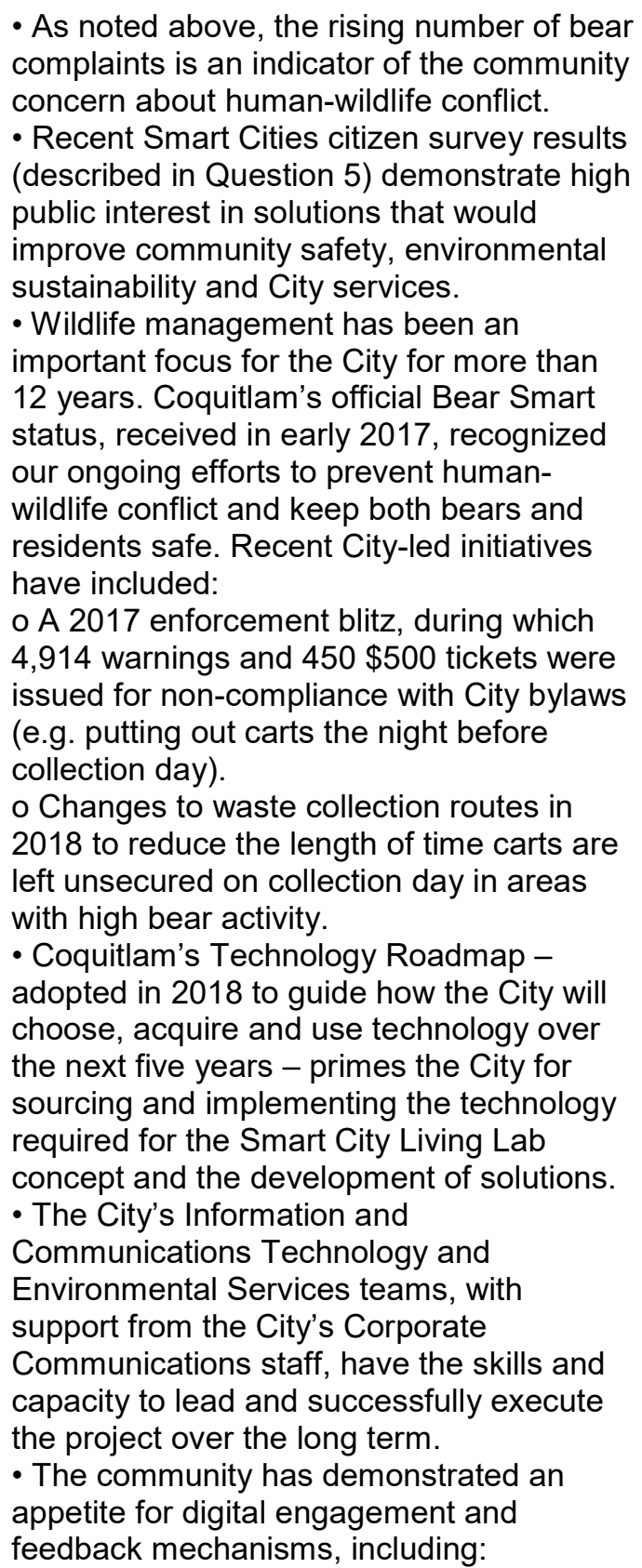 \\
\hline
\end{tabular}




\begin{tabular}{|c|c|}
\hline & $\begin{array}{l}\text { o Membership in Viewpoint, the City's } \\
\text { online survey community, has grown to } \\
\text { almost } 1,000 \text { by April } 2018 \text { since its launch } \\
\text { in March } 2017 \text {. The membership } \\
\text { represents a broad cross-section of ages, } \\
\text { neighbourhoods and housing types. } \\
\text { o Last year approximately } 1,050 \text { people } \\
\text { used or viewed the City's interactive online } \\
\text { budget tool, introduced in } 2014 \text { as an } \\
\text { innovative way to provide budget } \\
\text { information and collect feedback. } \\
\text { o The City's statistically valid Citizen } \\
\text { Satisfaction Survey by Ipsos Reid in } 2017 \\
\text { showed an increase in the number of } \\
\text { respondents interested in providing input } \\
\text { through online surveys ( } 68 \% \text {, up from } 65 \% \\
\text { in } 2015 \text { ). }\end{array}$ \\
\hline $\begin{array}{l}\text { Question } 9 \\
\text { Describe your plan for using the } \$ 250,000 \\
\text { grant, should you be selected as a finalist. } \\
\text { Provide a high-level breakdown of } \\
\text { spending categories and an } \\
\text { accompanying rationale. }\end{array}$ & $\begin{array}{l}\text { Spending categories would include: } \\
\text { - Project management: Hiring an external } \\
\text { project manager to work with in-house staff } \\
\text { and provide external expertise to develop } \\
\text { the business case and manage the project } \\
\text { development and roll-out. The use of } \\
\text { external resources would ensure timely } \\
\text { progress. } \\
\text { - Business case development: Including } \\
\text { research, identification and planning of } \\
\text { scope, components, deployment sites, } \\
\text { partnerships, data needs and analysis, and } \\
\text { terms of reference. } \\
\text { - Proof-of-concept: Planning a small-scale } \\
\text { version of project in a defined area, e.g. a } \\
\text { neighbourhood. }\end{array}$ \\
\hline $\begin{array}{l}\text { Question } 10 \\
\text { Describe the partners that are or will be } \\
\text { involved in your proposal. Where partners } \\
\text { are not yet determined, describe the } \\
\text { process for selecting them. } \\
\text { This section should include: } \\
\text { - A description of existing partners } \\
\text { (what type of organization, what } \\
\text { they do, etc.), their relevance, and } \\
\text { expected contribution to the } \\
\text { outcome (or outcomes). } \\
\text { Where partners are not yet } \\
\text { determined or where it is } \\
\text { anticipated that additional partners }\end{array}$ & $\begin{array}{l}\text {-A post-secondary institution (e.g. Douglas } \\
\text { College, Simon Fraser University or } \\
\text { University of British Columbia) will be } \\
\text { engaged for assistance with data collection } \\
\text { and analysis. The City will pursue these } \\
\text { partnerships initially through its existing } \\
\text { relationships with local educational } \\
\text { institutions. } \\
\text { - Conservation stakeholders (e.g. Burke } \\
\text { Mountain Naturalists, Metro Vancouver } \\
\text { Parks, Coquitlam Sustainability and } \\
\text { Environmental Advisory Committee, other } \\
\text { local environmental groups and BC } \\
\text { Conservation Officer Service) will be } \\
\text { approached to participate in providing input } \\
\text { and feedback. Invitations will be extended } \\
\text { through existing relationships with these } \\
\text { groups. }\end{array}$ \\
\hline
\end{tabular}




\begin{tabular}{|c|c|}
\hline $\begin{array}{l}\text { are required, describe the process } \\
\text { for selecting them. }\end{array}$ & $\begin{array}{l}\text { - Local residents (particularly those who } \\
\text { live in areas with wildlife-interface issues) } \\
\text { will be engaged to collect data through the } \\
\text { mobile app and provide input and feedback } \\
\text { through online discussion forums and the } \\
\text { Smart City Living Lab working group. } \\
\text { Invitations will be extended directly through } \\
\text { neighbourhood representatives (e.g. } \\
\text { Northeast Coquitlam Ratepayers } \\
\text { Association) as well as to the community } \\
\text { as a whole through media multi-media } \\
\text { outreach campaign. } \\
\text { - A technology partner will be sought for } \\
\text { data-collection tools (e.g. sensors) and Wi- } \\
\text { Fi expansion. Invitations will be extended } \\
\text { through existing relationships the City has } \\
\text { developed with technology partners } \\
\text { through its QNET fibre-optic utility. } \\
\text { - At the time of this submission, the City } \\
\text { had issued a Request for Proposals for } \\
\text { development of a City services mobile app } \\
\text { to be deployed in } 2018 \text {. This partner would } \\
\text { be engaged in the future roll-out of wildlife } \\
\text { reporting, alerts and discussion functions } \\
\text { as funding becomes available }\end{array}$ \\
\hline ther requirements & \\
\hline $\begin{array}{l}\text { Question } 12 \\
\text { Provide a summary of your preliminary } \\
\text { proposal. This summary, along with your } \\
\text { Challenge Statement, will be posted online } \\
\text { in both official languages. } \\
\text { You have the option of providing the } \\
\text { summary in both official languages. If you } \\
\text { provide it in one official language, } \\
\text { Infrastructure Canada will translate it prior } \\
\text { to posting online. }\end{array}$ & $\begin{array}{l}\text { Coquitlam is a vibrant and rapidly growing } \\
\text { community of more than } 140,000 \text { people } \\
\text { within Metro Vancouver, British Columbia. } \\
\text { Our urban setting within forests and parks, } \\
\text { combined with growth into new greenfield } \\
\text { areas, has contributed to a sharp rise in } \\
\text { human-wildlife conflict and related } \\
\text { complaints in recent years - despite } \\
\text { dedicated education and enforcement } \\
\text { efforts and a provincial Bear Smart } \\
\text { designation in 2017. With extensive } \\
\text { development planned for forested areas in } \\
\text { northeast Coquitlam in the coming } \\
\text { decades, new tools are required for the } \\
\text { City's waste management and wildlife } \\
\text { program to proactively address this } \\
\text { community challenge. } \\
\text { We are seeking to improve how we live } \\
\text { with wildlife by leveraging technology, data, } \\
\text { and an engaged population that places a } \\
\text { high value on environmental sustainability, } \\
\text { public safety, telecommunications and } \\
\text { enhanced City services. } \\
\text { As a Smart City Living Lab, Coquitlam }\end{array}$ \\
\hline
\end{tabular}




\begin{tabular}{||l|l||}
\hline & $\begin{array}{l}\text { would make use of available technology } \\
\text { and partnerships for both community } \\
\text { engagement and the collection of data to } \\
\text { inform decisions about smart waste- } \\
\text { management solutions, planning and } \\
\text { service delivery. The initiative would also } \\
\text { provide a template for addressing emerging } \\
\text { environmental sustainability issues in the } \\
\text { future. }\end{array}$ \\
\hline
\end{tabular}

